\author{
Universidade de São Paulo \\ Faculdade de Filosofia, Ciências e Letras de Ribeirão Preto \\ Departamento de Química \\ Programa de Pós-Graduação em Química
}

\title{
“Algumas Considerações sobre a Síntese de Complexos de Rutênio com Ligantes Tetraazamacrocíclicos Insaturados. Precursores para a formação de novos nitrosilo complexos para aplicações fotoquímicas".
}

Bruna Possato

Dissertação apresentada à Faculdade de Filosofia, Ciências e Letras de Ribeirão Preto da Universidade de São Paulo, como parte das exigências para a obtenção do título de Mestre em Ciências, Área: Química

RIBEIRÃO PRETO -SP 
Universidade de São Paulo

Faculdade de Filosofia, Ciências e Letras de Ribeirão Preto

Departamento de Química

Programa de Pós-Graduação em Química

\section{“Algumas Considerações sobre a Síntese de Complexos de Rutênio com Ligantes Tetraazamacrocíclicos Insaturados. Precursores para a formação de novos nitrosilo complexos para aplicações fotoquímicas".}

Bruna Possato

Orientador: Prof. Dr. Elia Tfouni

Dissertação apresentada à Faculdade de Filosofia, Ciências e Letras de Ribeirão Preto da Universidade de São Paulo, como parte das exigências para a obtenção do título de Mestre em Ciências, Área: Química

RIBEIRÃO PRETO -SP 


\section{FICHA CATALOGRÁFICA}

\section{Possato, Bruna}

"Algumas Considerações sobre a Síntese de Complexos de Rutênio com Ligantes Tetraazamacrocíclicos Insaturados. Precursores para a formação de novos nitrosilo complexos para aplicações fotoquímicas"

Ribeirão Preto, 2013.

103 p. : il. ; $30 \mathrm{~cm}$

Dissertação de Mestrado, apresentada à Faculdade de Filosofia, Ciências e Letras de Ribeirão Preto/USP - Área de concentração: Química

Orientador: Tfouni, Elia

1. Rutênio. 2. Tetraazamacrociclos insaturados. 3. Óxido Nítrico. 4. Terapia Fotodinâmica. 
Jesus disse: "Eu sou a ressurreição e a vida. Quem acredita em mim, mesmo que morra, viverá. E todo aquele que vive e acredita em mim, não morrerá para sempre. Você acredita nisso?" Ela respondeu: "Sim, Senhor. Eu acredito que tu és o Messias, o Filho de Deus que devia vir a este mundo." João 11, 25-27 
"Comece fazendo o que é necessário, depois o que é possível, e de repente estará fazendo o impossível."

(São Francisco de Assis) 
Dedico este trabalho à minha família, o alicerce de qualquer jornada. Aos meus pais, João e Terezinha, pois fizeram o inexplicável para me ajudar desde o começo, e também à minha avó, Aparecida, que, mesmo sem entender o porquê da minha ausência, sempre me incentivou a continuar estudando. Infelizmente, muitos já não se encontram entre nós. A efemeridade da vida é algo, muitas vezes, incompreensível, revoltante e triste. Dedico este trabalho também aos que permanecem vivos em nossos corações. 
Agradeço

Ao Professor Dr. Elia Tfouni primeiramente pela infindável paciência e compreensão com a agitação e ansiedade que habitam o meu ser. Muito obrigada por entender minha teimosia e por me deixar tentar. Se eu consegui, foi porque o senhor permitiu que eu tentasse. Obrigada pela orientação e pelas inúmeras discussões sobre o que estaria acontecendo de errado (e de certo também), pelos montes de esquemas ilustrativos (todos estão devidamente guardados) e por não desistir. Cada "puxão de orelha" foi merecido e fez com que eu enxergasse a necessidade de crescer, sempre. Crescer vem junto com responsabilidades. Obrigada por me ensinar isso também. E, por fim, obrigada por ver potencial em mim, quando nem eu mesma acreditava.

Ao "irmão mais velho" de laboratório, Prof. Dr. Kleber Queiroz Ferreira, pela paciência (que nunca faltou), pela ajuda (que nunca faltou), e por escutar (e ler) minhas inúmeras dúvidas e choradeiras.

Ao queridíssimo Prof. Dr. Fábio Gorzoni Doro, pelas excelentes sugestões, pelas ótimas conversas, pelos ótimos conselhos, e, é claro, pela paciência!

À Dra. Jeane Bordini, primeiramente por fazer com que eu enxergasse que a vida do jeito que ela deve ser: trabalho, responsabilidade, pontualidade, e diversão (sim!), sempre que houver tempo para isso. Obrigada por não me deixar explodir o prédio, por me ensinar como lidar com experimentos que, aparentemente, não deram certo, pelas sugestões e, é claro, pelas broncas e conversas sérias. 
Ao Prof. Dr. Maurício Caiut pelas sugestões fundamentais para a finalização deste trabalho.

À Prof ${ }^{a}$. Dra. Sofia Nikolaou pelas excelentes sugestões para a finalização e continuidade deste trabalho, pela paciência que teve ao me receber para as conversas e discussões, pela paciência que vai ter para lidar com as futuras conversas e discussões. Obrigada por confiar na minha competência e acreditar no meu potencial.

Ao Prof. Dr. Luís Gustavo Dias, por me ajudar a entender a complexidade dos resultados dos estudos teóricos e pelos sempre bons conselhos.

Aos Professores Dra. Aline Bruni e Dr. Grégroire Jean-François Demets pela supervisão nos estágios PAE realizados durante o mestrado e por me ensinarem muito sobre o que é a docência.

Ao pessoal do Laboratório de Fotoquímica Inorgânica, onde este trabalho foi realizado, Ms. Leonardo Figueiredo, Dunna Dorta de Medeiros, Gisdélia Silva, Ana Paula Gaspari, a companheira de mestrado que sempre esteve ali, não importa o tamanho da dificuldade, tristeza ou alegria, e à Prof. Dra. Ivy Calandreli, por me ensinar muito. Obrigada pela convivência desses anos.

Aos técnicos Aline Chiba, por ser nosso braço direito, esquerdo, cérebro e tudo o mais, Ms. Vinícius Pallareti, por ter tempo, paciência, disponibilidade, boas ideias, e por me ajudar a decifrar os espectros de RMN, Dra. Ivana Borin, por fazer o possivel e o impossível para nos auxiliar nas dificuldades diversas. 
Aos meus amigos, TODOS, que sempre tiveram uma palavra de carinho nos momentos difíceis, uma palavra de segurança nas horas de medo e uma bronca na ponta da língua quando o desespero era maior que a razão. Quero que vocês saibam que, na ausência de irmãos de sangue, Deus me concedeu o dom de conhecer pessoas especiais, e abalaram meus antigos conceitos e sacudiram a minha vida. Obrigada por ser minha família longe de casa, meus irmãos de alma e meus conselheiros.

A todos os funcionários e Professores que me ajudaram e tornaram este caminho um pouco menos difícil.

À FAPESP, CAPES e CNPq, pelo suporte financeiro e à CAPES pela bolsa de estudos concedida durante o desenvolvimento deste trabalho. 


\section{ÍNDICE}

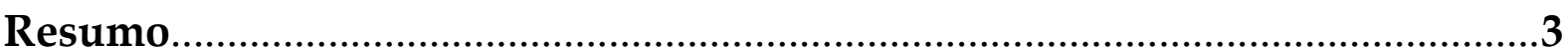

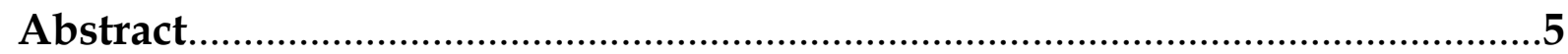

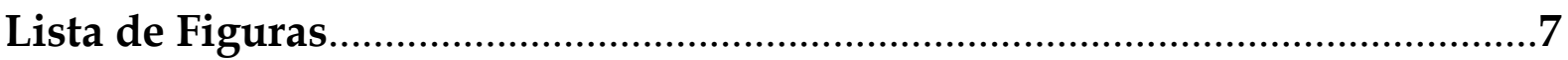

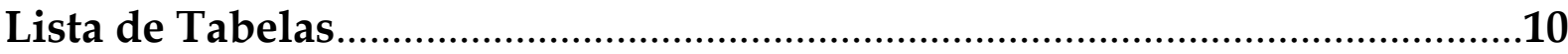

Lista de Equações..............................................................................................11

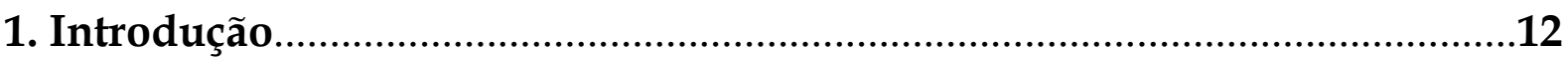

1.1. Complexos com ligantes macrocíclicos...................................................12

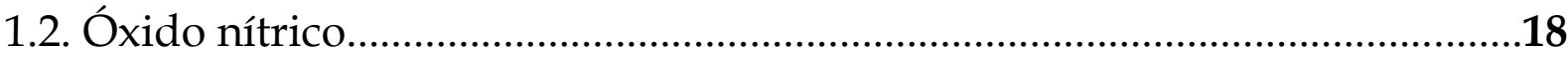

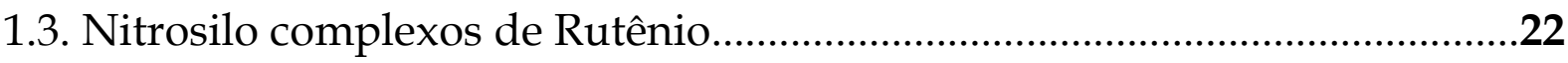

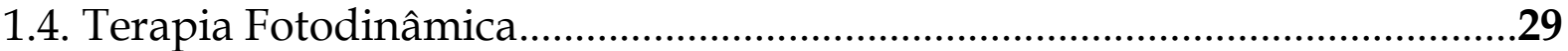

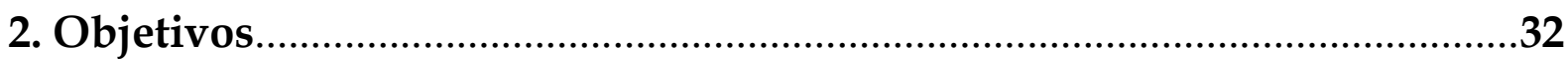

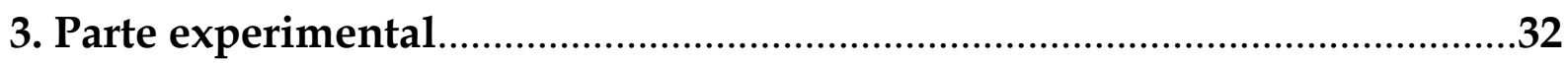

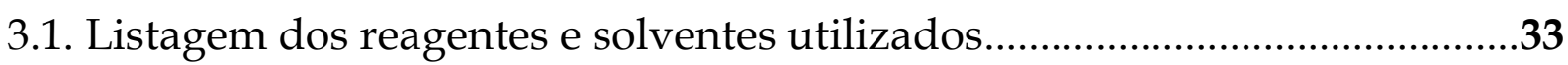

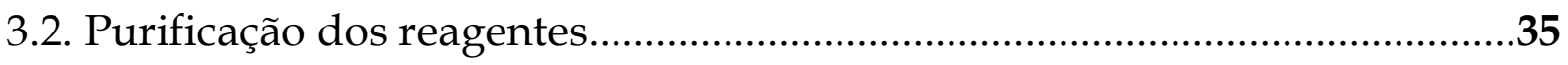

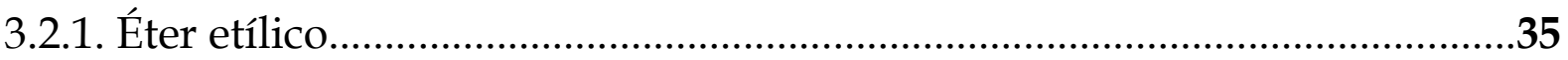

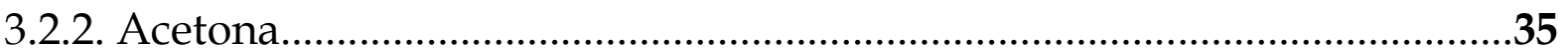

3.2.3. 1,3-Diaminopropano e N,N-Dimetilformamida............................................36

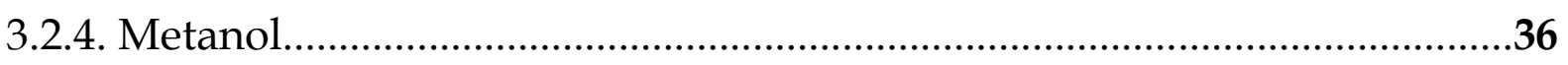

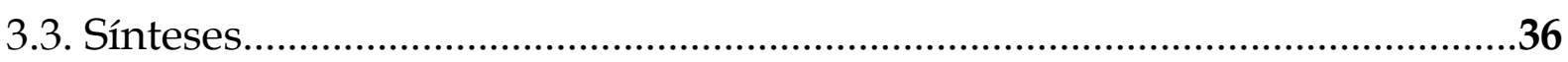

3.3.1. Síntese dos compostos utilizados como precursores.....................................36

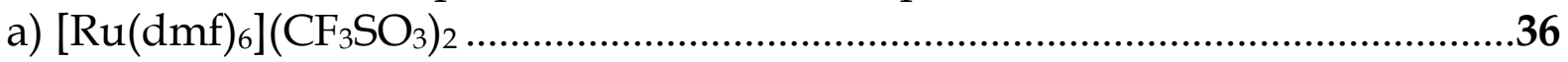

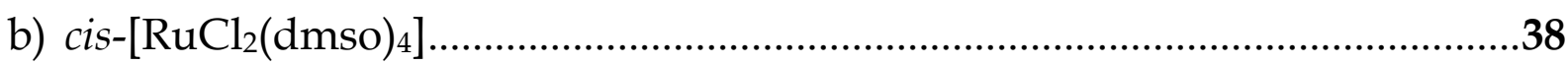

3.3.2. Sínteses dos ligantes macrocíclicos...............................................................38

a) Bis (trifluormetanossulfonato) de 5,7,7,12,14,14-hexametil-1,4,8,11-

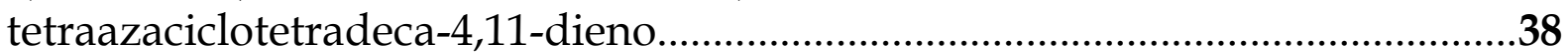


b) Diperclorato de 5,7,7,12,14,14-hexametil-1,4,8,11-tetraazaciclotetradeca-4,11dieno.

c) Hidrato de 5,7,7,12,14,14-hexametil-1,4,8,11-tetraazaciclotetradecano (isômeros meso e racêmico)

3.3.3. Síntese dos complexos metálicos...................................................................41

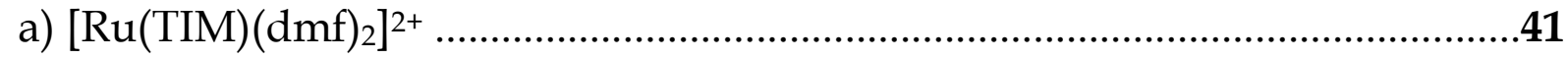

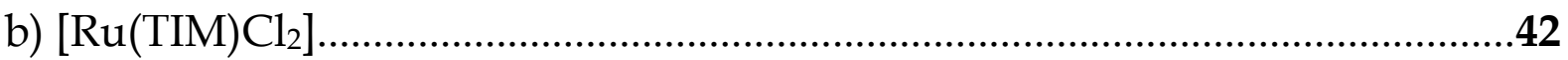

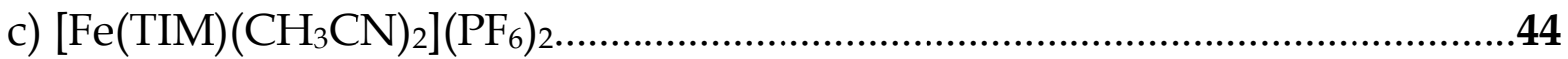

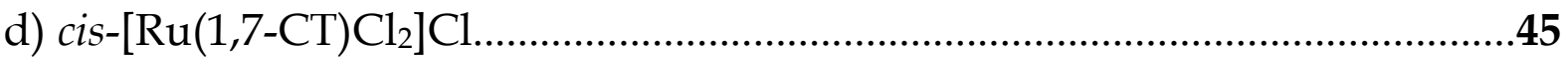

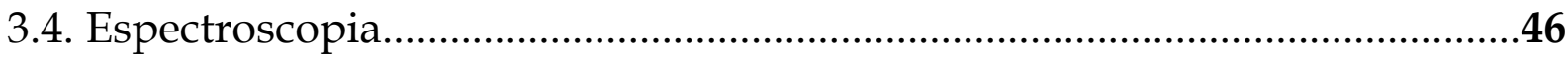

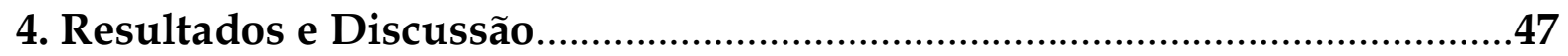

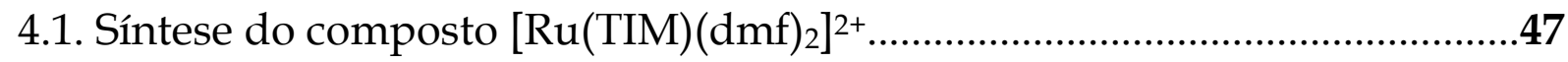

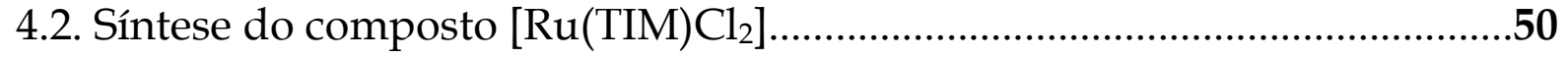

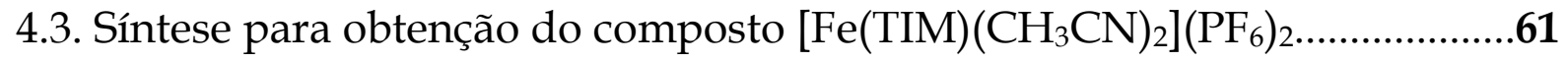

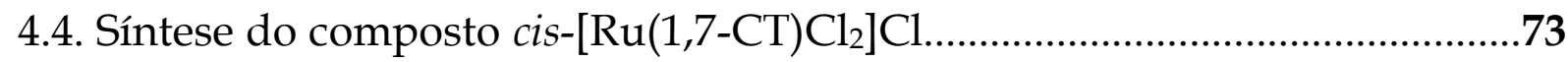

5. Conclusão

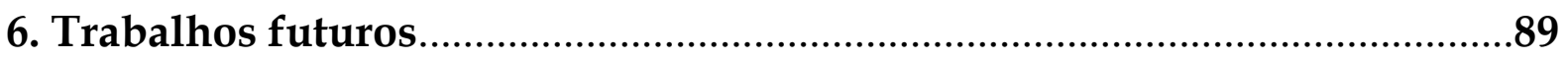

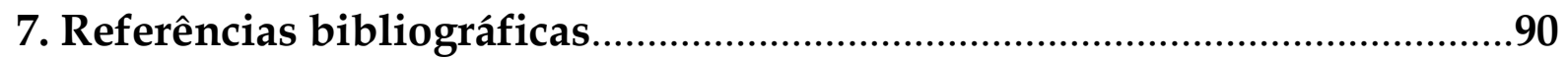




\section{RESUMO}

Neste trabalho, duas estratégias para obtenção de um complexo de rutênio com os tetraazamacrociclos insaturados 2,3,9,10-tetrametil-1,4,8,11tetraazaciclotetradeca-1,3,8,10-tetraeno (TIM) ou 5,7,712,14,14-hexamethil1,4,8,11-tetraazaciclotetradeca-4,11-dieno $\quad(1,7-\mathrm{CT})$ foram estudados. $\left[\mathrm{RuCl}_{2}(\mathrm{TIM})\right]$ e $\left[\mathrm{RuCl}_{2}(1,7-\mathrm{CT})\right]$ seriam precursores para obtenção de nitrosilo complexos capazes de liberar óxido nítrico fotoquimicamente pela irradiação com luz em comprimentos de onda na região do visível, como na Terapia Fotodinâmica. Essas duas estratégias são a reação utilizando o rutênio como template e a metalação do ligante previamente sintetizado.

A estratégia de metalação foi empregada com o ligante 1,7-CT e utilizando o complexo cis-[ $\left.\mathrm{RuCl}_{2}(\mathrm{dmso})\right]$ como precursor para obter o cis$\left[\mathrm{Ru}(1,7-\mathrm{CT}) \mathrm{Cl}_{2}\right] \mathrm{Cl}$. Este método foi aplicado com sucesso para sintetizar complexos de rutênio ligantes tetraazamacrocíclicos como cyclam, cyclen, imcyclen. O ligante 1,7-CT foi sintetizado com sucesso. $O$ espectro de infravermelho mostrou bandas em $3130 \mathrm{~cm}^{-1}, 2910 \mathrm{~cm}^{-1}, 1663 \mathrm{~cm}^{-1}$, e $1547 \mathrm{~cm}^{-1}$, em acordo com o relatado na literatura, e o espectro de RMN-1H mostrou singletes em 1.45 ppm, 2.04 ppm, 2.77 ppm, e tripletes em 2.92 ppm e 3.39 ppm, como esperado. Tentativas de síntese do complexo de rutênio correspondente não foram bem sucedidas, conforme se depreende pelos espectros de RMN-1H e de infravermelho. 
A estratégia que aplica o efeito template para a obtenção do complexo foi a que deu os melhores resultados, embora o complexo não tenha sido isolado do meio reacional. Os resultados das análises espectroscópicas obtidos do extrato seco da reação mostram que o complexo $\left[\mathrm{RuCl}_{2}\right.$ (TIM)] foi obtido. Os espectros de absorção no UV-visível foram feitos durante a reação e mostraram que os precursores estavam reagindo, pois novas bandas apareciam em detrimento do desaparecimento das originais, ao longo da reação. Há alguns indícios de que possa ter havido decomposição, pois o espectro de $\mathrm{RMN}-1 \mathrm{H}$ mostrou um pequeno singleto em 2.25 ppm que pode indicar a presença de 2,3-butanodiona como resultado da decomposição. $\mathrm{O}$ espectro de RMN-1H também mostrou um quintupleto em 2.09 ppm e um tripleto em 3.13 ppm, conforme esperado para o macrociclo. Os espectros de infravermelho mostraram a presença de bandas em $1690 \mathrm{~cm}^{-1}, 1429$ a $1374 \mathrm{~cm}^{-}$ 1, $1200 \mathrm{~cm}^{-1}$ e $942 \mathrm{~cm}^{-1}$, consistentes com a presença do TIM no complexo, além da banda em $448 \mathrm{~cm}^{-1}$, consistente com a presença de ligações Ru-N. A comparação entre os espectros de infravermelho do complexo de rutênio com os complexos análogos de níquel e ferro apoia essas atribuições. 


\begin{abstract}
In this work, two strategies to obtain a complex of ruthenium with the unsaturated tetraazamacrocycles 2,3,9,10-tetramethyl-1,4,8,11tetraazacyclotetradeca-1,3,8,10-tetraene (TIM) or 5,7,712,14,14-hexamethyl1,4,8,11-tetraazacyclotetradeca-4,11-diene (1,7-CT) were studied. [ $\mathrm{RuCl}_{2}$ (TIM)] and $\left[\mathrm{RuCl}_{2}(1,7-\mathrm{CT})\right]$ would be precursors to obtain nitrosyl complexes able to deliver nitric oxide photochemically by irradiation with visible light as in photodynamic therapy. These two strategies are the reaction using ruthenium as template and the metallation of the ligand previously synthesized.
\end{abstract}

The metallation strategy was used with the ligand 1,7-CT and the precursos cis- $\left[\mathrm{RuCl}_{2}(\mathrm{dmso})_{4}\right]$ to obtain cis- $\left[\mathrm{Ru}(1,7-\mathrm{CT}) \mathrm{Cl}_{2}\right] \mathrm{Cl}$. This method is successfuly applied to synthesize ruthenium complexes with tetraazamacrocyclic ligands as cyclam, cyclen, imcyclen. The 1,7-CT was successfully synthesized. The infrared spectrum of 1,7-CT showed bands about $3130 \mathrm{~cm}^{-1}, 2910 \mathrm{~cm}^{-1}, 1663 \mathrm{~cm}^{-1}$, and $1547 \mathrm{~cm}^{-1}$, in agreement with the data found in the literature, and the ${ }^{1} \mathrm{H}-\mathrm{NMR}$ spectrum showed singlets at 1.45 ppm, $2.04 \mathrm{ppm}, 2.77 \mathrm{ppm}$, and triplets at $2.92 \mathrm{ppm}$ and $3.39 \mathrm{ppm}$, as expected. Attempts to synthesize the corresponding ruthenium complex were unsuccessful as long as ${ }^{1} \mathrm{H}$ NMR and infrared spectroscopy are concerned.

The strategy applying the template effect to obtain the complex was the one that gave the more positive results, although the complex was not isolated 
from the reaction media. Spectral analysis from the dry extract of the reaction drove us to believe that the complex $\left[\mathrm{RuCl}_{2}(\mathrm{TIM})\right]$ was obtained. The UVvisible absorption spectra taken during the reaction showed that the precursors were properly reacting because new bands were taking place of the originals bands of the precursors during the reaction course. There are some indications that some decomposition may have taken place, as the ${ }^{1} \mathrm{H}$ NMR spectrum showed a small singlet at $2.25 \mathrm{ppm}$ that could indicate the presence of 2,3-butanedione as a result of this decomposition. The ${ }^{1} \mathrm{H}$ NMR spectrum also showed a quintuplet at $2.09 \mathrm{ppm}$ and a triplet at $3.13 \mathrm{ppm}$, as expected for the macrocycle. The infrared spectrum showed the presence of bands about $1690 \mathrm{~cm}^{-1}, 1429$ to $1374 \mathrm{~cm}^{-1}, 1200 \mathrm{~cm}^{-1}$ and $942 \mathrm{~cm}^{-1}$, consistent with the presence of TIM in the complex, and the presence of bands about $448 \mathrm{~cm}^{-1}$, consistent with the presence of $\mathrm{Ru}-\mathrm{N}$ bonds. Comparison of the ruthenium complex infrared spectrum to those of the nickel and iron analogous complexes supports this assumption. 


\section{LISTA DE FIGURAS}

Figura 1: Diagrama dos orbitais moleculares do NO

Figura 2: Estrutura dos complexos desejados com os ligantes TIM e 1,7-CT....29

Figura 3: Esquema mostrando a penetração na pele de laser de diferentes comprimentos de onda .30

Figura 4: Esquema mostrando o decorrer da reação para formação do composto $\left[\mathrm{Ru}(\mathrm{TIM}) \mathrm{Cl}_{2}\right]$.

Figura 5: Espectros de absorção na região do UV-visível dos complexos $\left[\mathrm{Ru}(\mathrm{dmf})_{6}\right]^{3+}$ e $\left[\mathrm{Ru}(\mathrm{dmf})_{6}\right]^{2+}$ obtidos em DMF

Figura 6: Espectros de absorção na região UV-visível, obtidos em metanol, da reação para obtenção do composto $\left[\mathrm{Ru}(\mathrm{TIM}) \mathrm{Cl}_{2}\right]$ 52

Figura 7: Espectros de infravermelho do complexo com ligante TIM em pastilhas de $\mathrm{KBr}$ .54

Figura 8: Espectro de infravermelho do extrato seco da reação para obtenção do complexo $\left[\mathrm{Ru}(\mathrm{TIM}) \mathrm{Cl}_{2}\right]$ em pastilhas de $\mathrm{KBr}$ .55

Figura 9: Espectro de infravermelho feito em pastilhas de $\mathrm{KBr}$ do extrato seco após a adição de nitrito de sódio .57

Figura 10: Espectro de $\mathrm{RMN}-{ }^{1} \mathrm{H}$ do extrato seco do meio reacional, obtido em $\mathrm{CD}_{3} \mathrm{OD}$ e DCl. Não há sinais acima de 5.2 ppm.

Figura 11: Ampliação do espectro de $\mathrm{RMN}-{ }^{1} \mathrm{H}$ do extrato seco do meio reacional, obtido em $\mathrm{CD}_{3} \mathrm{OD}$ e $\mathrm{DCl}$

Figura 12: Espectros de absorção na região do UV-visível do complexo $\left[\mathrm{Fe}(\mathrm{TIM})\left(\mathrm{CH}_{3} \mathrm{CN}\right)_{2}\right]^{2+}$ feitos em acetonitrila 
Figura 13: Fotografia das soluções do composto $\left[\mathrm{Fe}(\mathrm{TIM})\left(\mathrm{CH}_{3} \mathrm{CN}\right)_{2}\right]\left(\mathrm{PF}_{6}\right)_{2} \mathrm{em}$ acetonitrila e água

Figura 14: Espectros de absorção na região do UV-visível do composto $\left[\mathrm{Fe}(\mathrm{TIM})\left(\mathrm{CH}_{3} \mathrm{CN}\right)_{2}\right]\left(\mathrm{PF}_{6}\right)_{2}$ dissolvido em água.

Figura 15: Sobreposição dos espectros de absorção na região do UV-visível das soluções do composto $\left[\mathrm{Fe}(\mathrm{TIM})\left(\mathrm{CH}_{3} \mathrm{CN}\right)_{2}\right]\left(\mathrm{PF}_{6}\right)_{2}$ em acetonitrila e água. .65

Figura 16: Espectro de infravermelho do composto $\left[\mathrm{Fe}(\mathrm{TIM})\left(\mathrm{CH}_{3} \mathrm{CN}\right)_{2}\right]\left(\mathrm{PF}_{6}\right)_{2}$ feito em pastilhas de $\mathrm{KBr}$. .66

Figura 17: Ampliação do espectro de infravermelho do composto $\left[\mathrm{Fe}(\mathrm{TIM})\left(\mathrm{CH}_{3} \mathrm{CN}\right)_{2}\right]\left(\mathrm{PF}_{6}\right)_{2}$.

Figura 18: Espectro de infravermelho do produto da decomposição do composto $\left[\mathrm{Fe}(\mathrm{TIM})\left(\mathrm{CH}_{3} \mathrm{CN}\right)_{2}\right]\left(\mathrm{PF}_{6}\right)_{2}$ feito em pastilhas de $\mathrm{KBr}$. .68

Figura 19: Sobreposição dos espectros de infravermelho dos compostos $\left[\mathrm{Ru}(\mathrm{TIM}) \mathrm{Cl}_{2}\right],\left[\mathrm{Fe}(\mathrm{TIM})\left(\mathrm{CH}_{3} \mathrm{CN}\right)_{2}\right]\left(\mathrm{PF}_{6}\right)_{2}$ e $[\mathrm{Ni}(\mathrm{TIM})]\left(\mathrm{PF}_{6}\right)_{2}$

Figura 20: Correlação entre os espectros de infravermelho dos compostos $[\mathrm{Ni}(\mathrm{TIM})]\left(\mathrm{PF}_{6}\right)_{2},\left[\mathrm{Fe}(\mathrm{TIM})\left(\mathrm{CH}_{3} \mathrm{CN}\right)_{2}\right]\left(\mathrm{PF}_{6}\right)_{2}$ e $\left[\mathrm{Ru}(\mathrm{TIM}) \mathrm{Cl}_{2}\right]$ .70

Figura 21: Espectro de RMN do composto $\left[\mathrm{Fe}(\mathrm{TIM})\left(\mathrm{CH}_{3} \mathrm{CN}\right)_{2}\right]\left(\mathrm{PF}_{6}\right)_{2}$ feito em $\mathrm{CD}_{3} \mathrm{CN}$ .72

Figura 22: Espectro de $\mathrm{RMN}$ do composto $\left[\mathrm{Fe}(\mathrm{TIM})\left(\mathrm{CH}_{3} \mathrm{CN}\right)_{2}\right]\left(\mathrm{PF}_{6}\right)_{2}$ feito em $\mathrm{D}_{2} \mathrm{O}$ 72

Figura 23: Espectro de Infravermelho do composto cis-[ $\left.\mathrm{RuCl}_{2}(\mathrm{dmso})_{4}\right]$ em pastilha de $\mathrm{KBr}$. .74

Figura 24: Espectro de Infravermelho do 5,7,7,12,14,14-hexametil-1,4,8,11tetraazaciclotetradeca-4,11-dieno (1,7-CT) feito em pastilha de $\mathrm{KBr}$ .76 
Figura 25: Espectro de $\mathrm{RMN}-{ }^{1} \mathrm{H}$ do 5,7,7,12,14,14-hexametil-1,4,8,11tetraazaciclotetradeca-4,11-dieno (1,7-CT) em $\mathrm{CD}_{3} \mathrm{OD}$.

Figura 26: Ampliação do espectro de RMN - ${ }^{1} \mathrm{H}$ do 5,7,7,12,14,14-hexametil1,4,8,11-tetraazaciclotetradeca-4,11-dieno (1,7-CT) em $\mathrm{CD}_{3} \mathrm{OD}$ .77

Figura 27: Espectro de $\mathrm{RMN}-{ }^{1} \mathrm{H}$ em $\mathrm{D}_{2} \mathrm{O}$ do suposto complexo de rutênio com o ligante $1,7-\mathrm{CT}$. .79

Figura 28: Ampliação do espectro de $\mathrm{RMN}-{ }^{1} \mathrm{H}$ em $\mathrm{D}_{2} \mathrm{O}$ do suposto complexo de rutênio com o ligante 1,7-CT. .80

Figura 29: Espectro de infravermelho do suposto composto cis-[Ru(1,7CT) $\left.\mathrm{Cl}_{2}\right] \mathrm{Cl}$ feito em pastilhas de $\mathrm{KBr}$ .82

Figura 30: Sobreposição dos espectros de infravermelho do suposto composto cis- $\left[\mathrm{Ru}(1,7-\mathrm{CT}) \mathrm{Cl}_{2}\right] \mathrm{Cl}$ e de seu precursor cis-[ $\left.\mathrm{Ru}(\mathrm{dmso})_{4} \mathrm{Cl}_{2}\right]$. .83

Figura 31: Sobreposição dos espectros de infravermelho do suposto composto cis-[ $\left.\mathrm{Ru}(1,7-\mathrm{CT}) \mathrm{Cl}_{2}\right] \mathrm{Cl}$ e do ligante 1,7-CT. .83

Figura 32: Sobreposição dos espectros de infravermelho do suposto composto cis- $\left[\mathrm{Ru}(1,7-\mathrm{CT}) \mathrm{Cl}_{2}\right] \mathrm{Cl}$, de seu precursor cis- $\left[\mathrm{Ru}(\mathrm{dmso})_{4} \mathrm{Cl}_{2}\right]$ e do ligante $1,7-\mathrm{CT}$ 84

Figura 33: Modelos teóricos dos complexos com ligante TIM. .86 


\section{LISTA DE TABELAS}

Tabela 1: Potenciais de redução de alguns nitrosilo complexos de rutênio......25

Tabela 2: Potenciais de redução de algumas reações importantes biologicamente.....25

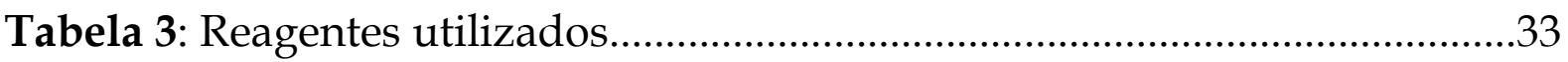

Tabela 4: Ligantes tetraazamacrocíclicos e seus respectivos complexos de

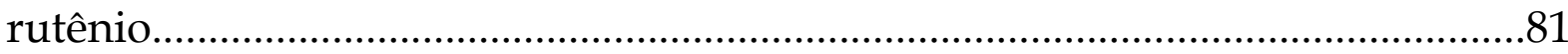




\section{LISTA DE EQUAÇÕES}

Equação 1: Reação entre perclorato de tris(etilenodiamina)níquel(II) e acetona

Equação 2: Reação entre 2,3-pentanodiona-bis(mercaptoetilimino)níquel(II) com a, a'-dibromo-o-xileno. .14

Equação 3: Finalização da reação de formação do complexo $[\mathrm{Ni}(\mathrm{cyclam})]^{2+}$...14

Equações 4: Liberação de NO eletroquimicamente .24

Equações 5: Liberação de NO fotoquimicamente. .26

Equação 6: Reação de hidrólise do pentóxido de fósforo . .35 Equação 7: Reação para obtenção do hexaflurofosfato de bis(acetonitrila)(2,3,9,10-tetrametil-1,4,8,11-tetraazaciclotetradeca-1,3,8,10tetraeno) ferro(II) 


\section{INTRODUÇÃO}

\subsection{Complexos com ligantes macrocíclicos}

A química de compostos macrocíclicos apresentou um grande crescimento a partir de meados da década 50 devido, também, à síntese de diversos compostos macrocíclicos que poderiam ser utilizados como ligantes para dar origem a complexos metálicos. Complexos de porfirinas, corrinas, e ftalocianinas foram investigados devido à sua ocorrência natural, como a clorofila, por exemplo, e/ou devido à sua potencial aplicação como corantes ${ }^{1}$. Um dos primeiros trabalhos sobre síntese de compostos macrocíclicos e o estudo de seus complexos de magnésio, cobre e níquel foi publicado por Linstead e Whalley, em $1952^{2}$, mas foi na década de 60 que os trabalhos sobre síntese destes compostos começaram a ser vistos do ponto de vista da química de coordenação.

Em 1960, Curtis, descreveu a reação de condensação entre perclorato de tris(etilenodiamina)níquel(II) e acetona 3, e, mais tarde, atribuiu o produto desta reação a um complexo de níquel(II) com ligante tetraazamacrocíclico 4, como mostra a equação: 


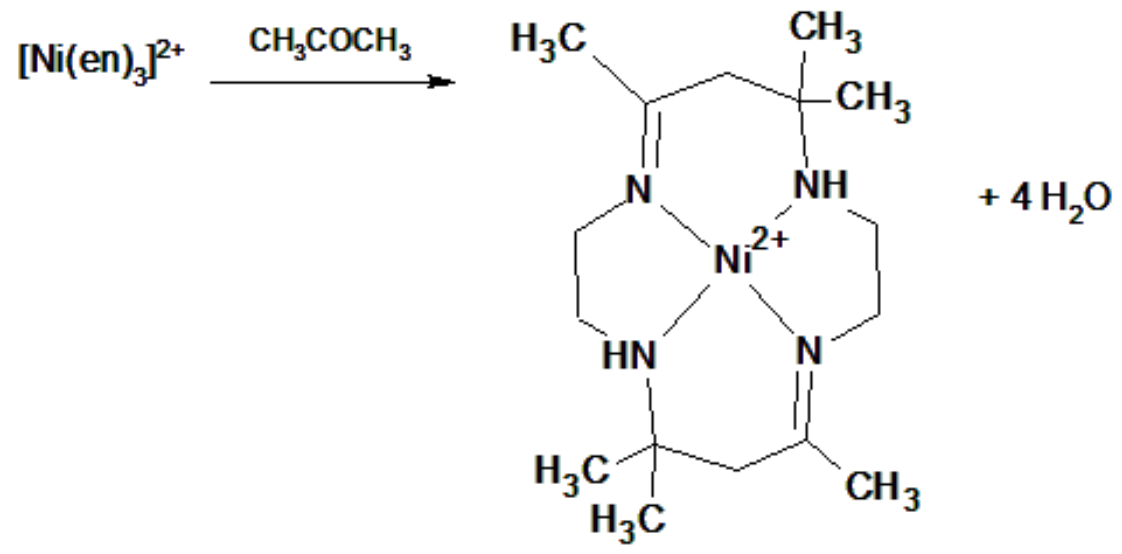

Equação 1: Reação entre perclorato de tris(etilenodiamina)níquel(II) e acetona.

O primeiro complexo metálico com ligante macrocíclico sintetizado deliberadamente foi obtido por Thompson e Busch 5, nos Estados Unidos, ao mesmo tempo em que Curtis estudava a reação anterior na Nova Zelândia. Neste trabalho, os autores utilizam o que eles chamaram, até então, de "hipótese template" para explicar a influência do metal no curso da reação. Em um trabalho posterior, Busch e Blinn ${ }^{6}$ trazem evidências espectrofotométricas sobre o direcionamento da reação do 2,3-pentanodionabis(mercaptoetilimino)níquel(II) com a, $a^{\prime}$-dibromo-o-xileno no sentido da fechamento do ciclo em torno do metal, sem que haja a formação de intermediário, o efeito template, o que deu origem ao primeiro complexo metálico com ligante macrocíclico sintetizado deliberadamente A equação abaixo mostra a etapa final para obtenção deste composto: 
<smiles>CC1=C(C)N2CC[SnH+][N+]23[SH2]CCN13</smiles>

Equação

2: $\quad$ Reação

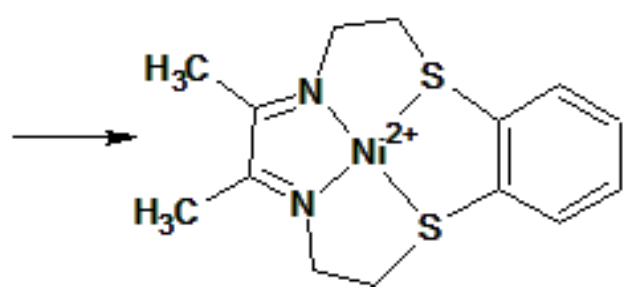

bis(mercaptoetilimino)níquel(II) com a,a'-dibromo-o-xileno.

Embora a síntese do cyclam (1,4,8,11-tetraazaciclotetradecano) tenha sido relatada por Van Alphen em 1936 7, Bosnich, Poon e Tobe ${ }^{8}$ sintetizaram o primeiro complexo metálico com este ligante em 1965, modificando o procedimento de Van Alphen, porém com um rendimento de apenas 5\%. Barefield ${ }^{9}$, em 1972, propôs a síntese do cyclam via formação de um complexo com níquel pelo efeito template, na qual, após a formação do complexo, o níquel é extraído do anel com excesso de cianeto no meio, formando o complexo $\left[\mathrm{Ni}\left(\mathrm{CN}_{4}\right)\right]^{2-}$, deixando o ligante macrocíclico livre, com um rendimento relatado de $20 \%$. A equação abaixo mostra reação de formação deste complexo metálico:
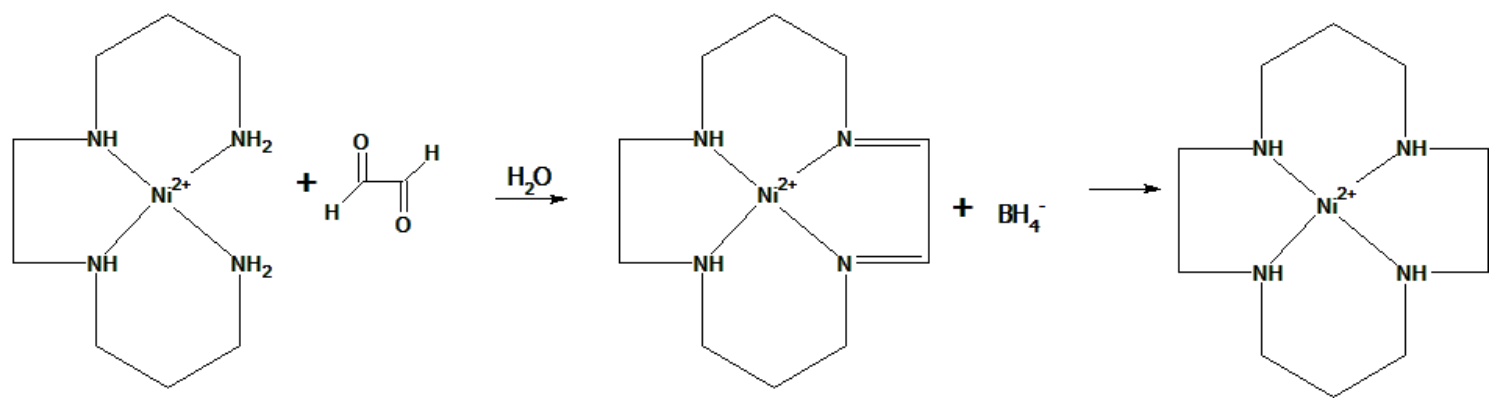

Equação 3: Finalização da reação de formação do complexo [Ni(cyclam) ${ }^{2+}$. 
Muito foi estudado com relação aos complexos de metais de transição com ligantes macrocíclicos, seja pelo estudo da mudança nas propriedades do complexo pelo aumento do grau de insaturação do ligante macrocíclico 10,11, ou pela mudança do íon metálico, como é o caso do $\left[\mathrm{Fe}(\mathrm{TIM})\left(\mathrm{CH}_{3} \mathrm{CN}\right)_{2}\right]\left(\mathrm{PF}_{6}\right)_{2}$ $(\mathrm{TIM}=$ 2,3,9,10-tetrametil-1,4,8,11-tetraazaciclotetradeca-1,3,8,10-tetraeno), sintetizado e caracterizado por Rose et alii. ${ }^{12}$.

Embora o primeiro trabalho envolvendo a síntese de complexos de metais $4 \mathrm{~d}$ com ligantes macrocíclicos tenha sido publicado por Collman e Schneider em 1966 13, a primeira síntese de um composto de rutênio com ligante macrocíclico, o trans-[Ru(cyclam) $\left.\mathrm{Cl}_{2}\right] \mathrm{Cl}$, foi descrita por Poon em 1975 14, que utilizou o aquapentaclororutenato(III) de potássio como precursor, refluxado com o ligante livre, cyclam, em metanol. Mais tarde, em 1980, Isied 15 relatou a separação do isômero cis deste composto. A síntese dos complexos de rutênio com os ligantes [15]aneN 4 (1,4,8,12-tetraazaciclopentadecano) e [16]aneN $\mathrm{N}_{4}(1,5,9,13$-tetraazaciclohexadecano) foi relatada por Walker e Taube em 1981 16, porém, a síntese do complexo de rutênio com cyclen $(1,4,7,10-$ tetraazaciclotetradodecano), cis- $\left[\mathrm{RuCl}_{2}(\text { cyclen })\right]^{2+}$, somente foi publicada em 2002 por Ferreira et alii. ${ }^{17}$. Antes da síntese do complexo de rutênio com cyclen, Tfouni et alii. relataram a síntese, caracterização e o estudo das propriedades fotoquímicas dos complexos trans- $[\mathrm{RuCl}(\text { cyclam }) \mathrm{L}]^{+}$, onde $\mathrm{L}=4$ pic (4-picolina), py (piridina), isn (isonicotinamida), 4-acpy (4-acetilpiridina) $)^{18-}$ 
20. A síntese do trans-[RuCl(cyclam)NO $]^{2+}$ também foi bastante importante, pois a liberação de NO neste composto é controlada, devido à estabilidade do complexo com ligante macrocíclico ${ }^{21}$.

O desenvolvimento de compostos de metais de transição com ligantes macrocíclicos é interessante não só pelo estudo da química de coordenação envolvida, ou pelo fato destes compostos sintéticos servirem como modelos para as espécies biologicamente importantes, mas também pelas propriedades que tais ligantes conferem ao complexo. Uma destas propriedades, a estabilidade do composto, bem como a estabilização de estados de oxidação não usuais dos metais, pode ser atribuída ao "efeito macrocíclico", termo introduzido por Cabiness e Margerum em 1969 22. Este efeito está ligado à grande estabilidade termodinâmica dos complexos contendo ligantes macrocíclicos, quando comparados aos análogos de cadeia aberta ${ }^{1}$.

A estabilidade do $\left[\mathrm{Fe}(\mathrm{TIM})\left(\mathrm{CH}_{3} \mathrm{CN}\right)_{2}\right]\left(\mathrm{PF}_{6}\right)_{2}$ em solução foi estudada, 25 anos após a síntese ser publicada, por Shepherd et alii. ${ }^{23}$, que, neste mesmo trabalho, mostrou como a coordenação de um ligante n-receptor forte, como é o caso do NO, muda a estabilidade em solução, bem como as propriedades espectrofotométricas do composto $\left[\mathrm{Fe}(\mathrm{TIM})\left(\mathrm{CH}_{3} \mathrm{CN}\right)(\mathrm{NO})\right]^{2+}$, quando comparado ao seu precursor $\left[\mathrm{Fe}(\mathrm{TIM})\left(\mathrm{CH}_{3} \mathrm{CN}\right)_{2}\right]^{2+}$. Mesmo que o nitrosilo complexo seja mais estável em solução do que seu precursor, ambos são instáveis, quando comparados, por exemplo, ao trans- $\left[\mathrm{RuCl}(\mathrm{NO})(\text { cyclam) }]^{2+}\right.$, 
que, ao liberar o NO, forma somente o aquacomplexo, e este não sofre reações de decomposição, havendo apenas reações de desprotonação em solução aquosa dependentes do $\mathrm{pH}{ }^{24}$.

Além da síntese do complexo de rutênio com o ligante cyclam, Poon et alii. relataram a síntese de outros complexos de rutênio com ligantes macrocíclicos, como a síntese template para obtenção do perclorato de bisaqua(2,12-dimetil-3,7,11,17-tetraazabiciclo[11.3.1]heptadeca-1(17),2,11,13,15pentaeno)rutênio(II) ${ }^{25}$, a metalação dos ligantes tetratiamacrocíclicos para obtenção dos complexos como o trans-dicloro(1,4,8,10-tetratiaciclotetradecano) 26. Em 1981, Poon e Che 27 relataram a desidrogenação oxidativa dos complexos de rutênio com ligantes meso- e rac-5,7,7,12,14,14-hexametil-1,4,8,11tetraazaciclotetradecano, obtendo o complexo de rutênio com o ligante 5,7,7,12,14,14-tetraazaciclotetradeca-1,3,8,10-tetraeno. Che et alii. ${ }^{28}$ relataram a metalação do 1,4,7,10-tetrametil-1,4,7,10-tetraazaciclotridecano, dando origem ao complexo cis-[ $\left.\mathrm{Ru}(\mathrm{L}) \mathrm{Cl}_{2}\right] \mathrm{ClO}_{4}$, onde Lé o referido macrociclo.

Os trabalhos mais recentes sobre os complexos de metais de transição com ligantes tetraazamacrocíclicos insaturados exploraram os estudos cinéticos destes compostos e as propriedades eletroquímicas dos composto. Butler e Linck 29,30, por exemplo, estudaram a cinética de substituição, em meio aquoso, dos ligantes axiais em complexos do tipo $[\mathrm{Fe}(\mathrm{TIM}) \mathrm{XY}]^{2+}$ e realizaram estudos fotoquímicos de complexos $[\mathrm{Fe}(\mathrm{TIM})(\mathrm{CO})(\mathrm{X})]^{2+}$. Em 2009, Wieghardt et alii. 31 
estudavam a série redox do ligante TIM, quando, ao reduzir o $\left[\mathrm{Fe}(\mathrm{TIM})\left(\mathrm{CH}_{3} \mathrm{CN}\right)_{2}\right]^{2+}$, produziram o dímero $\left[\{\mathrm{Fe}(\mathrm{TIM})\}_{2}\right]$, onde a ligação metalmetal não é mantida por nenhum ligante em ponte, tratando-se de uma ligação Fe-Fe. Este mesmo grupo publicou, em 2010, um trabalho sobre a série redox do ligante TIM e o estudo teórico de seus complexos com ferro e zinco, onde é mostrado que o ligante é reduzido preferencialmente do que o metal ${ }^{32}$.

\section{2. Óxido nítrico}

O óxido nítrico é uma molécula diatômica, um gás incolor à temperatura ambiente, solúvel em solventes apolares, com um comprimento de ligação médio de $1,15 \AA$, fato que pode ser explicado pela sua estrutura ressonante (a teoria do orbital molecular prediz uma ordem de ligação de 2,5), consistente com um comprimento de ligação entre $\mathrm{N}_{2}(1,06 \AA)$ e $\left.\mathrm{O}_{2}(1,18 \AA)\right)$. Sua configuração eletrônica é KK $\left(\sigma_{2 s}\right)^{2}\left(\sigma_{2 s}{ }^{*}\right)^{2}\left(\sigma_{2 p z}\right)^{2}\left(\pi_{2 p x, 2 p y}\right)^{4}\left(\pi_{2 p x, 2 p y}{ }^{*}\right)^{1}$, onde há um elétron desemparelhado num orbital $\pi$ antiligante, o que torna o NO paramagnético, além de radical, o que pode ser visto pela reação de $\bullet \mathrm{NO}$ com o radical superóxido formando peroxinitrito, por exemplo ${ }^{33}$.

A figura 1 mostra a distribuição dos elétrons em um diagrama de orbitais moleculares, mostrando o elétron desemparelhado e a combinação dos orbitais atômicos de $\mathrm{N}$ e O. 


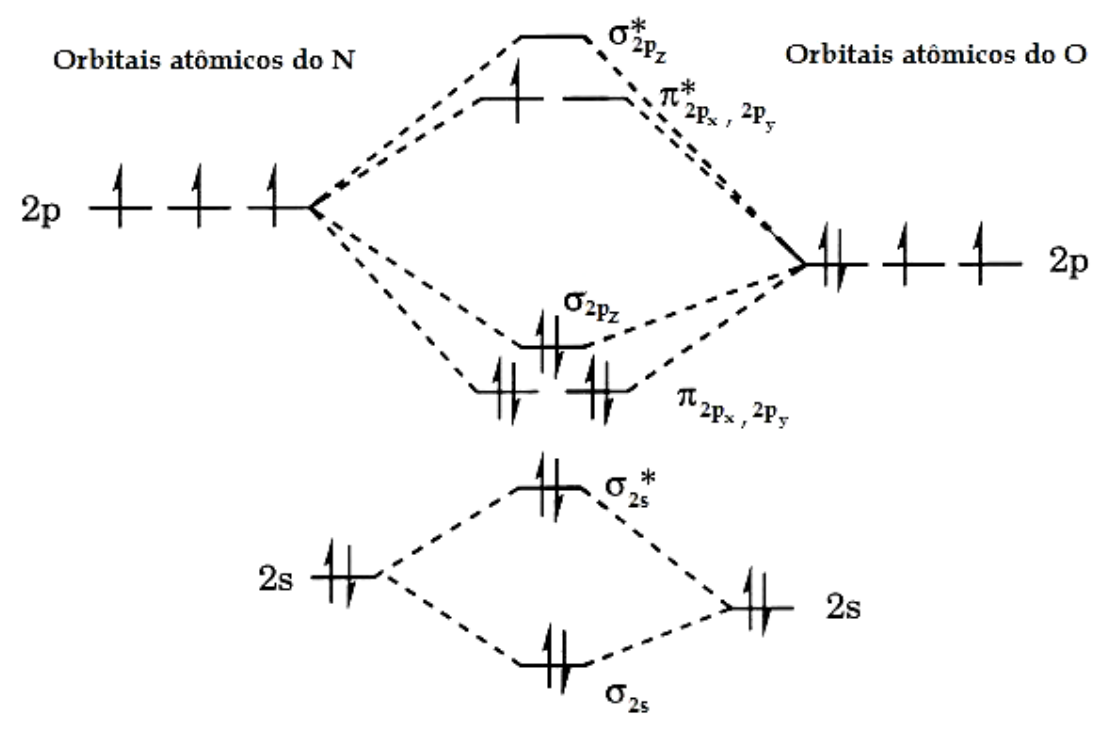

Figura 1: Diagrama dos orbitais moleculares do NO 33

Durante muito tempo, o óxido nítrico foi associado à sua toxicidade, como constituinte da poluição atmosférica, e às suas propriedades potencialmente carcinogênicas. Porém, durante a década de 80, Furgchott, Murad e Ignarro relacionaram o óxido nítrico ao fator relaxante derivado do endotélio (EDRF) e, consequentemente, ao controle da pressão arterial 33-35, o que lhes rendeu o Prêmio Nobel em Medicina e Fisiologia no ano de 1998. Desde então, os trabalhos publicados ligados à pesquisa com NO crescem a cada dia, e este grande volume de publicações traz consigo as possíveis propriedades benéficas que poderão ser aplicadas para o tratamento de algumas doenças como hipertensão arterial, Doença de Chagas (e outras doenças negligenciadas) e câncer, ou seja, o óxido nítrico é o monstro, mas também é o médico (assim como Dr. Jekyll e Mr. Hyde), pois ao mesmo tempo em que ele pode gerar um câncer, também pode curar. O NO participa de 
processos fisiológicos, regulatórios, imunológicos e patologias, apresentando, entre outras funções, vasodilatação, ação antiplaquetária, neurotransmissão, ação antitumoral ${ }^{33}$.

O NO é endogenamente produzido no endotélio vascular, cérebro, e sistema imunológico pela transformação de L-arginina em L-citrulina, reação mediada por NADPH. Tal reação é catalisada por uma classe de enzimas, as NOsintetases (NOS), que apresentam diferentes isoformas baseadas na distribuição dos tecidos ${ }^{33}$.

A descoberta da face benéfica do óxido nítrico trouxe também o interesse no desenvolvimento de novos doadores de NO, além do entendimento do mecanismo de ação de muitos conhecidos, para que pudessem ser utilizados no tratamento das patologias já citadas. Entre os doadores de NO, pode-se citar os diazenodiolatos ${ }^{36}$, como o sal de Angeli $\left(\mathrm{Na}_{2} \mathrm{~N}_{2} \mathrm{O}_{3}\right)$, os S-nitrosotióis, como a S-nitrosoglutationa (GSNO) ${ }^{37}$, e os nitrosilo complexos de metais de transição, o trans$\left[\mathrm{Cr}(\mathrm{cyclam})(\mathrm{ONO})_{2}\right]\left(\mathrm{BF}_{4}\right)^{38,39}$ e trans- $\left[\mathrm{Cr}(\mathrm{L})(\mathrm{ONO})_{2}\right]\left(\mathrm{BF}_{4}\right)$, onde $\mathrm{L}=\mathrm{mbc}(5,7-$ dimetil-6-benzilcyclam), mac (5,7-dimetil-6-antracil-8,11-cyclam) e hbc (5,7dimetil-6-( $p$-hidroximteilbenzil)-1,4,8,11-cyclam ${ }^{40}$, e os de manganês, como o $\left[\mathrm{Mn}\left(\mathrm{PaPy}_{2} \mathrm{Q}\right)(\mathrm{NO})\right]\left(\mathrm{ClO}_{4}\right)$, onde $\mathrm{PaPy}_{2} \mathrm{Q}^{-}=\mathrm{N}, \mathrm{N}$-bis(2-piridilmetil)amina-N-etil2-quinolina-2-carboxamida, e o $\left[\mathrm{Mn}\left(\mathrm{PaPy}_{3}\right)(\mathrm{NO})\right]\left(\mathrm{ClO}_{4}\right)$, onde $\mathrm{PaPy}_{3}{ }^{-}=\mathrm{N}, \mathrm{N}$ bis(2-piridilmetil)amina- $N$-etil-2-piridina-2-carboxamida ${ }^{41}$, os de rutênio, como 
as trans- $\left[\mathrm{Ru}\left(\mathrm{NH}_{3}\right)_{4}(\mathrm{NO})(\mathrm{L})\right]^{3+}$, onde $\mathrm{L}=\mathrm{P}(\mathrm{OEt})_{3}$, isn, nic, L-hist, py, 4-pic, pz ${ }^{*}{ }^{4-}$ 45, o trans- $[\mathrm{RuCl}(\text { cyclam }) \mathrm{NO}]^{2+}{ }^{21,24}$, complexos como $\left[\mathrm{Ru}(\mathrm{NO}) \mathrm{Cl}_{3}(\mathrm{~L})\right]^{2-}$, onde L=gly-gly-gly-H, gly-gly-his- $\mathrm{H}+46, \quad[\mathrm{Ru}(\mathrm{NO})(\mathrm{bpb}) \mathrm{Cl}] \quad\left(\mathrm{bpb}=\mathrm{N}, \mathrm{N}^{\prime}-\mathrm{bis}(2-\right.$ piridinacarboxamida)-1,2-benzeno) ${ }^{47}$, e os de ferro, como o nitroprussiato de sódio, $\mathrm{Na}_{2}\left[\mathrm{Fe}(\mathrm{CN})_{5}(\mathrm{NO})\right] \cdot 2 \mathrm{H}_{2} \mathrm{O} 48$.

Embora a síntese e utilização clínica do nitroprussiato de sódio, $\mathrm{Na}_{2}\left[\mathrm{Fe}(\mathrm{CN})_{5}(\mathrm{NO})\right] \cdot 2 \mathrm{H}_{2} \mathrm{O}$, seja anterior à descoberta do $E D R F$, este é um complexo doador de NO muito utilizado nos casos onde os pacientes apresentam crises hipertensivas e enfartes, pois a liberação do NO é rápida, restaurando rapidamente a pressão arterial. Este metalofármaco traz consigo o inconveniente da liberação também dos íons cianeto, que são labilizados após a liberação do $\mathrm{NO}$ 48, sendo bastante tóxicos em meio biológico, já que interrompem a cadeia transportadora de elétrons, e, consequentemente, a respiração celular e produção de ATP ${ }^{49}$. Existem maneiras de controlar a toxicidade dos íons cianeto in vivo, como a administração de tiossulfato de sódio para estimular sua biotransformação em tiocianato, e a administração de hidroxocobalamina (vitamina $B_{12}$ ), que forma a cianocobalamina em uma velocidade de reação da ordem de $10^{12} \mathrm{M}^{-1}$ 50,51.

O excesso de NO no organismo pode causar choque séptico, que é a hipotensão arterial que tem início devido à uma infecção, por exemplo. Em casos como estes, complexos sequestradores de $\mathrm{NO}$, como o $\mathrm{K}[\mathrm{RuCl}(\mathrm{edta})]$ 
(EDTA, do inglês Ethylenediamine tetraacetic acid), onde a constante de velocidade de segunda ordem para formação do complexo com NO é da ordem de $10^{8} \quad \mathrm{M}^{-1} \quad \mathrm{~s}^{-1} \quad{ }^{52}$, ou $\quad\left[\mathrm{Ru}_{2}(\mathrm{ttha})\left(\mathrm{H}_{2} \mathrm{O}\right)_{2}\right]^{2-} \quad($ ttha6- $=$ trietiletilenotetraaminahexaacetato), onde a constante velocidade observada na formação do $\left[(\operatorname{Ru}(\mathrm{NO}))_{2}(\text { ttha })\right]^{2-}$, é da ordem de $22,7 \mathrm{M}^{-1} \mathrm{~s}^{-153}$, poderiam ser utilizados em casos como este.

A síntese de novos compostos liberadores e sequestradores de NO é feita para, cada vez mais, controlar os aspectos cinéticos e termodinâmicos da liberação de NO, buscando aplicações clínicas, por exemplo.

\subsection{Nitrosilo complexos de Rutênio}

O rutênio é um metal da série de transição, que, como outros metais da série, apresenta uma grande variedade de estados de oxidação, onde os mais comuns são $\mathrm{Ru}(\mathrm{II})$ e $\mathrm{Ru}(\mathrm{III})$ em compostos hexacoordenados. A diferença de um elétron nos estados de oxidação +2 e +3 traz alterações significativas na reatividade das duas espécies como o fato de $\mathrm{Ru}(\mathrm{II})$ ser um $\sigma$-doador e $\mathrm{Ru}(\mathrm{III})$ um $\pi$-receptor, $\mathrm{Ru}(\mathrm{III})$ formar complexos inertes e $\mathrm{Ru}(\mathrm{II})$ lábeis em relação às reações de substituição, por exemplo ${ }^{54}$. Porém a estabilidade da ligação metalligante pode ser aumentada pela retrodoação na qual os elétrons $d_{\Pi}$ do $R u(I I)$ participam quando este está ligado a um ligante cujo orbital $\Pi^{*}$ apresente 
simetria e energia apropriadas, como é o caso dos complexos com $\mathrm{N}_{2}$, pirazina, organonitrilas, e, especialmente, $\mathrm{NO} 55,56$.

A utilização de aminas de rutênio é vantajosa pelo fato de que as sínteses são acessíveis e os complexos são estáveis com estruturas previsíveis 57 , sendo que as nitrosiloaminas de rutênio apresentam propriedades importantes como a liberação do NO por redução com potenciais acessíveis em meio biológico, e também quando irradiadas em comprimentos de onda adequados, sendo que, em ambos os casos, a liberação é bastante "limpa", havendo apenas a formação do respectivo aquacomplexo, além do NO liberado ${ }^{42-44}$.

Como exemplo, as trans-nitrosiltetraaminas de rutênio, com estrutura geral trans- $\left[\mathrm{Ru}\left(\mathrm{NH}_{3}\right)_{4}(\mathrm{NO})(\mathrm{L})\right]^{3+}$, onde $\mathrm{L}=\mathrm{P}(\mathrm{OEt})_{3}$, isn, nic, L-hist, py, 4-pic, pz, entre outros ${ }^{42-44}$, os complexos com estrutura geral trans- $[\mathrm{RuCl}(\mathrm{L}) 4(\mathrm{NO})]^{3+}$, onde $L=$ py, 4-acpy, isn, 3-acpy $\ddagger 58,59$ e os compostos com ligantes

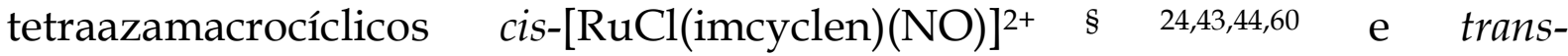
$[\mathrm{RuCl}(\text { cyclam })(\mathrm{NO})]^{2+}$ 21,24,43,44 tem sido estudados por suas importantes propriedades como liberação controlada de $\mathrm{NO}$, a liberação de $\mathrm{NO}$ quando irradiados em comprimentos de onda adequados e a liberação de NO quando reduzidos em potenciais biologicamente acessíveis. As tabelas 1 e 2 exemplificam este comportamento. 
Os nitrosilo complexos de rutênio, como os citados, apresentam propriedades bastante interessantes como doadores de NO devido à baixa toxicidade, alta solubilidade em água, e estabilidade contra oxidação pelo ar. Além disso, apresentam características importantes como a liberação do NO ativada fotoquimicamente, fazendo com que eles possam ser utilizados na Terapia Fotodinâmica, e atividade biológica como agentes antiinfecciosos e antitumorais, sendo que, devido à atividade biológica destes compostos, eles são potencialmente interessantes para aplicação clínica ${ }^{44}$.

As equações a seguir mostram a liberação do NO dos complexos após redução. Para o caso do complexo com cyclam, a labilização do íon cloreto ocorre antes da saída do NO:

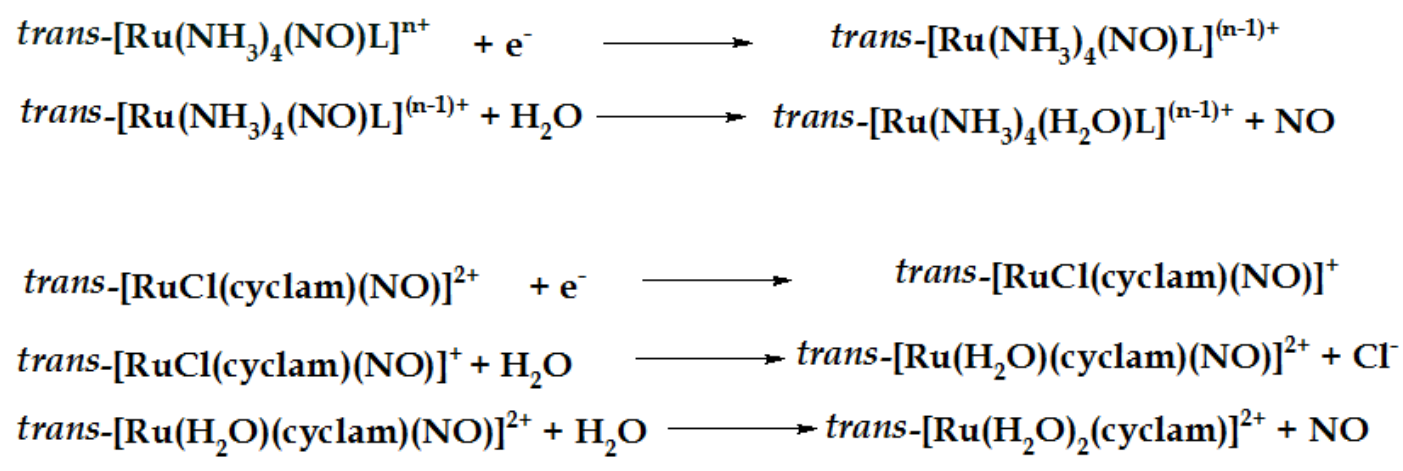

Equações 4: Liberação de NO eletroquimicamente 21,24,42-45. 
Tabela 1: Potenciais de redução de alguns nitrosilo complexos de rutênio $21,24,42-45$.

\begin{tabular}{|c|c|}
\hline Complexo & $\mathrm{E}_{(\mathrm{NO}+\text { NO-) }}(\mathrm{V}$ vs. $\mathrm{NHE})$ \\
\hline trans-[Ru($\left.\left(\mathrm{NH}_{3}\right)_{4}(\mathrm{NO})\left(\mathrm{P}(\mathrm{Oet})_{3}\right)\right]\left(\mathrm{PF}_{6}\right)_{3}$ & 0,132 \\
\hline trans-[Ru($\left.\left(\mathrm{NH}_{3}\right)_{4}(\mathrm{NO})(\mathrm{py})\right]\left(\mathrm{BF}_{4}\right)_{3}$ & 0,012 \\
\hline trans-[Ru($\left.\left(\mathrm{NH}_{3}\right)_{4}(\mathrm{NO})(\mathrm{imN})\right]\left(\mathrm{BF}_{4}\right)_{3}$ & $-0,118$ \\
\hline trans-[RuCl(cyclam)(NO)] $\left(\mathrm{PF}_{6}\right)_{2}$ & $-0,078$ \\
\hline
\end{tabular}

Tabela 2: Potenciais de redução de algumas reações importantes biologicamente ${ }^{49}$.

\begin{tabular}{|lc|} 
Reação & Potencial de redução (V vs. NHE) \\
\hline Fumarato2- $2 \mathrm{H}^{+}+2 \mathrm{e}^{-} \rightarrow$ Sucinato $^{--}$ & 0,31 \\
\hline Piruvato $^{-}+2 \mathrm{H}^{+}+2 \mathrm{e}^{-} \rightarrow$ Lactato & $-0,185$ \\
\hline FAD $^{+}+2 \mathrm{H}^{+}+2 \mathrm{e}^{-} \rightarrow$ FADH & $-0,219$ \\
\hline $\mathrm{NAD}^{+}+\mathrm{H}^{+}+2 \mathrm{e}^{-} \rightarrow \mathrm{NADH}$ & $-0,320$ \\
\hline
\end{tabular}

$\mathrm{Na}$ liberação fotoquímica do NO do complexo trans$[\operatorname{RuCl}(\text { cyclam })(\mathrm{NO})]^{2+}$ não ocorre a labilização do íon cloreto antes da saída do NO, diferente do caso da liberação eletroquímica. As equações a seguir mostram a liberação do NO fotoquimicamente: 


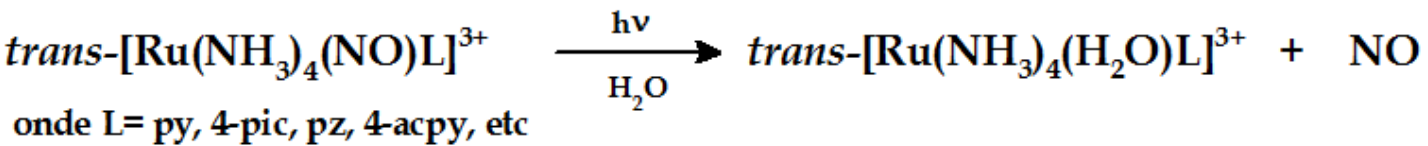

$$
\begin{aligned}
& \text { trans-[Ru( } \left.\left(\mathrm{NH}_{3}\right)_{4}\left(\mathrm{H}_{2} \mathrm{O}\right) \mathrm{L}\right]^{3+} \rightleftharpoons \text { trans- }\left[\mathrm{Ru}\left(\mathrm{NH}_{3}\right)_{4}(\mathrm{OH}) \mathrm{L}\right]^{2+}+\mathrm{H}^{+}
\end{aligned}
$$

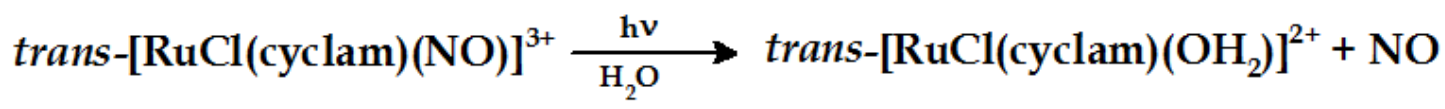
trans-[RuCl(cyclam) $\left.\left(\mathrm{H}_{2} \mathrm{O}\right) \mathrm{L}\right]^{3+} \rightleftharpoons \operatorname{trans}-[\mathrm{RuCl}(\mathrm{cyclam})(\mathrm{HO}) \mathrm{L}]^{2+}+\mathrm{H}^{+}$

Equações 5: Liberação de NO fotoquimicamente 21,24,42-45.

Um dos pontos fortes sobre a síntese dos nitrosilo complexos de rutênio, além do que já foi dito, é que as propriedades destes compostos podem ser moduladas de acordo com os ligantes aos quais eles estão coordenados. As mudanças nos ligantes mudam também propriedades como a velocidade de liberação, ou captura, do NO, a absorção no espectro UV-visível, os potenciais de redução, além da sua atividade biológica. Assim, é possível projetar complexos com as propriedades desejadas fazendo-se uma escolha adequada dos ligantes 21,24,42-45.

A imobilização dos nitrosilo complexos de rutênio em matrizes também é bastante promissora principalmente no sentido do desenvolvimento de Drug Delivery Systems (DDS), que controlariam a liberação do complexo e/ou NO 45. Pode-se citar o exemplo do trans- $\left[\mathrm{Ru}(\mathrm{NO})\left(\mathrm{NH}_{3}\right)_{4}(\mathrm{py})\right]\left(\mathrm{BF}_{4}\right)_{3} \cdot \mathrm{H}_{2} \mathrm{O}$, que foi imobilizado eficientemente em micropartículas de PLGA (do inglês, poly(lacticco-glycolic) acid)61, uma matriz polimérica biodegradável. Os ensaios de 
citotoxidade deste sistema mostraram que na ausência de luz, não há morte celular, porém, quando irradiado, o complexo encapsulado é capaz de gerar NO suficiente para ser citotóxico.

Quando começaram a ser sintetizados, esperava-se que os compostos de rutênio com cyclam (1,4,8,11-tetraazaciclotetradecano) tivessem propriedades similares às tetraaminas, devido ao fato de o cyclam ter energia de campo ligante equivalente a quatro amônias, porém, tais compostos apresentam grandes diferenças, por exemplo, o aumento da afinidade por cloretos no complexo trans-[ $\mathrm{RuCl}_{2}(\text { cyclam) }]^{2+}$ quando comparado a compostos de $\mathrm{Ru}(\mathrm{II})$ com aminas ${ }^{18}$. Outras mudanças relativas à estabilidade e propriedades fotoquímicas também podem ser observadas, além de alteração na velocidade de liberação do NO, quando este também está coordenado ao metal21,24,42-45.

Embora apresentem esta propriedade de liberação do NO quando irradiados por luz, os espectros eletrônicos de trans- $\left[\mathrm{Ru}\left(\mathrm{NH}_{3}\right)_{4} \mathrm{~L}(\mathrm{NO})\right]^{\mathrm{n}+}$ e dos $[\mathrm{Ru}(\mathrm{mac}) \mathrm{L}(\mathrm{NO})]^{\mathrm{n}+},(\mathrm{mac}=$ tetraazamacrociclo saturado $)$ não apresentam bandas de absorção acima de 400 nm 21,24,42-45,62, o que não é vantajoso do ponto de vista para aplicação destes compostos para Terapia Fotodinâmica (TFD), pois os tratamentos terapêuticos exigem que os compostos absorvam em comprimentos de onda na região da janela terapêutica. Os compostos citados não absorvem nesta faixa, mas podem ser utilizados para tratamento tópico como, por exemplo, em dermatologia ${ }^{63}$. Existem várias maneiras de 
obter a liberação de $\mathrm{NO}$ em comprimentos de onda maiores, como a coordenação a ligantes com alto grau de insaturação, como o complexo de rutênio com ftalocianina, $\left[\mathrm{Ru}(\mathrm{NO})\left(\mathrm{NO}_{2}\right)(\mathrm{pc})\right]$, que apresenta a banda de absorção em 690 nm e libera NO quando irradiado em 660 nm 64, os complexos cis-[Ru'II(bpy) $\left.{ }_{2} \mathrm{~L}\left(\mathrm{NO}^{0}\right)\right]^{2+}$ (L=4-pic, py, 4-acpy), que absorvem luz no visível e liberam NO quando irradiados a $532 \mathrm{~nm}$ 65, e nitrosilo complexos de rutênio coordenado à corantes, como a resorufina, que apresenta uma forte banda de absorção no visível, acima de $600 \mathrm{~nm}$, dentro da janela terapêutica66. Além disso, Ford et alii. 67,68 estudaram o processo de transferência de energia dos quantum dots (QD) para complexos de metais de transição com NO, com o objetivo de facilitar sua liberação em comprimentos de onda maiores, variando o tamanho do QD. Como dito anteriormente, Ford et alii 40 também sintetizaram complexos de crômio com diferentes tipos de cyclam com um cromóforo como substituinte. Todos os compostos relatados possuem bandas de absorção acima de $550 \mathrm{~nm}$. Complexos binucleares de rutênio também são uma alternativa para alcançar comprimentos de onda maiores, como o $\left[\mathrm{Ru}\left(\mathrm{NH}_{3}\right)_{5}(\mathrm{pz}) \mathrm{Ru}(\mathrm{bpy})_{2}(\mathrm{NO})\right]^{5+}{ }^{69}$, que tem bandas de absorção por volta de $550 \mathrm{~nm}$, e quando irradiado por luz de $532 \mathrm{~nm}$, libera o NO.

Uma maneira de modificar a absorção dos nitrosilo complexos de rutênio é inserir insaturações no anel do macrociclo, criando uma deslocalização eletrônica em torno do centro metálico, o que pode alterar não só a cinética de 
liberação de NO nestes compostos, como deslocar as bandas de absorção para a região do visível, tornando a TFD mais acessível para esta nova classe de compostos, assim como para o complexo com ftalocianina, $\left[\mathrm{Ru}(\mathrm{NO})\left(\mathrm{NO}_{2}\right)(\mathrm{pc})\right]$ 64, que apresenta insaturações no anel e, desta forma, torna a absorção mais acessível em comprimentos de onda maiores. E foi baseado nestas informações que tentou-se a síntese de dois complexos diferentes, com quatro insaturações, TIM, e com duas insaturações, 1,7-CT $(5,7,7,12,14,14$-hexametil-1,4,8,11tetraazaciclotetradeca-4,11-dieno), visando estudar suas propriedades e possível aplicação na TFD.
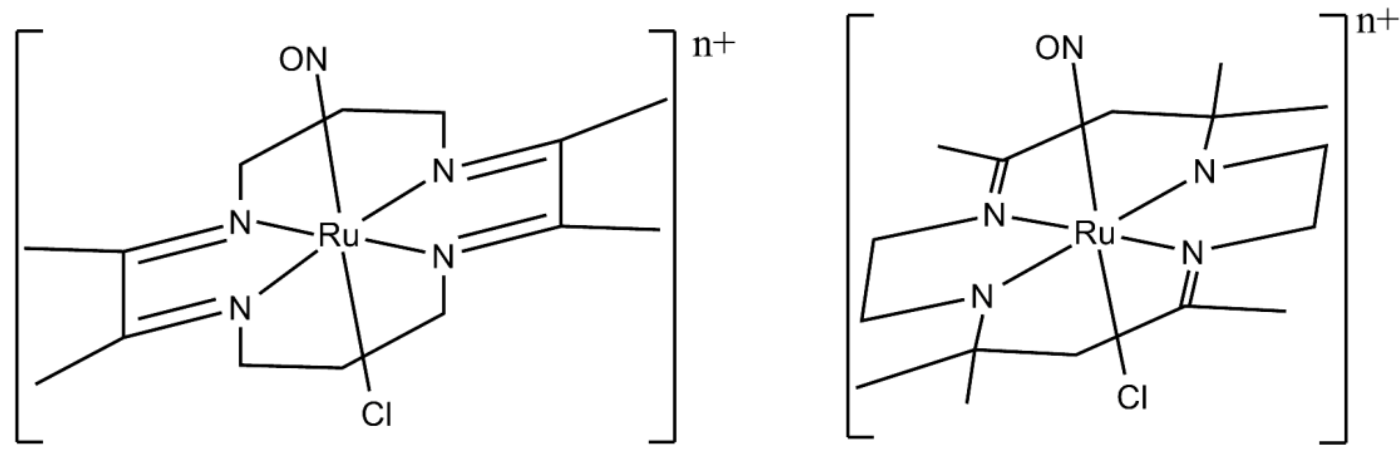

Figura 2: Estrutura dos complexos desejados com os ligantes TIM e 1,7-CT, respectivamente.

\subsection{Terapia Fotodinâmica}

A Terapia Fotodinâmica (TFD) é um tratamento relativamente novo para o combate de câncer e condições benignas caracterizadas pelo crescimento excessivo de células indesejadas. Ela utiliza fármacos 
fotossensibilizadores e luz em comprimentos de onda na região do vermelho e infravermelho próximo (comprimentos compatíveis com o espectro do fármaco) para gerar espécies reativas (como oxigênio singlete e óxido nítrico), que induzem as células, geralmente, à apoptose, o "suicídio" das células, processo fisiológico essencial para manutenção do equilibro dos tecidos, regulado por estímulos intra e extracelulares, sendo que este processo não gera inflamações, ao contrário da necrose, onde os danos celulares são altos, as células sofrem lise, e um processo inflamatório é iniciado no tecido ${ }^{70}$. Os melhores comprimentos de onda para TFD são aqueles de 800 a $1100 \mathrm{~nm}$, pois é nesta faixa que a luz penetra a pele até a hipoderme. Em comprimentos de onda maiores que $1100 \mathrm{~nm}$ a radiação infravermelha é 90\% absorvida pela água da pele, diminuindo a eficiência da penetração da luz 71, e de 500 a 800 nm ela penetra até a derme, como mostra a figura abaixo:

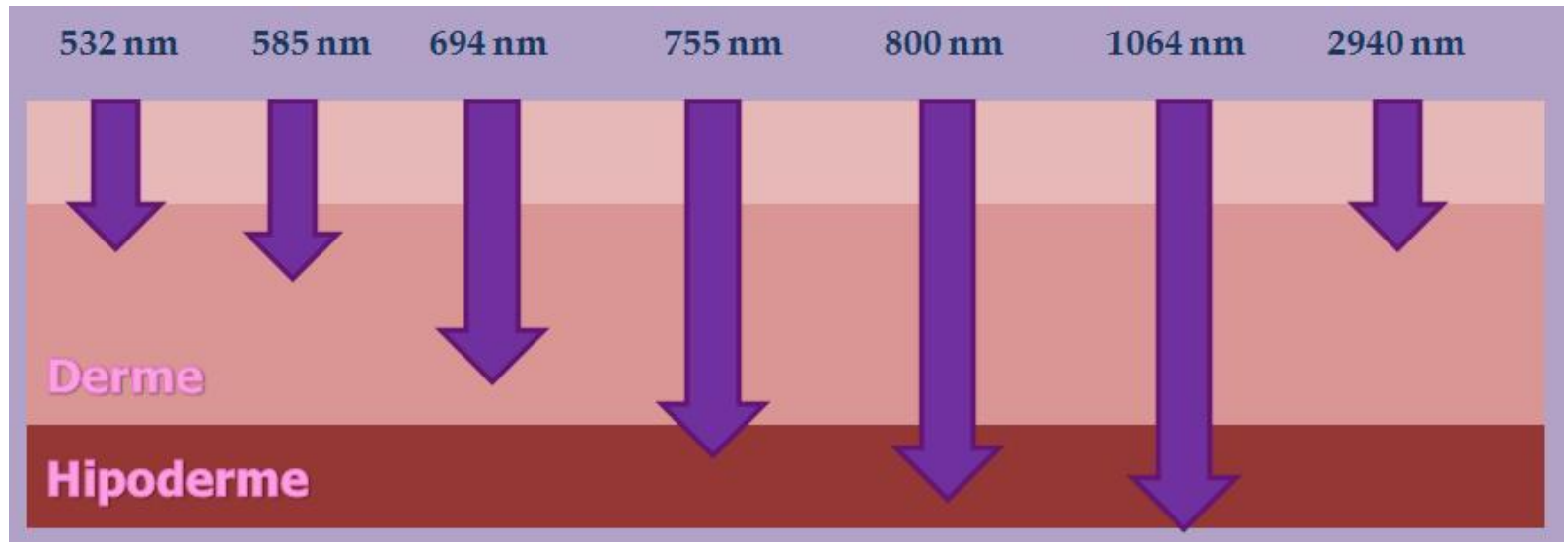

Figura 3: Esquema mostrando a penetração na pele de laser de diferentes comprimentos de onda. 
Como dito anteriormente, para que a TFD seja eficaz, com relação à penetração nos tecidos, é preciso que o espectro de absorção do fármaco esteja dentro da janela terapêutica, que começa por volta de $600 \mathrm{~nm}$, mas, mais especificamente, de 800 a $1100 \mathrm{~nm}$.

O uso da TFD para tratamento de doenças como câncer traz consigo a vantagem do controle da localização (o fármaco só é ativado pela absorção de luz) e controle da dosagem por tempo de irradiação e intensidade luminosa, tornando a terapia mais e eficiente e menos agressiva para o paciente.

Existem compostos que apresentam a propriedade de liberação de NO quando irradiados em comprimentos de onda adequados, como é o caso dos nitrosilo complexos de rutênio, que, quando irradiados, liberam o óxido nítrico e formam o aquacomplexo correspondente. Como dito anteriormente, os nitrosilo complexos de rutênio liberam $\mathrm{NO}$ quando irradiados em comprimentos de onda adequados. As modificações inseridas nas estruturas de alguns complexos trazem suas absorções para cada vez mais perto da janela terapêutica. Além disso, a imobilização destes complexos em matrizes como o PLGA 61 faz com que o complexo não seja citotóxico quando não estiver sendo irradiado, durante a terapia, por exemplo. 


\section{OBJETIVOS}

O objetivo inicial deste trabalho foi a síntese, caracterização e estudo das propriedades fotoquímicas de nitrosilo complexos de rutênio com ligantes tetraazamacrocíclicos, como TIM (2,3,9,10-tetrametil-1,4,8,11tetraazaciclotetradeca-1,3,8,10-tetraeno) e 1,7-CT (5,7,7,12,14,14-hexametil1,4,8,11-tetraazaciclotetradeca-4,11-dieno), visando sua aplicação na TFD. Porém as sínteses para obtenção destes complexos não se mostraram triviais. Desta forma, o foco do trabalho mudou e o objetivo principal passou a ser a interpretação dos resultados obtidos para os complexos de rutênio, comparando-os aos sistemas com ligantes tetraazamacrocíclicos insaturados já descritos na literatura, de forma que sua instabilidade e dificuldades de obtenção pudessem ser entendidas.

\section{PARTE EXPERIMENTAL}

\subsection{Listagem dos reagentes e solventes utilizados}

Os reagentes e solventes utilizados nas sínteses foram adquiridos comercialmente, e, na maioria das vezes, utilizados sem tratamento prévio. Aqueles que necessitaram de purificação foram tratados seguindo instruções presentes na literatura ${ }^{72}$. 
Tabela 3: Reagentes utilizados

\begin{tabular}{|c|c|c|}
\hline Reagente & Procedência & Pureza \\
\hline 1,3-diaminopropano & Aldrich & $99 \%$ \\
\hline 2,2-dimetoxipropano & Acros & $98 \%$ \\
\hline 2,3-butanodiona & Aldrich & $97 \%$ \\
\hline Acetato de potássio & $\begin{array}{lr}\text { Obtido } & \text { pela } \\
\text { neutralização } & \text { do } \\
\text { ácido acético } & \text { com } \\
\text { hidróxido } & \text { de } \\
\text { potássio } & \\
\end{array}$ & - \\
\hline Acetona & Synth & $99,5 \%$ \\
\hline Acetona- $\mathrm{d}_{6}$ & Acros & $99,9 \% \mathrm{D}$ \\
\hline Acetonitrila- $\mathrm{d}_{3}$ & Acros & $99,6 \% \mathrm{D}$ \\
\hline Ácido clorídrico & Synth & $36,5-38 \%$ em massa \\
\hline $\begin{array}{l}\text { Ácido clorídrico }-\mathrm{DCl} \\
35 \% \mathrm{em} \mathrm{D}_{2} \mathrm{O}\end{array}$ & Aldrich & $98 \% \mathrm{D}$ \\
\hline Ácido perclórico & Aldrich & $70 \%$ \\
\hline Ácido sulfúrico & Chemco & P. A. \\
\hline Ácido trifluoracético (TFA) & Acros & $99 \%$ \\
\hline $\begin{array}{l}\text { Ácido } \\
\text { trifluorometanossulfônico }\end{array}$ & Aldrich & $\geq 99 \%$ \\
\hline Água-d 2 & Aldrich & $99,9 \% \mathrm{D}$ \\
\hline Brometo de potássio - KBr & Aldrich & Grau Espectroscópico \\
\hline Cloreto de cálcio - $\mathrm{CaCl}_{2}$ & Vetec & Grau Espectroscópico \\
\hline $\begin{array}{l}\text { Cloreto de estanho(II) - } \\
\mathrm{SnCl}_{2} .2 \mathrm{H}_{2} \mathrm{O}\end{array}$ & Carlo Erba & $98 \%$ \\
\hline
\end{tabular}




\begin{tabular}{|c|c|c|}
\hline $\begin{array}{l}\text { Cloreto de rutênio(III) - } \\
\mathrm{RuCl}_{3 .} \times \mathrm{xH}_{2} \mathrm{O}\end{array}$ & Strem & $\begin{array}{llll}40-43 \% & \text { em massa de } \\
\text { Rutênio } & & & \end{array}$ \\
\hline Dimetilsulfóxido (DMSO) & Vetec & $\begin{array}{ll}99,7 \% & \text { (Grau } \\
\text { espectroscópico) } & \end{array}$ \\
\hline Dimetilsulfóxido-d $\mathrm{d}_{6}$ & Aldrich & $99,96 \% \mathrm{D}$ \\
\hline Etanol & Synth & $99,5 \%$ \\
\hline Éter Etílico & Vetec & - \\
\hline Etilenodiamina & Merck & $99 \%$ \\
\hline $\begin{array}{l}\text { Hexafluorofosfato de } \\
\text { amônio - } \mathrm{NH}_{4} \mathrm{PF}_{6}\end{array}$ & Strem & $99 \%$ \\
\hline Metanol & Vetec & 99\% (Grau HPLC) \\
\hline Metanol-d 4 & Aldrich & $99,96 \% \mathrm{D}$ \\
\hline $\begin{array}{l}\text { N,N-dimetilformamida } \\
\text { (DMF) }\end{array}$ & Aldrich & $\begin{array}{l}99,8 \% \text { (Grau } \\
\text { espectroscópico) }\end{array}$ \\
\hline Paládio em carbono & Aldrich & $10 \mathrm{wt} \%$ \\
\hline $\begin{array}{l}\text { Pentóxido de fósforo - } \\
\mathrm{P}_{4} \mathrm{O}_{10}\end{array}$ & Aldrich & $98 \%$ \\
\hline Sódio metálico & Aldrich & $99 \%$ \\
\hline $\begin{array}{l}\text { Sulfato de ferro(II) } \\
\text { heptahidratado } \\
\text { FeSO }_{4} .7 \mathrm{H}_{2} \mathrm{O}\end{array}$ & Aldrich & P.A. \\
\hline Tetrahidrofurano (THF) & Nuclear & $99,0 \%$ de pureza \\
\hline $\begin{array}{l}\text { Trifluorometanossulfonato } \\
\text { de Prata - } \mathrm{AgCF}_{3} \mathrm{SO}_{3}\end{array}$ & Aldrich & $99+\%$ de pureza \\
\hline
\end{tabular}




\subsection{Purificação dos reagentes}

\subsection{1. Éter etílico}

Adicionou-se, gota a gota, $100 \mathrm{~mL}$ de ácido sulfúrico em $1 \mathrm{~L}$ de éter, e a mistura resultante foi colocada sob refluxo durante, aproximadamente, $1 \mathrm{~h}$, e, após este período, o éter foi coletado por destilação. Ao produto da destilação, adicionou-se sódio metálico cortado em lascas finas, e, após observar que a produção de hidrogênio havia cessado, o éter foi novamente destilado e armazenado na presença de peneiras moleculares previamente lavadas, secas e ativadas.

\subsubsection{Acetona}

A acetona foi tratada a fim de que a água presente fosse retirada. Para isso, a acetona foi refluxada na presença de $\mathrm{P}_{4} \mathrm{O}_{10}$, que sofreu hidrólise, formando ácido fosfórico, e a mistura foi mantida sob refluxo até que uma coloração vermelha bastante intensa fosse observada.. Após isto, a acetona foi destilada, e o produto da destilação foi armazenado em peneiras moleculares previamente lavadas, secadas e ativadas.

$$
\mathrm{P}_{4} \mathrm{O}_{10(\mathrm{~s})}+6 \mathrm{H}_{2} \mathrm{O}_{(\mathrm{l})} \longrightarrow 4 \mathrm{H}_{3} \mathrm{PO}_{4(\mathrm{aq})}
$$

Equação 6: Reação de hidrólise do pentóxido de fósforo. 


\subsubsection{1,3-diaminopropano e $\mathrm{N}, \mathrm{N}$-dimetilformamida}

Tanto o 1,3-diaminopropano, quanto a N,N-dimetilformamida foram tratados para a retirada de traços de água. Para isso, em ambos os casos, utilizou-se $\mathrm{P}_{4} \mathrm{O}_{10}$, em um processo de microdestilação sob pressão reduzida, devido aos elevados pontos de ebulição destes reagentes (1,3-diaminopropano, $140{ }^{\circ} \mathrm{C}$, e N,N-dimetilformamida, $153{ }^{\circ} \mathrm{C}$ ). O produto de cada destilação foi armazenado na presença de peneiras moleculares previamente lavadas, secadas e ativadas.

\subsubsection{Metanol}

Embora o metanol utilizado nas sínteses fosse grau HPLC, este foi submetido à destilação na presença do agente secante $\mathrm{CaCl}_{2}$, para que fossem removidos quaisquer traços de água presentes. O produto da destilação foi armazenado na presença de peneiras moleculares previamente lavadas, secas e ativadas.

\section{3. $\quad$ Sínteses}

\subsubsection{Síntese dos compostos utilizados como precursores}

\section{a) $\left[\mathrm{Ru}(\mathrm{dmf})_{6}\right]\left(\mathrm{CF}_{3} \mathrm{SO}_{3}\right)_{2}$}

Esta síntese foi adaptada da literatura ${ }^{73}$. Em um balão de três bocas, adicionou-se $0,6 \mathrm{~g}\left(1,9 \times 10^{-3} \mathrm{~mol}\right)$ de $\mathrm{RuCl}_{3 .} n \mathrm{H}_{2} \mathrm{O}$, dissolvidos em $40 \mathrm{~mL}$ de DMF, e, a esta solução marrom, 1-2 mg de paládio adsorvido em carbono. Em 
seguida, borbulhou-se hidrogênio durante três horas, até que a solução ficasse saturada, o que pode ser observado pela mudança de cor do meio de marrom para azul. Após a saturação do meio, substituiu-se o hidrogênio por argônio, que formou a atmosfera inerte no sistema. Na etapa seguinte, adicionou-se 2,16 g $\left(8.4 \times 10^{-3} \mathrm{~mol}\right)$ de $\mathrm{AgCF}_{3} \mathrm{SO}_{3}$, sendo possível observar a formação de precipitado $(\mathrm{AgCl})$ logo após a adição. Então, o sistema foi colocado em refluxo a $153{ }^{\circ} \mathrm{C}$ durante quarenta minutos. Após este tempo, a solução, agora amarela, foi resfriada a $0{ }^{\circ} \mathrm{C}$ e filtrada, e, então, o solvente (DMF) foi retirado utilizando um evaporador rotativo. Nesta etapa, foram obtidos 2,0 $\mathrm{g}\left(1,9 \times 10^{-3}\right.$ mol) de produto, $\left[\mathrm{Ru}\left(\mathrm{C}_{3} \mathrm{H}_{7} \mathrm{ON}\right)_{6}\right]\left(\mathrm{CF}_{3} \mathrm{SO}_{3}\right)_{3}$, cerca de $81 \%$ de rendimento . O produto da etapa anterior foi diluído em $60 \mathrm{~mL}$ de $\mathrm{DMF}$, e, a cada alíquota de 20 mL, e adicionou-se 1-2 mg de paládio adsorvido em carbono. Borbulhou-se hidrogênio por, aproximadamente $2 \mathrm{~h}$, e, após este tempo, observou-se a mudança de cor do meio, de amarelo para vermelho. O paládio em carbono foi retirado do meio por filtração e o produto foi mantido em solução para imediata utilização na síntese do composto $\left[\mathrm{Ru}(\mathrm{TIM})(\mathrm{dmf})_{2}\right]^{2+}$. O rendimento do produto, $\left[\mathrm{Ru}\left(\mathrm{C}_{3} \mathrm{H}_{7} \mathrm{ON}\right)_{6}\right]\left(\mathrm{CF}_{3} \mathrm{SO}_{3}\right)_{2}$, é de, aproximadamente, $88 \%(1,5 \mathrm{~g}$; $\left.1,8 \times 10^{-3} \mathrm{~mol}\right)$, com relação à etapa anterior. 


\section{b) $\operatorname{cis}-\left[\mathrm{RuCl}_{2}\left(\mathrm{dmso}_{4}\right]\right.$}

A síntese deste composto foi realizada de acordo com o descrito na literatura ${ }^{74}$. Em $10 \mathrm{ml}$ de dimetilsulfóxido (DMSO), dissolveu-se 1,00 g $\left(4,00 \times 10^{-3} \mathrm{~mol}\right)$ de $\mathrm{RuCl}_{3} \cdot n \mathrm{H}_{2} \mathrm{O}$ e refluxou-se a solução a $160{ }^{\circ} \mathrm{C}$ durante 5 minutos, em atmosfera de argônio e protegida da luz. Após este período, resfriou-se a solução em banho de gelo por 30 minutos, e já foi possível observar a formação de precipitado amarelo. Este foi recolhido por filtração, lavado com etanol e secado a vácuo. Adicionando-se acetona ao sobrenadante recolhido, é possível obter um pouco mais de composto, mas a quantidade obtida não foi levada em consideração. (Rendimento $\left[\mathrm{RuCl}_{2}\left(\mathrm{C}_{2} \mathrm{H}_{6} \mathrm{OS}\right)_{4}\right]: 1,65 \mathrm{~g}$; $\left.3,4 \times 10^{-3} \mathrm{~mol} ; 85 \%\right)$.

\subsubsection{Síntese dos ligantes macrocíclicos}

As sínteses dos ligantes tetraazamacrocíclicos foram feitas segundo o descrito na literatura 75 , inserindo algumas modificações, quando necessário.

\section{a) Bis (trifluormetanossulfonato) de 5,7,7,12,14,14-hexametil-1,4,8,11-}

\section{tetraazaciclotetradeca-4,11-dieno}

Em um frasco cônico, adicionou-se 1,8 mL (3,0x10-2 mol) de etilenodiamina a $30 \mathrm{~mL}$ de metanol anidro, e, lentamente, gotejou-se $5 \mathrm{~g}\left(3 \times 10^{-2} \mathrm{~mol}\right)$ de ácido trifluorometanossulfônico, utilizando um funil de adição, sempre mantendo a agitação da solução. Após a adição do ácido, a solução foi filtrada à quente, e o 
solvente retirado em um evaporador rotativo. Observou-se a formação de um sólido com coloração bege claro, que foi colocado para secar a vácuo em um dessecador na presença de pentóxido de fósforo. O sólido anidro foi então dissolvido em acetona anidra, e, à solução, adicionou-se 2-3 gotas de 2,2dimetoxipropano. A mistura foi refluxada por 2 h, até que a solução adquirisse uma coloração vermelha escura, já sendo possível observar a formação de alguns cristais brancos. Após o resfriamento da solução à temperatura ambiente, evaporou-se metade do volume do solvente utilizando-se um evaporador rotativo, e coletou-se o sólido por meio de filtração, lavando-o com éter etílico e tetrahidrofurano (THF). (Rendimento $\mathrm{C}_{16} \mathrm{H}_{32} \mathrm{~N}_{4} \cdot 2 \mathrm{CF}_{3} \mathrm{SO}_{3}: 6,0 \mathrm{~g}$; $\left.1,0 \times 10^{-2} \mathrm{~mol} ; 69 \%\right)$.

b) Diperclorato de 5,7,7,12,14,14-hexametil-1,4,8,11-tetraazaciclotetradeca-

\section{4,11-dieno}

Em um béquer de $250 \mathrm{~mL}$, adicionou-se $50 \mathrm{~mL}$ de acetona anidra e 2,0 $\mathrm{g}$ $\left(2,2 \mathrm{~mL}, 3 \times 10^{-2} \mathrm{~mol}\right)$ de etilenodiamina. Esta solução foi agitada enquanto 5,5 g (3,3 mL, 5,5×10-2 mol) de ácido perclórico $60 \%$ eram adicionados gota a gota. Observou-se o aumento da temperatura do meio reacional, e a mudança de cor de incolor para vermelho ao final da adição do ácido. A solução foi, então, agitada rapidamente e resfriada à temperatura ambiente, quando foi possível observar a formação do precipitado branco, que foi retirado por filtração, 
lavado com acetona e secado a vácuo. (Rendimento $\mathrm{C}_{16} \mathrm{H}_{32} \mathrm{~N}_{4} \cdot 2 \mathrm{HClO}_{4}: 5,83$ g; 1,21×10-2 mol; $73 \%)$.

As sínteses dos seguintes macrociclos foram feitas visando sua aplicação para oxidação do ligante após complexação com o metal.

c) Hidrato de 5,7,7,12,14,14-hexametil-1,4,8,11-tetraazaciclotetradecano (mistura de isômeros)

5,0 $\mathrm{g}$ de diperclorato de 5,7,7,12,14,14-hexametil-1,4,8,11tetraazaciclotetradeca-4,11-dieno foram dissolvidos em $25 \mathrm{~mL}$ de metanol. A solução foi agitada e 1,0 $\mathrm{g}$ de boroidreto de sódio $\left(2,6 \times 10^{-2} \mathrm{~mol}\right)$ e $0,83 \mathrm{~g}$ de hidróxido de sódio foram adicionados alternadamente por aproximadamente 30 minutos. Concluída a adição, a solução foi agitada durante 1 hora e, então, refluxada por 15 minutos. Após seu resfriamento, 2,5 g de hidróxido de sódio em $50 \mathrm{~mL}$ de água foram adicionados à solução, que foi agitada até que a precipitação do produto estivesse completa. O produto foi lavado com água gelada e secado a vácuo durante uma noite. (Rendimento: 2,35 g; 83\%)

Diastereoisômeros: $(\mathrm{R}, \mathrm{S})$ e $(\mathrm{S}, \mathrm{R})-\mathbf{5 , 7 , 7 , 1 2 , 1 4 , 1 4 - h e x a m e t i l - 1 , 4 , 8 , 1 1 -}$ tetraazaciclotetradecano

O produto da síntese anterior $\left(2,35 \mathrm{~g} ; 8,35 \times 10^{-3} \mathrm{~mol}\right)$ foi dissolvido em 30 $\mathrm{mL}$ de metanol à temperatura de refluxo $\left(65^{\circ} \mathrm{C}\right)$ e filtrado ainda quente para retirar um sólido marrom que permanece após o aquecimento. O filtrado é diluído para $30 \mathrm{~mL}$ novamente, e a solução é reaquecida até refluxo. $18 \mathrm{~mL}$ 
foram adicionados à solução quente, que foi agitada e resfriada à temperatura ambiente. O precipitado com textura fina é o isômero meso, que é removido da solução por filtração, lavado com água gelada e secado à vácuo na presença de $\mathrm{P}_{4} \mathrm{O}_{10}$. (Rendimento $\mathrm{C}_{16} \mathrm{H}_{34} \mathrm{~N}_{4} \cdot 2 \mathrm{H}_{2} \mathrm{O}: 0,85 \mathrm{~g} ; 2,67 \times 10^{-3} \mathrm{~mol} ; 36 \%$ ).

Estereoisômeros $\quad(\mathrm{R}, \mathrm{R}) \quad$ e $\quad(\mathrm{S}, \mathrm{S})-\quad$ 5,7,7,12,14,14-hexametil-1,4,8,11-

\section{tetraazaciclotetradecano}

Ao filtrado resultante após a remoção do isômero meso, adicionou-se cerca de $10 \mathrm{~mL}$ de água e a solução foi agitada rapidamente, havendo a formação de precipitado, que é retirado da solução por filtração (mistura dos isômeros meso e racêmico). O filtrado foi secado em um evaporador rotativo, e o sólido resultante foi lavado com água gelada e seco à vácuo na presença de $\mathrm{P}_{4} \mathrm{O}_{10}$. (Rendimento $\mathrm{C}_{16} \mathrm{H}_{34} \mathrm{~N}_{4} \cdot \mathrm{H}_{2} \mathrm{O}: 0,75 \mathrm{~g} ; 2,50 \times 10^{-3} \mathrm{~mol} ; 32 \%$ ).

\subsubsection{Síntese dos complexos metálicos}

\section{a) Síntese do $\left[\operatorname{Ru}(\mathrm{TIM})(\mathrm{dmf})_{2}\right]^{2+}$}

A solução de $\left[\mathrm{Ru}(\mathrm{dmf})_{6}\right]^{2+}$, contendo, aproximadamente, $1 \mathrm{~g}\left(1 \times 10^{-3} \mathrm{~mol}\right)$ do complexo, foi colocada em um funil de adição, e borbulhou-se argônio. Em um balão de três bocas, DMF $(15 \mathrm{~mL})$ foi resfriada e mantida em temperaturas abaixo de $5^{\circ} \mathrm{C}$ durante as adições sucessivas de 1,3-diaminopropano $(2,15 \mathrm{~mL}$ - 2,55x10-2 mol), ácido trifluoroacético (1,91 mL - 2,49x10-2 mol) e 2,3butanodiona (2,25 mL - 2,59×10-2 mol), porém não observou-se a formação do 
intermediário de coloração amarela, como descrito na literatura ${ }^{12}$. Então o sistema foi fechado, e passou-se argônio durante 50 minutos. Após este período, o conteúdo do funil foi adicionado ao balão, porém não se observou nenhuma mudança com relação à cor e/ou formação de precipitado. Mesmo assim, tentou-se isolar o produto da síntese, mas a tentativa não foi bem sucedida, como será discutido na próxima seção, não sendo possível estimar o rendimento da reação.

\section{b) Síntese do [Ru(TIM)Cl 2$]$}

A síntese a seguir foi feita com adaptações de acordo com o descrito na literatura para o complexo de ferro análogo ${ }^{12}$. A $25 \mathrm{~mL}$ de metanol, adicionouse $0,52 \mathrm{~g}$ de cloreto de rutênio(III) $\left(\mathrm{RuCl}_{3} \cdot n \mathrm{H}_{2} \mathrm{O} ; 2,0 \times 10^{-3} \mathrm{~mol}\right)$ e, à solução obtida, $2,3 \mathrm{~g}\left(1,0 \times 10^{-2} \mathrm{~mol}\right)$ de $\mathrm{SnCl}_{2} \cdot 2 \mathrm{H}_{2} \mathrm{O}$ (cerca de dez vezes em excesso). Com a adição do redutor, o meio passa de marrom para azul marinho (formação do azul de rutênio) ${ }^{76}$. A solução resultante foi colocada em um funil de adição, e deixou-se passar argônio durante 40 minutos. Em um balão, metanol $(50 \mathrm{~mL})$ foi resfriado e mantido em temperaturas abaixo de $5{ }^{\circ} \mathrm{C}$ durante as adições sucessivas de 1,3-diaminopropano $\left(6,70 \mathrm{~mL}-8,03 \times 10^{-2}\right.$ mol), ácido trifluoroacético $\left(6,00 \mathrm{~mL}-7,84 \times 10^{-2} \mathrm{~mol}\right)$ e uma solução de 2,3butanodiona $\left(7,00 \mathrm{~mL}-8,05 \times 10^{-2} \mathrm{~mol}\right)$ em $7 \mathrm{~mL}$ de metanol. A solução resultante, de coloração amarela, foi mantida em banho de gelo e sob 
atmosfera de argônio durante 40 minutos e, após este período, adicionou-se, gota a gota, a solução de azul de rutênio, durante meia hora, aproximadamente. Após o gotejamento das primeiras gotas da solução do funil, acetato de potássio $\left(0,40 \mathrm{~g}-4,08 \times 10^{-3} \mathrm{~mol}\right)$ foi adicionado ao balão. Após o término da adição do precursor, tanto a atmosfera inerte, quanto o banho de gelo foram mantidos, até que houvesse a mudança de cor do meio de índigo para roxo. O conteúdo do balão foi evaporado em temperatura ambiente e sob pressão reduzida em um evaporador rotativo e, depois, armazenado em um dessecador hermeticamente fechado, porém não houve sucesso nas tentativas de isolamento e purificação, e, devido a isto, não foi possível estimar o rendimento da reação.
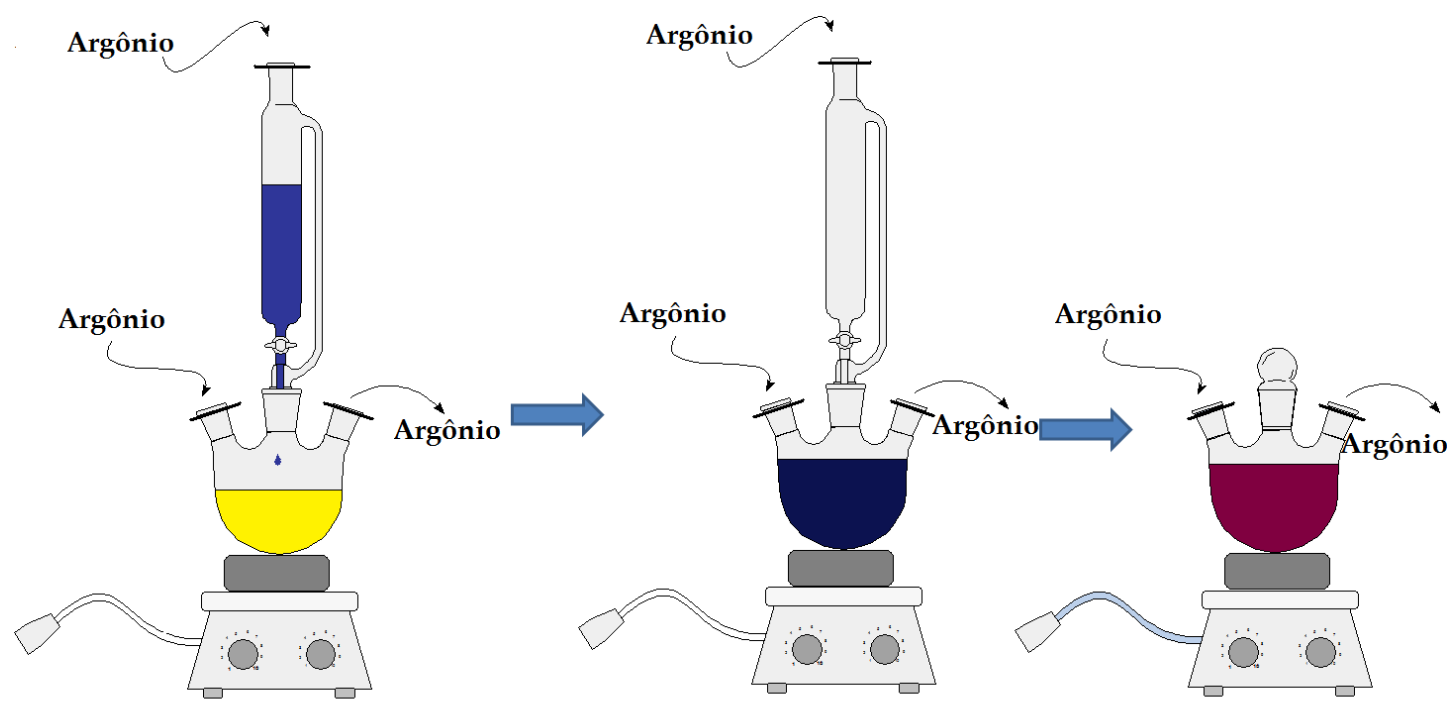

Figura 4: Esquema mostrando o decorrer da reação para formação do composto desejado [Ru(TIM) $\left.\mathrm{Cl}_{2}\right]$. 


\section{c) Síntese do $\left[\mathrm{Fe}(\mathrm{TIM})\left(\mathrm{CH}_{3} \mathrm{CN}\right)_{2}\right]\left(\mathrm{PF}_{6}\right)_{2}$}

A síntese deste composto foi feita de acordo com o descrito na literatura, com algumas modificações ${ }^{12}$. A $125 \mathrm{~mL}$ de metanol, adicionou-se $2,3 \mathrm{~g}$ (1,0x10$2 \mathrm{~mol}$ ) de $\mathrm{SnCl}_{2} \cdot 2 \mathrm{H}_{2} \mathrm{O}$ e passou-se argônio durante 15 minutos, à solução obtida. Ainda em atmosfera de argônio, adicionou-se 22,0 g de sulfato de ferro(II) heptaidratado $\left(\mathrm{FeSO}_{4} .7 \mathrm{H}_{2} \mathrm{O} ; 8,0 \times 10^{-2} \mathrm{~mol}\right)$ e o sistema foi colocado sob refluxo durante 10 minutos. Em um balão, metanol $(50 \mathrm{~mL})$ foi resfriado e mantido em temperaturas abaixo de $5{ }^{\circ} \mathrm{C}$ durante as adições sucessivas de 1,3diaminopropano $\left(6,70 \mathrm{~mL}-8,03 \times 10^{-2} \mathrm{~mol}\right)$, ácido trifluoroacético $(6,00 \mathrm{~mL}-$ $\left.7,84 \times 10^{-2} \mathrm{~mol}\right)$ e uma solução de 2,3-butanodiona $\left(7,00 \mathrm{~mL}-8,05 \times 10^{-2} \mathrm{~mol}\right)$ em $7 \mathrm{~mL}$ de metanol. A solução resultante, de coloração amarela, foi mantida em banho de gelo e sob atmosfera de argônio durante 40 minutos e, após este período, adicionou-se, gota a gota, a solução verde pálido de $\mathrm{Fe}^{2+}$, contendo o redutor. A solução resultante é azul profundo. Após a adição das primeiras gotas da solução do funil, acetato de potássio $\left(0,40 \mathrm{~g}-4,08 \times 10^{-3} \mathrm{~mol}\right)$ foi adicionado ao balão, e, quando toda a solução de sulfato ferroso foi adicionada ao balão, deixou-se que este esquentasse à temperatura ambiente, mas a atmosfera de argônio foi mantida até a adição de $25 \mathrm{~mL}$ de ácido acético glacial $(0,4 \mathrm{~mol})$ e $25 \mathrm{~mL}$ de acetonitrila $(0,4 \mathrm{~mol})$, observando-se a mudança da cor do meio de oliva para vermelho. A solução foi filtrada e o volume resultante foi diminuído pela metade utilizando-se um evaporador rotativo, sem que a solução fosse aquecida. A solução foi novamente filtrada, e o 
sobrenadante foi resfriado a $10{ }^{\circ} \mathrm{C}$, e, então, uma solução de hexafluorofosfato de amônio (10 g , 6,1×10-2 mol) em $80 \mathrm{~mL}$ de água foi adicionada. Após agitação, foi possível observar a formação do precipitado fúcsia microcristalino, que foi removido da solução por filtração e secado a vácuo na presença de $\mathrm{P}_{4} \mathrm{O}_{10}$. (Rendimento: 3,80 g; 6,05×10-3 $\mathrm{mol} ; 7 \%$ ).

\section{d) Síntese do cis-[Ru(1,7-CT) $\left.\mathrm{Cl}_{2}\right] \mathrm{Cl}$}

A síntese deste composto foi baseada no método para obtenção do cis$\left[\mathrm{RuCl}_{2}\right.$ (cyclam) $] \mathrm{Cl}{ }^{74}$. A $25 \mathrm{~mL}$ de etanol, adicionou-se $0,250 \mathrm{~g}\left(5,15 \times 10^{-4} \mathrm{~mol}\right)$ de $c i s-\left[\mathrm{RuCl}_{2}(\mathrm{dmso})_{4}\right]$, e, para que o composto fosse completamente dissolvido, aqueceu-se a mistura. O ligante $(1,7-\mathrm{CT})\left(0,300 \mathrm{~g}-5,15 \times 10^{-4} \mathrm{~mol}\right)$ foi dissolvido em 40 mL de etanol, e esta solução foi transferida para um funil de adição e, então, o sistema foi mantido em atmosfera de argônio. Após o término da adição do conteúdo do funil, a temperatura foi aumentada para $70{ }^{\circ} \mathrm{C}$ e o refluxo foi mantido por $2 \mathrm{~h}$. Ao final deste período, adicionou-se, lentamente, 5 $\mathrm{ml}(0,06 \mathrm{~mol})$ de $\mathrm{HCl}$ concentrado e borbulhou-se ar na solução para oxidar o $\mathrm{Ru}(\mathrm{II})$ a $\mathrm{Ru}(\mathrm{III})$. Refluxou-se a mistura por $4 \mathrm{~h}$ a $70{ }^{\circ} \mathrm{C}$ e, após resfriar, adicionou-se éter etílico à solução, que foi deixada na geladeira para que o complexo precipitasse. A massa obtida foi em torno de $5 \mathrm{mg}$, o que seria $1 \times 10^{-5}$ mol, considerando que o composto foi formado, correspondente a $2 \%$ de rendimento. 


\subsection{Espectroscopia}

Os espectros de UV-visível foram obtidos utilizando-se o espectrofotômetro de arranjo de diodos Hewlett Packard modelo HP8452A, em cubetas de quartzo com 1,00 cm de caminho óptico. Os espectros de RMN ${ }^{1} \mathrm{H}$ foram gerados pelos espectrômetros Bruker modelo DRX-400 (400 MHz) e DRX-500 (500 MHz), e os espectros de infravermelho foram obtidos empregando o espectrofotômetro FTIR da Bomem modelo MB 102, utilizandose pastilhas de $\mathrm{KBr}$.

\section{RESULTADOS E DISCUSSÃO}

O objetivo original deste trabalho era a síntese e estudo das propriedades de nitrosilocomplexos de rutênio com ligantes tetraazamacrocíclicos insaturados e, para isso, tentou-se duas estratégias diferentes: a síntese template e a metalação do ligante, sendo que a primeira foi utilizada nas tentativas de obtenção dos complexos de rutênio com ligante TIM e a segunda, nas tentativas de obtenção do complexo 1,7-CT.

A síntese dos precursores e dos ligantes macrocíclicos foi feita de acordo com o descrito na literatura inserindo modificações, quando necessário. As 
adaptações e informações adicionais como dados espectroscópicos serão discutidos ao longo desta seção, de acordo com a necessidade.

\subsection{Síntese do composto $\left[\mathrm{Ru}(\mathrm{TIM})(\mathrm{dmf})_{2}\right]^{2+}$}

A primeira estratégia para obtenção do complexo de rutênio tendo o macrociclo TIM como ligante foi a síntese template utilizando o trifluorometanossulfonato de hexakis(N,N-dimetilformamida) rutênio(II) $\left(\left[\mathrm{Ru}(\mathrm{dmf})_{6}\right]\left(\mathrm{CF}_{3} \mathrm{SO}_{3}\right)_{2}\right)$ como precursor. Este composto foi escolhido devido ao fato de que nele a N,N-dimetilformamida é lábil em relação à substituição, o que favoreceria a formação do composto com o ligante macrocíclico, além de que todos os seus ligantes são iguais, não havendo preferência pela troca de um em detrimento de outro (formação de isômeros). Em linhas gerais, a síntese do precursor deveria ser simples, já que o solvente é o próprio ligante e os cloretos provenientes do cloreto de rutênio(III) seriam retirados do meio como cloreto de prata após a adição do trifluorometanossulfonato de prata. Porém nunca se conseguiu obter um sólido cristalino como o descrito na literatura ${ }^{73}$. Tanto para $\mathrm{Ru}(\mathrm{III})$ quanto para $\mathrm{Ru}(\mathrm{II})$, o que se obteve ao final das sínteses era uma espécie de sólido deliquescente. Devido a isto, utilizou-se espectrofotometria de UV-visível para observar a formação dos complexos $\left[\mathrm{Ru}(\mathrm{dmf})_{6}\right]^{3+} \mathrm{e}\left[\mathrm{Ru}(\mathrm{dmf})_{6}\right]^{2+}$, onde as soluções foram feitas em DMF para evitar 
a troca dos ligantes. A figura 5 traz os espectros das espécies $\left[\mathrm{Ru}(\mathrm{dmf})_{6}\right]^{3+}$ e $\left[\operatorname{Ru}(\mathrm{dmf})_{6}\right]^{2+}:$
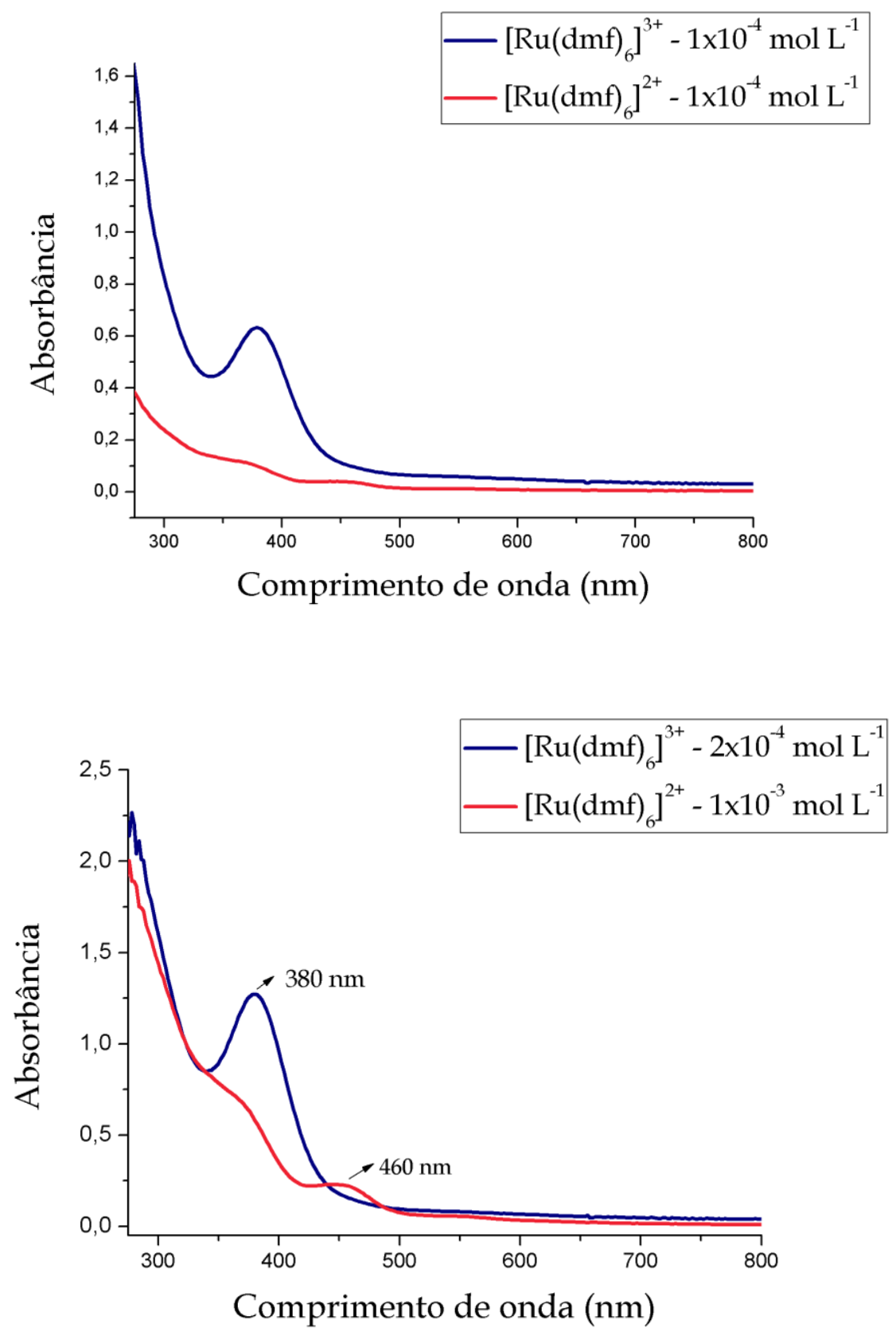

Figura 5: Espectros de absorção na região do UV-visível dos complexos $\left[\mathrm{Ru}(\mathrm{dmf})_{6}\right]^{3+} \mathrm{e}\left[\mathrm{Ru}(\mathrm{dmf})_{6}\right]^{2+}$ obtidos em DMF. 
No espectro do complexo $\left[\mathrm{Ru}(\mathrm{dmf})_{6}\right]^{3+}$ observa-se uma intensa banda de absorção atribuída a uma transição de transferência de carga do ligante para o metal (TCLM) ${ }^{73}$ na região de $380 \mathrm{~nm}$, que se soma à fraca absorção de uma transição d-d, diferente do complexo $\left[\mathrm{Ru}(\mathrm{dmf})_{6}\right]^{2+}$, cujo espectro não apresenta a TCLM, podendo-se observar a banda de absorção da transição d-d na região de $460 \mathrm{~nm}{ }^{73}$. Esta foi uma forma qualitativa de observar se a redução do centro metálico estava, de fato, ocorrendo. Como dito anteriormente, a maior dificuldade com relação à síntese do precursor foi o fato de não ter sido possível obtê-lo na forma sólida, o que atrapalhou, por exemplo, a pesagem do complexo para preparação de soluções com concentração conhecida para o cálculo da absortividade molar do complexo $\left[\mathrm{Ru}(\mathrm{dmf})_{6}\right]^{2+}$. Embora o valor de $R^{2}$ não seja totalmente adequado $(0,989)$, a absortividade molar encontrada foi bastante próxima ao descrito na literatura $73,186 \mathrm{M}^{-1} \mathrm{~cm}^{-1}$ para o descrito e 187 $\mathrm{M}^{-1} \mathrm{~cm}^{-1}$ para o encontrado.

Uma vez sintetizado, o passo seguinte foi a utilização deste precursor para a obtenção do complexo $\left[\mathrm{Ru}(\mathrm{TIM})(\mathrm{dmf})_{2}\right]^{2+}$, seguindo o método adaptado da literatura ${ }^{12}$, utilizando a síntese template para obtenção do produto. Nesta etapa a grande labilidade dos ligantes do precursor $\left[\mathrm{Ru}(\mathrm{dmf})_{6}\right]^{2+}$ que, até então, havia sido a grande vantagem da sua utilização, tornou-se um empecilho para a escolha do meio onde a reação deveria acontecer. Tendo isto em vista, optou-se pelo uso do DMF como solvente da reação, porém, não 
houve sucesso nas tentativas de obtenção do complexo $\left[\operatorname{Ru}(\mathrm{TIM})(\mathrm{dmf})_{2}\right]^{2+}$, mesmo repetindo-se o processo várias vezes. Uma das falhas neste método foi, justamente, o uso do solvente aprótico, que não favoreceu a formação do ligante segundo o mecanismo apropriado, como pôde ser observado nas adições sucessivas de 1,3-diaminopropano, TFA e 2,3-butanodiona em metanol, um solvente prótico, como será discutido posteriormente. Além do não favorecimento do mecanismo de formação do ligante, o alto ponto de ebulição do $\operatorname{DMF}\left(153{ }^{\circ} \mathrm{C}\right.$, aproximadamente) não permitiu a retirada do solvente sem aquecimento, como é necessário em uma das etapas da síntese. Além disso, a alta concentração de DMF no meio favorece o deslocamento do equilíbrio no sentido dos reagentes (complexo precursor), prejudicando a formação do $\left[\mathrm{Ru}(\mathrm{TIM})(\mathrm{dmf})_{2}\right]^{2+}$. Por fim, a solubilidade do $\left[\mathrm{Ru}(\mathrm{dmf})_{6}\right]\left(\mathrm{CF}_{3} \mathrm{SO}_{3}\right)_{2}$ é muito baixa em metanol, o que pôs fim às tentativas de obtenção do composto de rutênio com ligante TIM por este método.

\subsection{Síntese do composto $\left[\mathrm{Ru}(\mathrm{TIM}) \mathrm{Cl}_{2}\right]$}

Ainda utilizando o efeito template como estratégia, tentou-se a obtenção do composto $\left[\mathrm{Ru}(\mathrm{TIM}) \mathrm{Cl}_{2}\right.$ ] seguindo o método descrito por Rose et alii. ${ }^{12}$ para a síntese do complexo $\left[\mathrm{Fe}(\mathrm{TIM})\left(\mathrm{CH}_{3} \mathrm{CN}\right)_{2}\right]\left(\mathrm{PF}_{6}\right)_{2}$, mantendo-se excesso de íons cloreto para que um dicloro complexo fosse obtido. 
A princípio, a síntese do composto com rutênio teve muitas similaridades com relação à com ferro, porém, a maior dificuldade de todas foi a tentativa de isolar o composto, não sendo possível, como poderá ser visto por meio dos espectros, obter o composto com um grau de pureza aceitável. Não havendo sucesso nas tentativas de precipitar o composto com solventes de diferentes polaridades, e com diferentes contraíons, o conteúdo do balão reacional foi secado sob pressão reduzida em um evaporador rotativo, obtendo-se, desta forma, o extrato seco da reação, e foi a partir dele que se obtiveram os espectros de infravermelho e de RMN. Os espectros na região do UV-visível foram feitos durante a reação com a finalidade de verificar sua ocorrência ou não, já que apenas visualmente não foi possível afirmar nada pela mudança de cor do meio. A figura 6 traz os espectros de absorção na região do UV-visível de alíquotas retiradas durante a reação. 


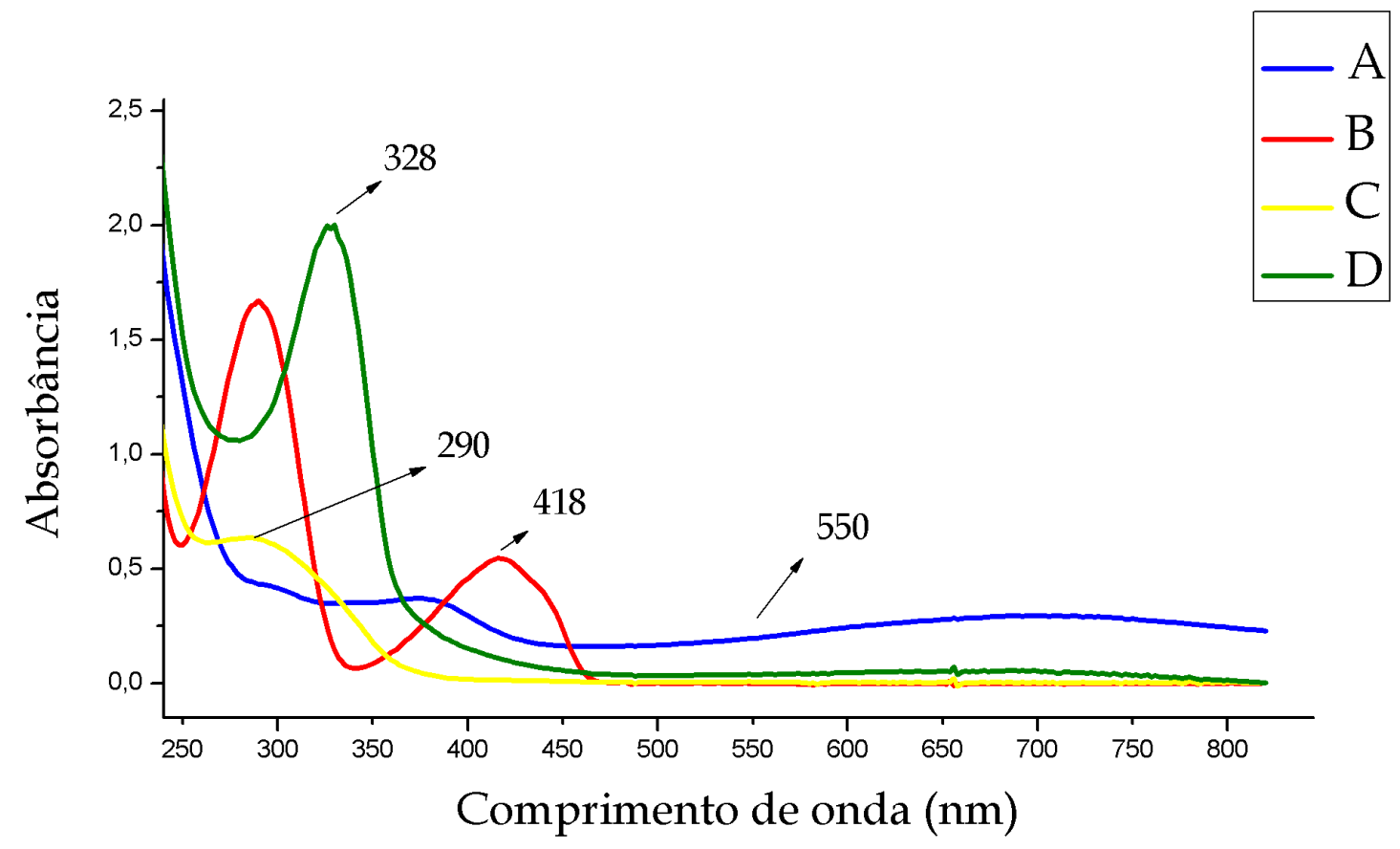

Figura 6: Espectros de absorção na região UV-visível obtidos em metanol. A: Espectro obtido a partir de uma alíquota de $160 \mu \mathrm{L}$ da solução de $\mathrm{RuCl}_{3} . n \mathrm{H}_{2} \mathrm{O}$ após a redução com $\mathrm{Sn}^{2+}$ (azul de rutênio). B: Espectro obtido a partir de $160 \mu \mathrm{L}$ de 2,3butadiona. C: Espectro obtido a partir de uma alíquota de $160 \mu \mathrm{L}$ que foi retirada 2 min após a mistura de 1,3-diaminopropano, TFA e 2,3-butadiona. D: Espectro obtido a partir de uma alíquota de $160 \mu \mathrm{L}$ retirada do meio reacional após 30 min do final da adição do precursor (A) (azul de rutênio) à mistura de 1,3-diaminopropano, TFA e 2,3-butadiona (C), após a adição de acetato de potássio.

A primeira curva (A) é o espectro da espécie azul de rutênio (Rublue), $\left[\mathrm{Ru}_{4} \mathrm{Cl}_{12}\right]^{4-} 76$, resultado da redução do $\mathrm{Ru}^{3+}$ pelos íons $\mathrm{Sn}^{2+}$. A maior dúvida sobre este precursor era se ele, de fato, reagiria com o ligante em formação, finalizando a reação template. O ligante em formação é o produto das adições sucessivas de 1,3-diaminopropano, TFA e 2,3-butanodiona, dando origem a um intermediário, com estrutura diferente dos reagentes, como mostram os 
espectros B e C, onde se observa o desaparecimento da banda de baixa intensidade na região de $418 \mathrm{~nm}$, atribuída à uma transição $\mathrm{n} \rightarrow \Pi^{*}$ característica de compostos carbonílicos ${ }^{77}$. A reação do precursor azul de rutênio com o intermediário pode ser observada pela diminuição da banda correspondente à transição intracluster (a banda alargada de baixa intensidade que começa na região de $550 \mathrm{~nm}$ e vai até, aproximadamente, $900 \mathrm{~nm}$ ), o que sugere que as ligações Ru-Ru foram quebradas, dando origem a novas, que podem ser as do complexo $\left[\mathrm{Ru}(\mathrm{TIM}) \mathrm{Cl}_{2}\right]$. O aparecimento da banda em $328 \mathrm{~nm}$ também sugere que houve reação entre o intermediário e o azul de rutênio, formando uma nova espécie que pode ser o complexo desejado.

Os espectros de infravermelho do extrato seco da reação foram feitos em pastilhas de KBr. Em um primeiro momento, retirou-se uma alíquota do meio reacional e esta foi secada totalmente, sem que o processo de rotoevaporação fosse interrompido. $\mathrm{O}$ espectro de infravermelho apresentou uma banda na região por volta de $2020 \mathrm{~cm}^{-1}$, característica da presença de nitrilas. Então, o restante do meio reacional foi secado de forma que o processo foi interrompido diversas vezes para retirada de um precipitado gelatinoso que se formava com a redução do volume. Após este procedimento, a referida banda diminuiu e pode-se observar modificações no espectro, como mostra a figura 7: 


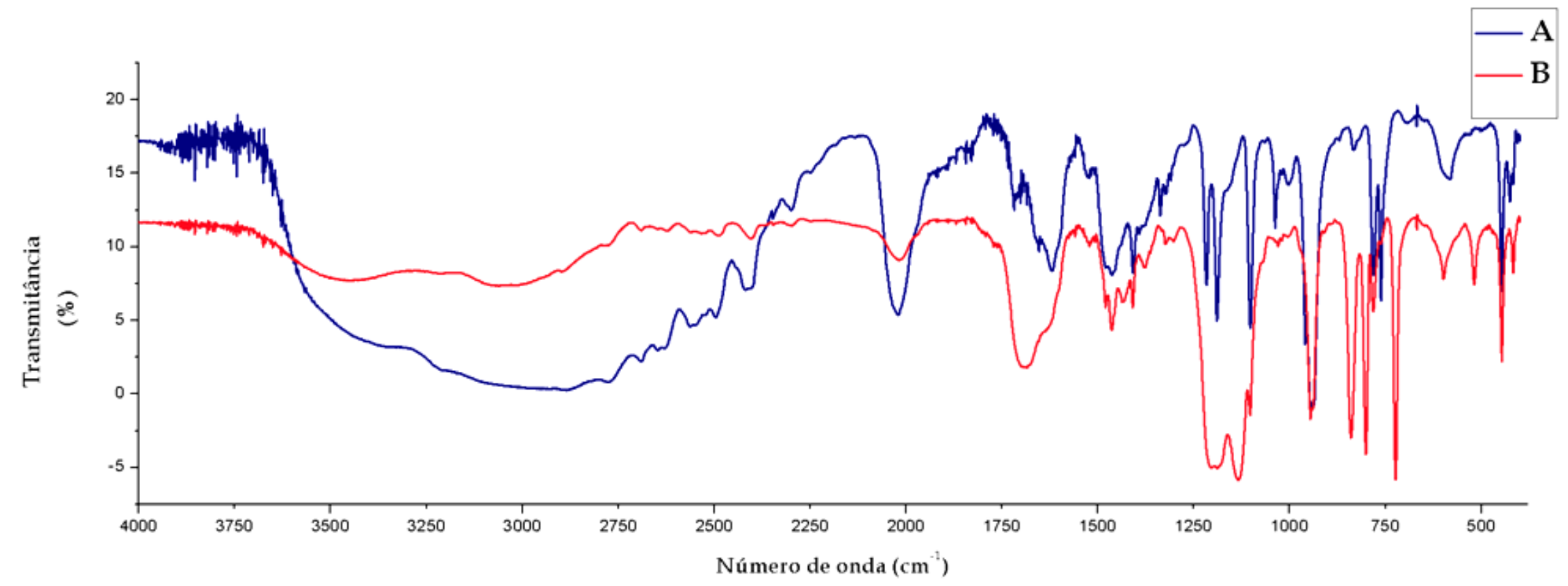

Figura 7: Espectros de infravermelho do complexo com ligante TIM em pastilhas de KBr. A: Espectro obtido a partir de uma amostra seca sem que o processo de secagem fosse interrompido B: Espectro obtido a partir de uma amostra que foi submetida a sucessivas filtragens durante $\mathrm{o}$ processo de secagem no evaporador rotativo. 
Neste trabalho, optou-se pela análise do espectro após as sucessivas filtragens, na região de $2200 \mathrm{~cm}^{-1}$ a $400 \mathrm{~cm}^{-1}$, que é a região onde a resolução das bandas é melhor. A figura 8 traz este espectro:

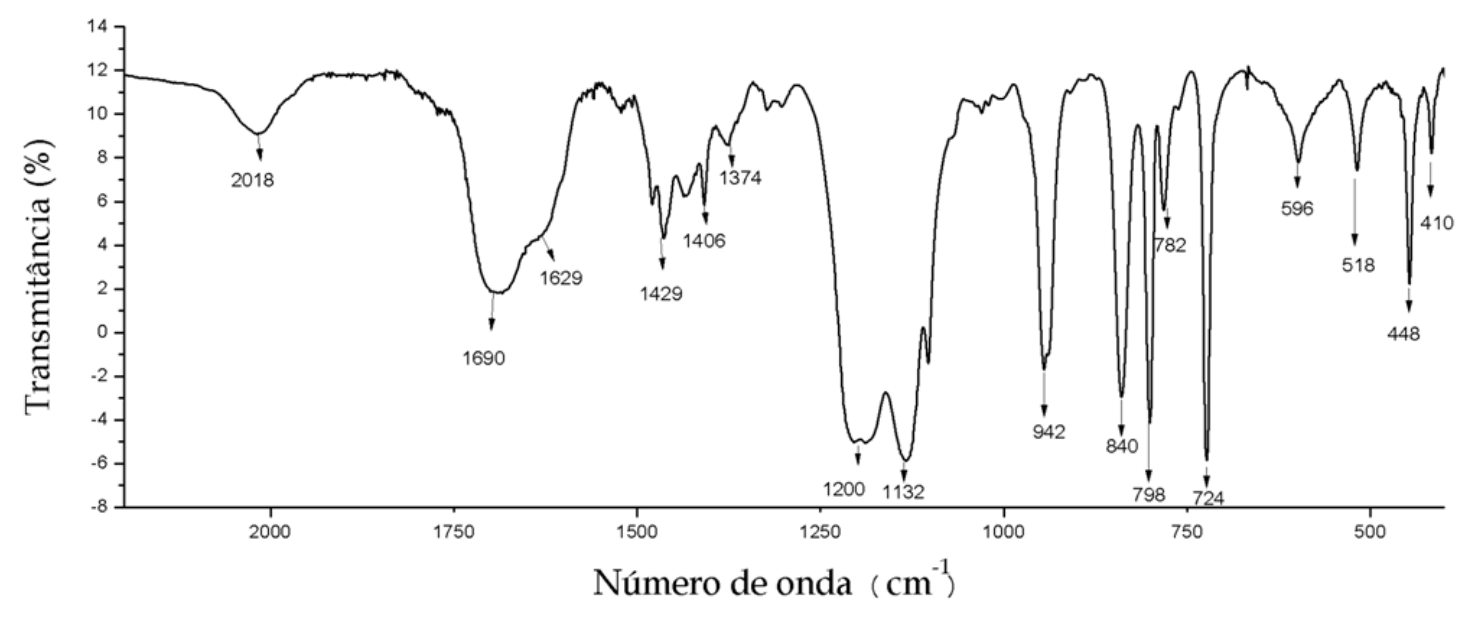

Figura 8: Espectro de infravermelho do extrato seco do meio reacional para obtenção do complexo $\left[\mathrm{Ru}(\mathrm{TIM}) \mathrm{Cl}_{2}\right]$ em pastilhas de $\mathrm{KBr}$.

Como foi dito anteriormente, a banda que aparece na região de $2020 \mathrm{~cm}^{-}$ 1 é bastante característica de nitrilas, $-\mathrm{C} \equiv \mathrm{N}$, que podem ter sido originadas da oxidação das aminas do 1,3-diaminopropano, em excesso no meio reacional. Os estiramentos das ligações $-\mathrm{C}=\mathrm{N}-$ presentes no anel do macrociclo TIM tem bandas na região de $1700 \mathrm{~cm}^{-1}$, aproximadamente, porém, o alargamento da banda nesta região pode ser creditado à existência de uma banda da carbonila devida ao excesso de 2,3-butanodiona, proveniente da possível decomposição do composto, como será discutido posteriormente, e que aparecem na região de $1600 \mathrm{~cm}^{-1}$. Rose et alii. ${ }^{12}$ relataram que a deslocalização 
eletrônica em torno no centro metálico no complexo com ferro diminui a intensidade e a resolução da referida banda. Bandas na região de $1400 \mathrm{~cm}^{-1}$ são bastante características das deformações angulares no plano (bendings) das ligações $\mathrm{C}-\mathrm{H}$, como 1429, 1406 e $1374 \mathrm{~cm}^{-1}$. Há uma grande quantidade de bandas que aparecem na região de $1200 \mathrm{~cm}^{-1}$, como das aminas primárias, secundárias, além dos alcanos e, como se trata do extrato seco da reação, quaisquer reações laterais que possam ter acontecido, podem ter gerado contaminantes, e isto pode ter causado a diminuição da resolução da banda nesta região, onde é possível ver os estiramentos do anel do ligante TIM, independente do metal ao qual ele está coordenado ${ }^{12}$. Os estiramentos dos anéis aparecem na região de 1600-1300 $\mathrm{cm}^{-1}$ 78, e, de fato, Rose et alii. ${ }^{12}$ relataram a presença de duas bandas referentes às vibrações do anel: a já citada banda na região de $1200 \mathrm{~cm}^{-1}$, que independe da coordenação ao metal e a banda por volta de $980 \mathrm{~cm}^{-1}$, que é dependente a qual metal o macrociclo está coordenado. Logo, é possível que a banda em $942 \mathrm{~cm}^{-1}$ seja da deformação angular (bending) do anel79, já que ela também está presente no espectro "sujo", no mesmo número de onda, assim como acontece com a banda em $448 \mathrm{~cm}^{-1}$, que pode ser atribuída ao estiramento ${ }^{79}$ da ligação $\mathrm{Ru}-\mathrm{N}$, que seria um indicativo da coordenação do metal ao tetraazamacrociclo.

Durante a realização de alguns "spots tests", adicionou-se algumas gotas de uma solução saturada de nitrito de sódio à solução metanólica do extrato seco do meio reacional, e observou-se a mudança de cor do meio de 
vinho para amarelo. Este resultado poderia indicar a formação do nitrosilo complexo, e, para a sua confirmação, fez-se um espectro de infravermelho do extrato seco resultante após a retirada dos solventes (água e metanol) em um evaporador rotativo. Esperava-se observar a banda fina e intensa, característica do estiramento da ligação Ru-NO, que ocorre em, aproximadamente, $1900 \mathrm{~cm}^{-1}$, como já descrito na literatura ${ }^{42-44}$, porém, tudo o que pode ser observado foram as bandas referentes ao acetato, e ao nitrito, como mostra a figura 9:

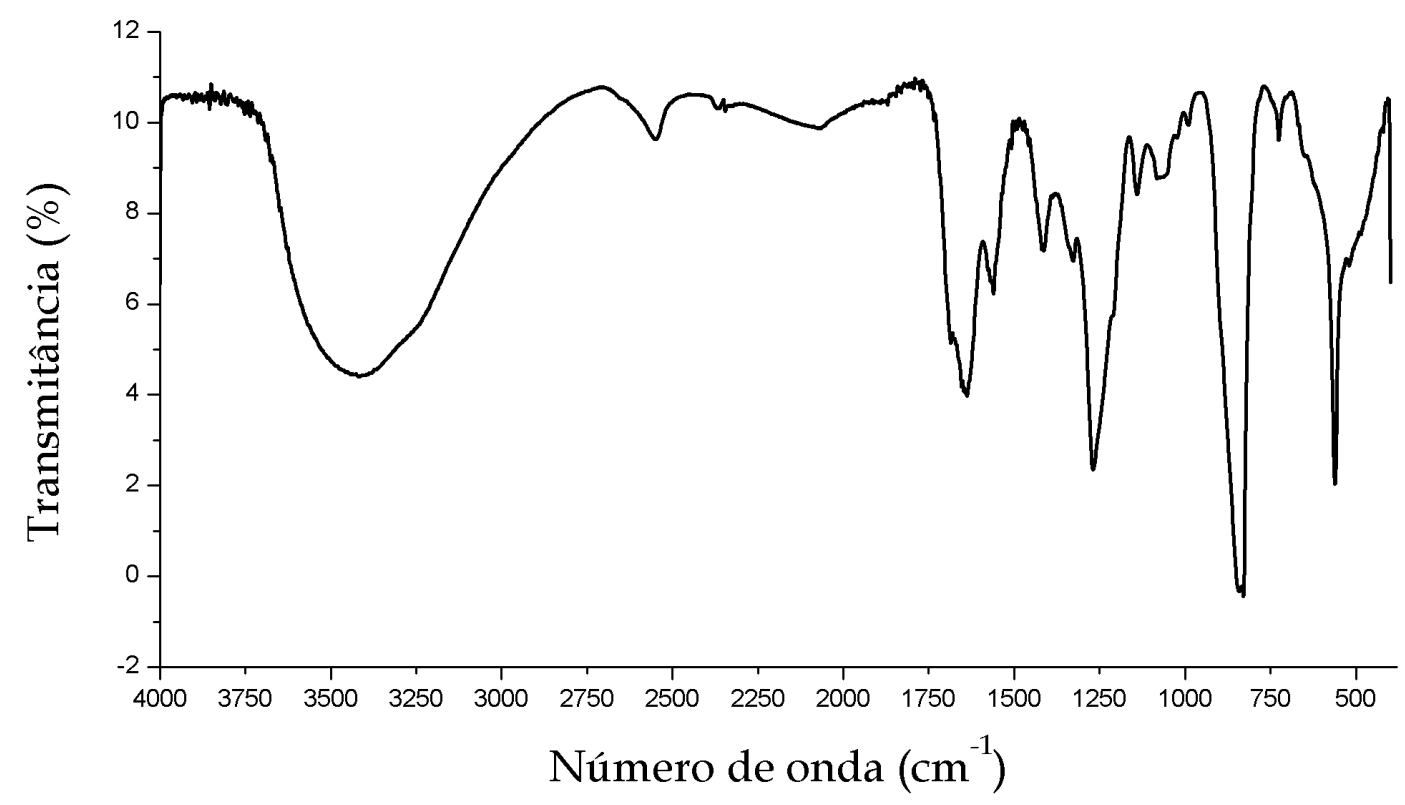

Figura 9: Espectro de infravermelho feito em pastilhas de $\mathrm{KBr}$ do extrato seco após a adição de nitrito de sódio 
Na região de $3500 \mathrm{~cm}^{-1}$, o estiramento das ligações $0-\mathrm{H}$ e as interações intramoleculares dão origem à banda alargada observada no espectro. Estas ligações podem ser das hidroxilas presentes no ácido acético, em equilíbrio com o acetato devido à umidade existente na amostra. Os estiramentos das carbonilas aparecem na região de $1660 \mathrm{~cm}^{-1} 78$, a deformação angular no plano $(\delta(\mathrm{CH}))$ das metilas na região de $1400 \mathrm{~cm}^{-1}$ e a banda intensa na região de 800 $\mathrm{cm}^{-1}$ é atribuída à $\delta_{\mathrm{s}}\left(\mathrm{NO}_{2}\right)$ do nitrito ${ }^{79}$, o que nos mostra que não houve a formação do nitrosilo complexo como era esperado. O espectro de $\mathrm{RMN}-{ }^{1} \mathrm{H}$ do extrato seco da reação foi feito em metanol- $\mathrm{d}_{4}\left(\mathrm{CD}_{3} \mathrm{OD}\right)$ e com algumas gotas de $\mathrm{DCl}$, pois, até então, pensava-se que o excesso de cloreto poderia deslocar o equilíbrio no sentido da formação do dicloro complexo, impedindo a formação do aquacomplexo no meio, o que estabilizaria a espécie [Ru(TIM) $\left.\mathrm{Cl}_{2}\right]$. A instabilidade do complexo $\left[\mathrm{Fe}(\mathrm{TIM})\left(\mathrm{CH}_{3} \mathrm{CN}\right)_{2}\right]^{2+}$ em água foi descrita por Shepherd et alii. ${ }^{23}$, e, neste trabalho, ele propõe um mecanismo para a decomposição do complexo $\left[\mathrm{Fe}(\mathrm{TIM})\left(\mathrm{H}_{2} \mathrm{O}\right)_{2}\right]^{2+}$, como será discutido a seguir. A figura 10 mostra o espectro de RMN do extrato seco do meio reacional para obtenção do complexo de rutênio com ligante TIM, e a ampliação, figura 11, traz a ampliação do espectro e integração dos sinais: 


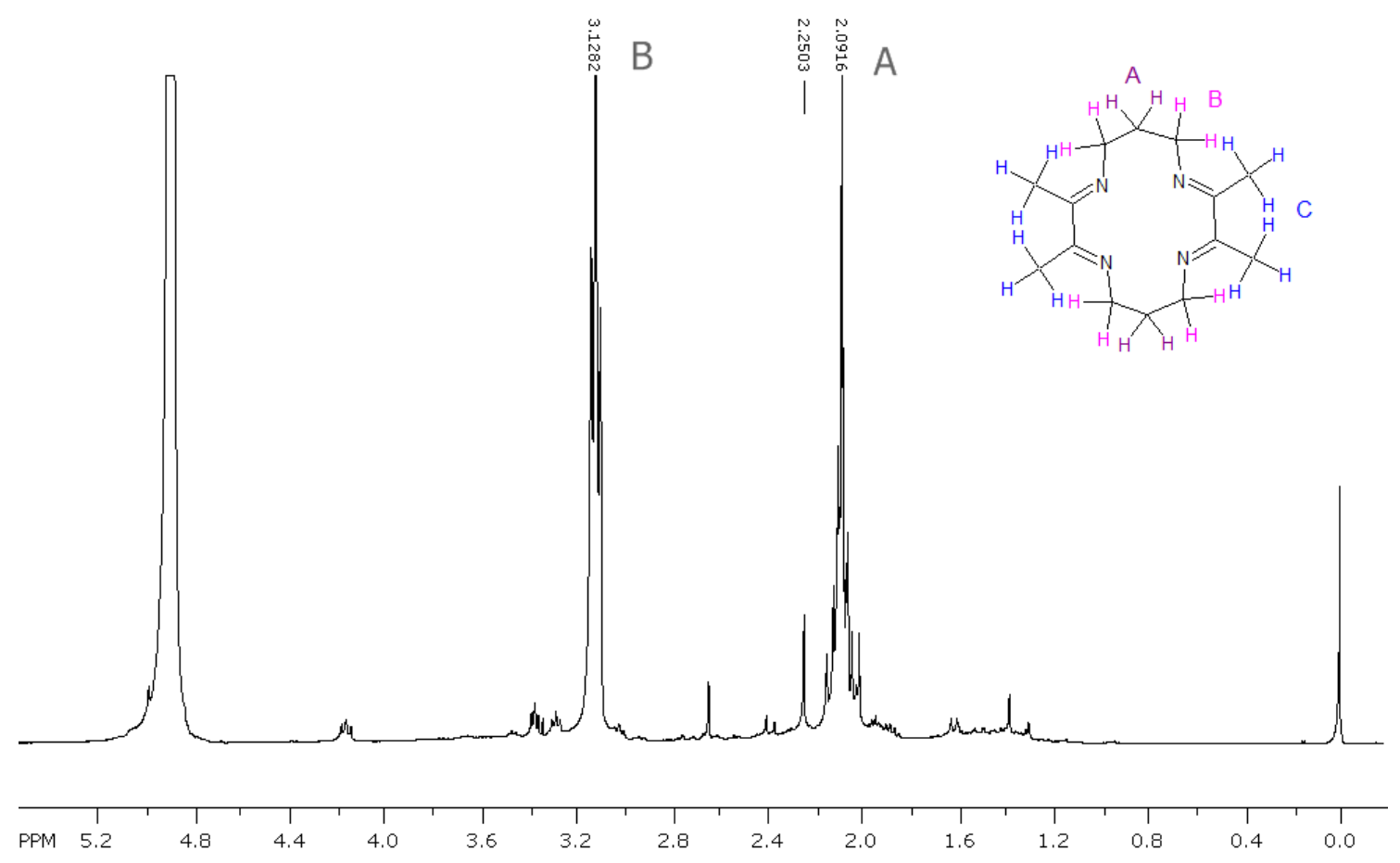

Figura 10: Espectro de $\mathrm{RMN}-{ }^{1} \mathrm{H}$ do extrato seco do meio reacional, obtido em $\mathrm{CD}_{3} \mathrm{OD}$ e DCl. Não há sinais acima de 5.2 ppm.

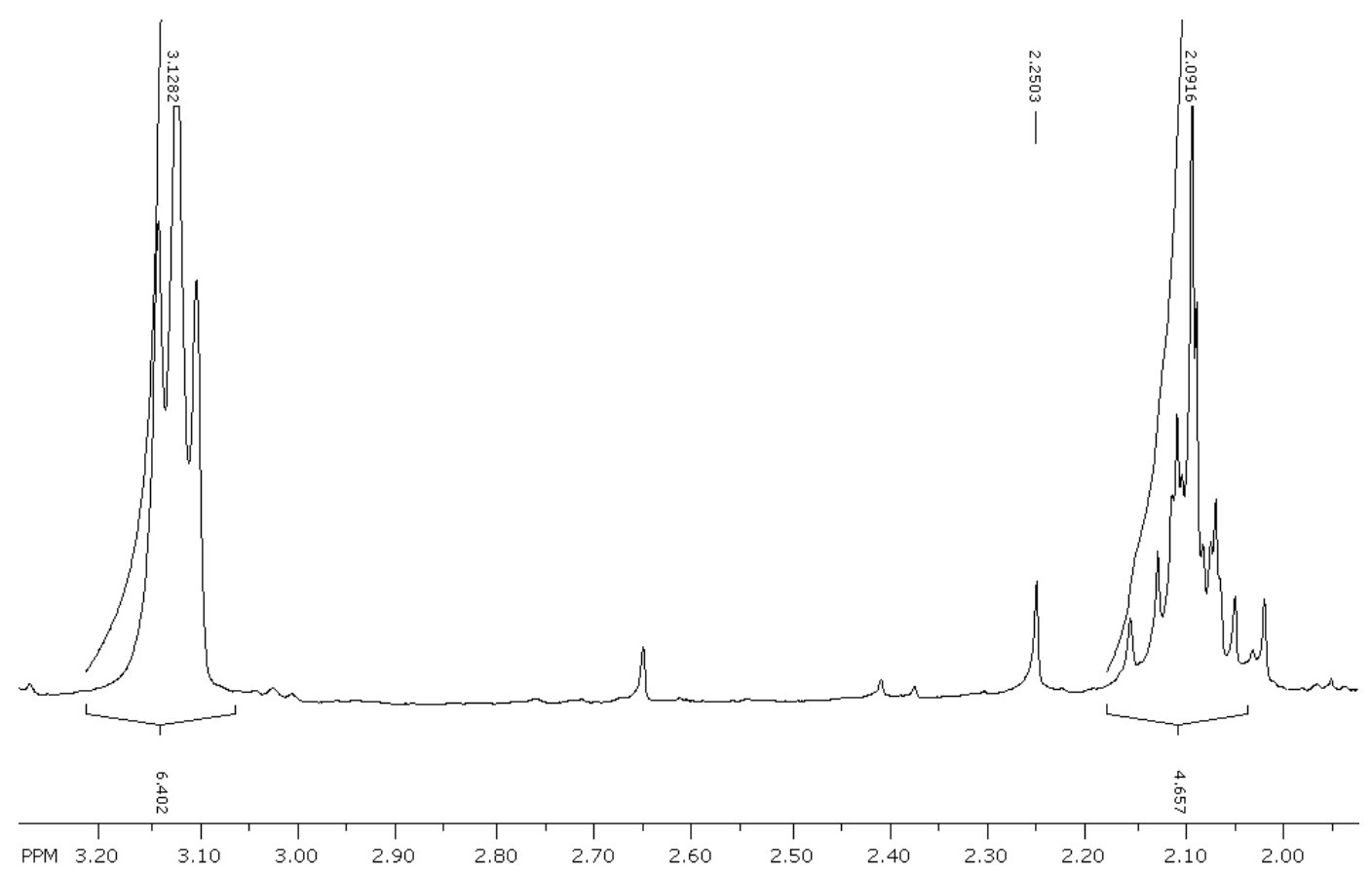

Figura 11: Ampliação do espectro de $\mathrm{RMN}-{ }^{1} \mathrm{H}$ do extrato seco do meio reacional, obtido em $\mathrm{CD}_{3} \mathrm{OD}$ e $\mathrm{DCl}$. 
No primeiro espectro de $\mathrm{RMN}-{ }^{1} \mathrm{H}$, o ligante foi representado em sua forma livre para melhor visualização dos grupos de hidrogênios, porém, há relatos de que, na verdade, ele não existe como ligante livre, como descrito por Busch et alii. que, após algumas tentativas, relataram o insucesso em isolar o TIM como macrociclo livre ${ }^{10}$. Os picos no espectro de $\mathrm{RMN}-{ }^{1} \mathrm{H}$ não apresentam uma excelente resolução, embora este tenha sido obtido em um equipamento de $500 \mathrm{MHz}$, devido à presença de contaminantes, o que torna a integração dos sinais imprecisa, porém é possível distinguir um quintupleto na região de 2.09 ppm e um tripleto na região de 3.13 ppm, o que é compatível com os desdobramentos dos grupos de hidrogênios assinalados como A e B respectivamente. Além disso, o pico em 2.25 ppm está ligado à presença de 2,3-butanodiona, como relatado por Shepherd et alii. ${ }^{23}$ para a decomposição do macrociclo. No caso do complexo com rutênio, a presença de 2,3butanodiona pode não ser somente, como dito anteriormente para os espectros de infravermelho, um contaminante remanescente da retirada ineficiente durante a secagem, mas também um indício da decomposição do composto.

Perante a dificuldade em isolar o composto de rutênio com o ligante TIM, optou-se por sintetizar o composto de ferro com este ligante, reproduzindo algumas das análises descritas na literatura, a fim de verificar as similaridades e diferenças, fazendo as devidas comparações com o primeiro, esclarecendo as dúvidas com relação à sua formação. 


\subsection{Síntese para obtenção do composto $\left[\mathrm{Fe}(\mathrm{TIM})\left(\mathrm{CH}_{3} \mathrm{CN}\right)_{2}\right]\left(\mathrm{PF}_{6}\right)_{2}$}

$\mathrm{O}$ composto $\left[\mathrm{Fe}(\mathrm{TIM})\left(\mathrm{CH}_{3} \mathrm{CN}\right)_{2}\right]\left(\mathrm{PF}_{6}\right)_{2}$ foi sintetizado de acordo com o descrito por Rose et alii. ${ }^{12}$, como mostra a equação 6 :

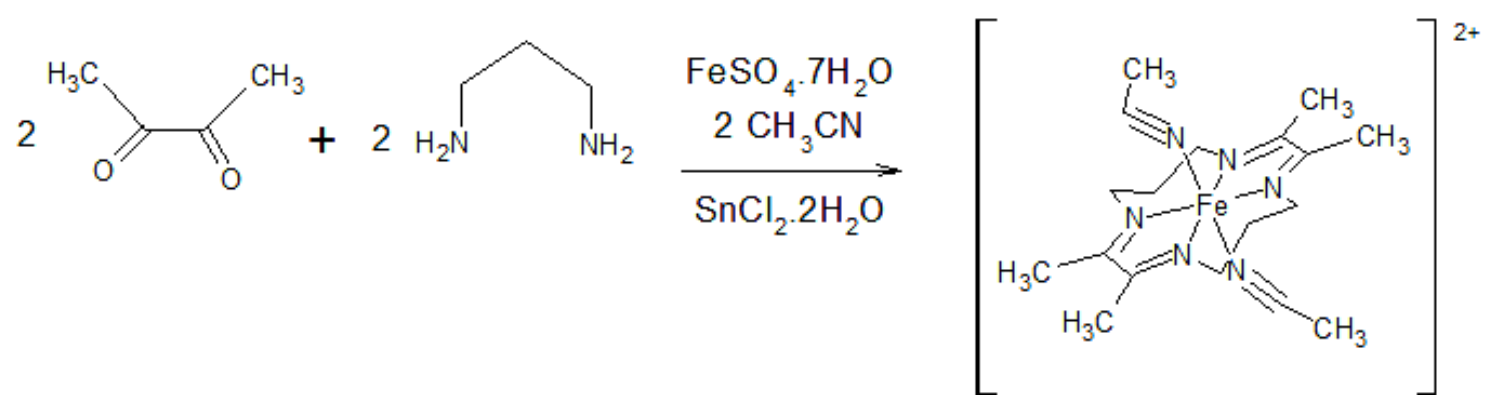

Equação 7: Reação para obtenção do hexaflurofosfato de bis(acetonitrila)(2,3,9,10-tetrametil-1,4,8,11-tetraazaciclotetradeca-1,3,8,10tetraeno) ferro(II).

Uma modificação foi inserida com relação à síntese original: como precursor, utiliza-se $\mathrm{FeCl}_{2} \cdot 4 \mathrm{H}_{2} \mathrm{O}$, mas, nesta síntese, utilizou-se o $\mathrm{FeSO}_{4} \cdot 7 \mathrm{H}_{2} \mathrm{O}$, por uma questão de disponibilidade

A seguir, as informações sobre os espectros de RMN, invfravermelho e de absorção na região UV-visível serão discutidas brevemente, pois tais dados já foram discutidos na literatura, por exemplo, por Rose et alii. ${ }^{12}$, por Shepherd et alii. ${ }^{23}$, e serão comparadas aos dados obtidos para o composto com rutênio. 
A figura 12 traz os espectros de absorção na região do UV-visível do complexo $\left[\mathrm{Fe}(\mathrm{TIM})\left(\mathrm{CH}_{3} \mathrm{CN}\right)_{2}\right]^{2+}$ feitos em acetonitrila em duas concentrações diferentes:

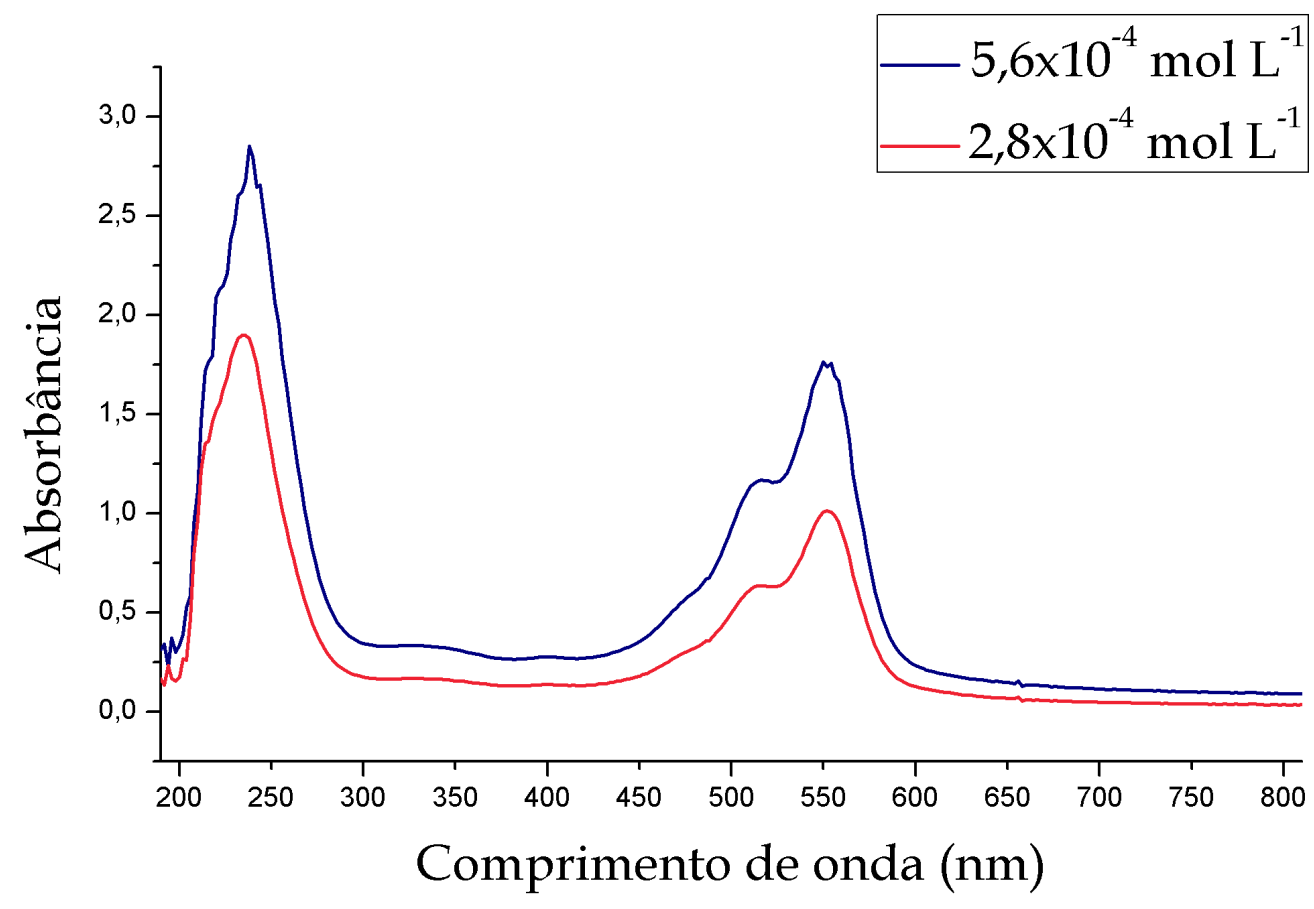

Figura 12: Espectros de absorção na região do UV-visível do complexo $\left[\mathrm{Fe}(\mathrm{TIM})\left(\mathrm{CH}_{3} \mathrm{CN}\right)_{2}\right]^{2+}$ feitos em acetonitrila.

$\mathrm{O}$ espectro de absorção do complexo $\left[\mathrm{Fe}(\mathrm{TIM})\left(\mathrm{CH}_{3} \mathrm{CN}\right)_{2}\right]^{2+}$ apresenta uma banda na região de $550 \mathrm{~nm}$, com $\varepsilon=3,15 \times 10^{3} \mathrm{M}^{-1} \mathrm{~cm}^{-1}$, que pode ser atribuída a uma TCML, $\mathrm{t}_{2 \mathrm{~g}} \rightarrow \Pi^{*}$, tão intensa que encobre o sinal da transição dd do Fe(II) ${ }^{80}$.

Quando o composto $\left[\mathrm{Fe}(\mathrm{TIM})\left(\mathrm{CH}_{3} \mathrm{CN}\right)_{2}\right]\left(\mathrm{PF}_{6}\right)_{2}$ foi dissolvido em água, notou-se que a solução apresentava uma cor bastante diferente da solução feita 
em acetonitrila: a solução em acetonitrila é fúcsia e a solução aquosa é laranjada (fig. 13).

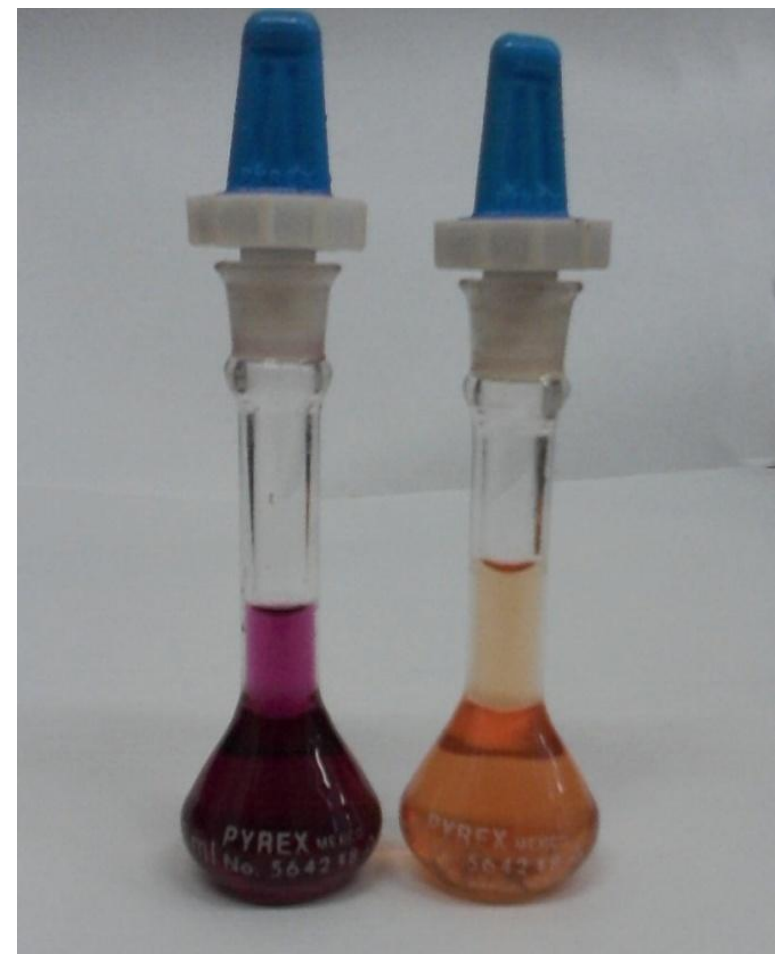

Figura 13: Fotografia das soluções do composto [Fe(TIM) $\left.\left(\mathrm{CH}_{3} \mathrm{CN}\right)_{2}\right]\left(\mathrm{PF}_{6}\right)_{2}$. O balão da esquerda contém a solução em acetonitrila e o da direita contém a solução aquosa.

A princípio, pensou-se que se tratava de um caso de solvatocromismo, porém, através de espectros de UV-visível e RMN, foi possível observar que a estrutura dos complexos muda de um solvente para outro, como será discutido.

A figura 14 traz os espectros de absorção na região do UV-visível do composto $\left[\mathrm{Fe}(\mathrm{TIM})\left(\mathrm{CH}_{3} \mathrm{CN}\right)_{2}\right]\left(\mathrm{PF}_{6}\right)_{2}$ dissolvido em água, em duas concentrações diferentes: 


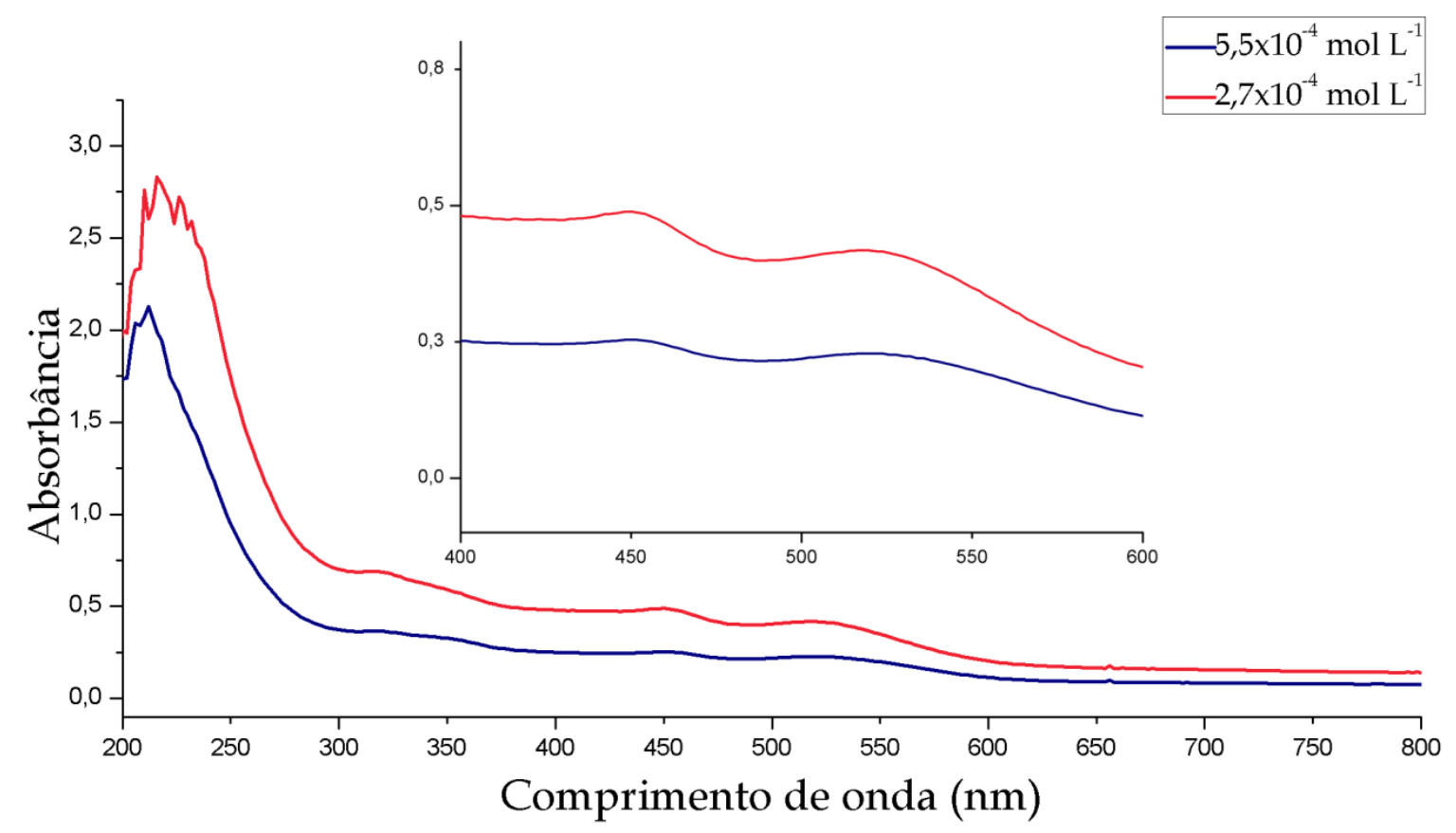

Figura 14: Espectros de absorção na região do UV-visível do composto [Fe(TIM) $\left.\left(\mathrm{CH}_{3} \mathrm{CN}\right)_{2}\right]\left(\mathrm{PF}_{6}\right)_{2}$ dissolvido em água. A ampliação é referente à região entre 400 e $600 \mathrm{~nm}$. 


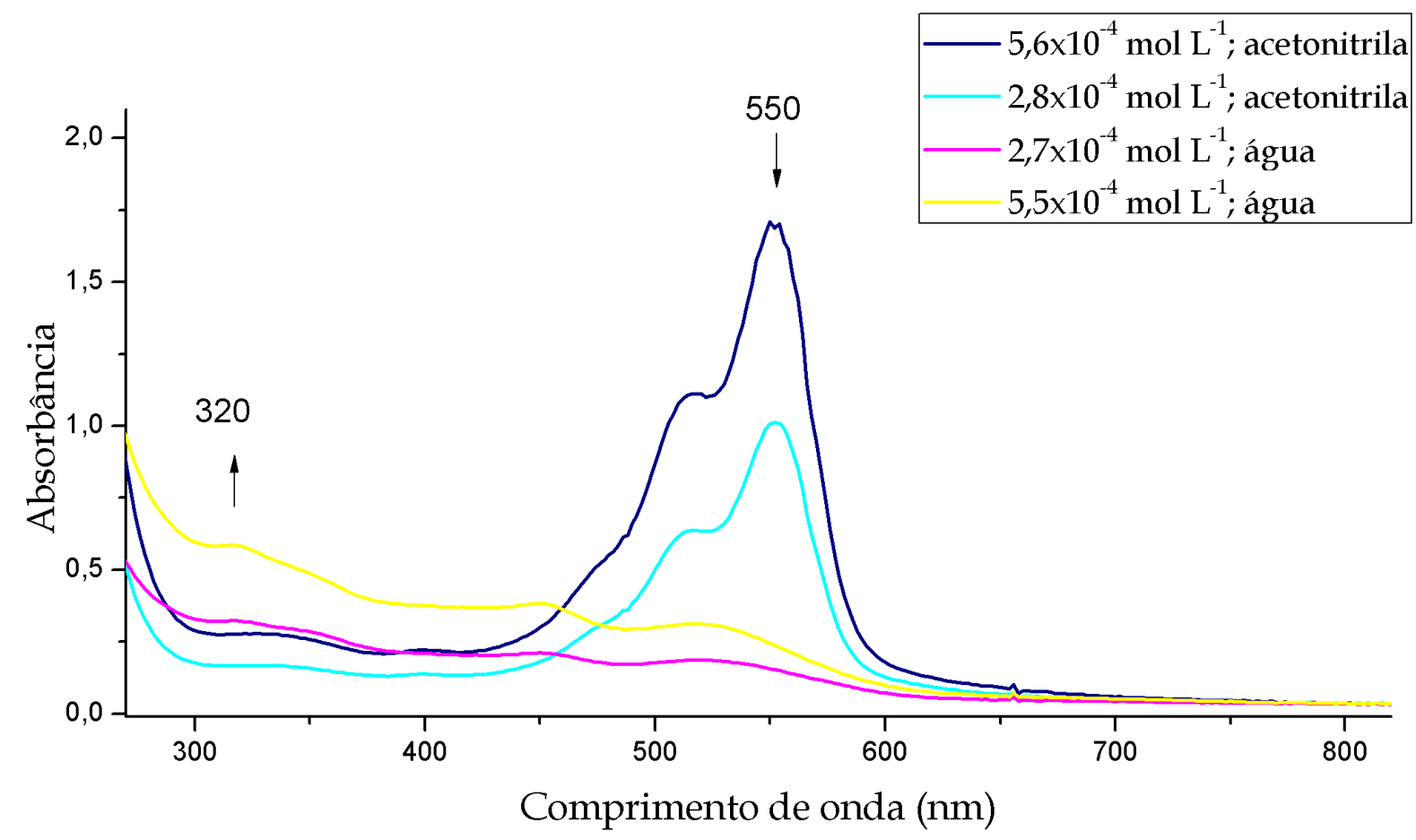

Figura 15: Sobreposição dos espectros de absorção na região do UVvisível das soluções do composto $\left[\mathrm{Fe}(\mathrm{TIM})\left(\mathrm{CH}_{3} \mathrm{CN}\right)_{2}\right]\left(\mathrm{PF}_{6}\right)_{2}$ em acetonitrila e água.

Como pode ser visto nos espectros, em água não se observa a presença da banda intensa na região de $550 \mathrm{~nm}$, o que muda a cor da solução. O desaparecimento desta banda está ligado à decomposição do complexo em meio aquoso, como relatado por Shepherd et alii.23: em atmosfera não inerte, o centro metálico é oxidado de $\mathrm{Fe}(\mathrm{II})$ a $\mathrm{Fe}(\mathrm{III})$ e o complexo $\left[\mathrm{Fe}(\mathrm{TIM})\left(\mathrm{H}_{2} \mathrm{O}\right)_{2}\right]^{3+}$ sofre decomposição formando, entre outros produtos, a 2,3-butanodiona novamente.

Embora este estudo não tenha sido feito para o complexo de rutênio com ligante TIM, visualmente também foi possível notar a mudança de cor do 
meio: as soluções metanólicas apresentavam cor roxa, enquanto as aquosas, castanha. A diferença com relação ao complexo análogo de ferro é que, aparentemente, a decomposição é mais rápida no caso do complexo de rutênio. E esta não ocorre somente em meio aquoso, mesmo em metanol, ou em outros solventes, não se observa uma grande estabilidade do complexo de rutênio com ligante TIM, o que foi o passo limitante para que este não fosse isolado e purificado.

$\mathrm{O}$ espectro de infravermelho do $\left[\mathrm{Fe}(\mathrm{TIM})\left(\mathrm{CH}_{3} \mathrm{CN}\right)_{2}\right]\left(\mathrm{PF}_{6}\right)_{2}$ foi feito em pastilhas de $\mathrm{KBr}$ e está de acordo com o descrito por Rose et alii. ${ }^{12}$ no trabalho que relata a síntese e caracterização deste composto. A figura 16 traz o espectro de infravermelho e a figura 18, a ampliação da região de 1750 a 1000 $\mathrm{cm}^{-1}$ aproximadamente:

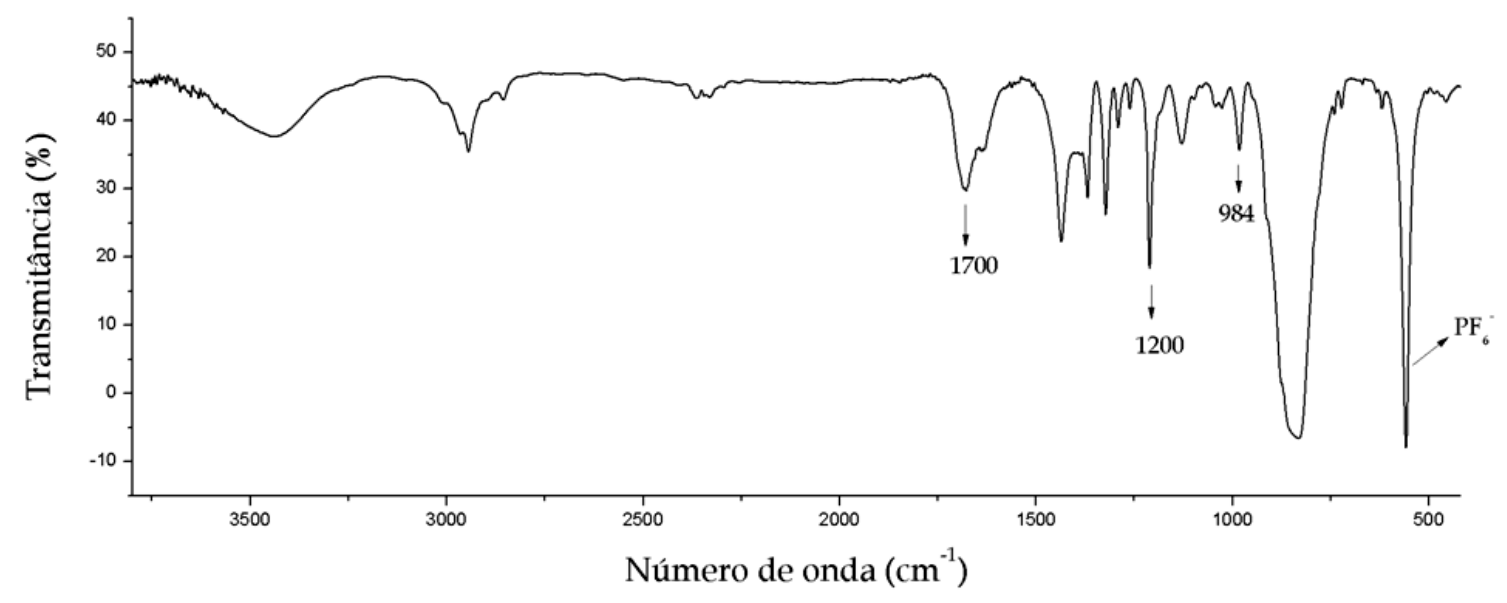

Figura 16: Espectro de infravermelho do composto [Fe(TIM) $\left.\left(\mathrm{CH}_{3} \mathrm{CN}\right)_{2}\right]\left(\mathrm{PF}_{6}\right)_{2}$ feito em pastilhas de $\mathrm{KBr}$ 


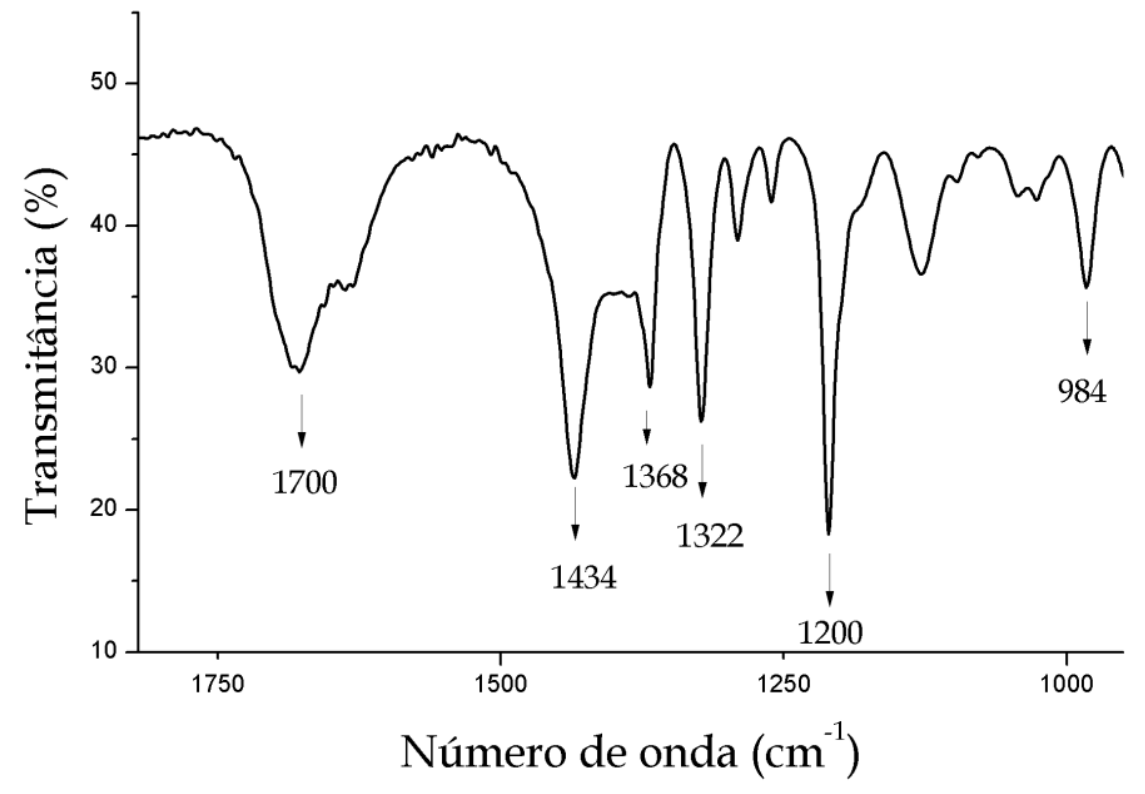

Figura 17: Ampliação do espectro de infravermelho do composto $\left[\mathrm{Fe}(\mathrm{TIM})\left(\mathrm{CH}_{3} \mathrm{CN}\right)_{2}\right]\left(\mathrm{PF}_{6}\right)_{2}$.

Os estiramentos da ligação $-\mathrm{C}=\mathrm{N}-$ aparecem na região de $1700 \mathrm{~cm}^{-1}$, e esta banda tem uma menor intensidade devido à deslocalização eletrônica em torno do metal. As bandas em 1434, 1368 e $1322 \mathrm{~cm}^{-1}$ são correspondentes às deformações da ligação $\mathrm{C}-\mathrm{H}$. O estiramento do anel do ligante TIM que acontece independente do metal ao qual ele está coordenado ocorre na região de $1200 \mathrm{~cm}^{-1}$ e a deformação do anel, que depende do metal ao qual está coordenado, neste caso, ferro, ocorre em $984 \mathrm{~cm}^{-1}$, sendo uma banda de intensidade média ${ }^{12}$.

A figura 18 mostra o espectro de infravermelho do produto isolado da decomposição do composto $\left[\mathrm{Fe}(\mathrm{TIM})\left(\mathrm{CH}_{3} \mathrm{CN}\right)_{2}\right]\left(\mathrm{PF}_{6}\right)_{2}$ em meio aquoso. 


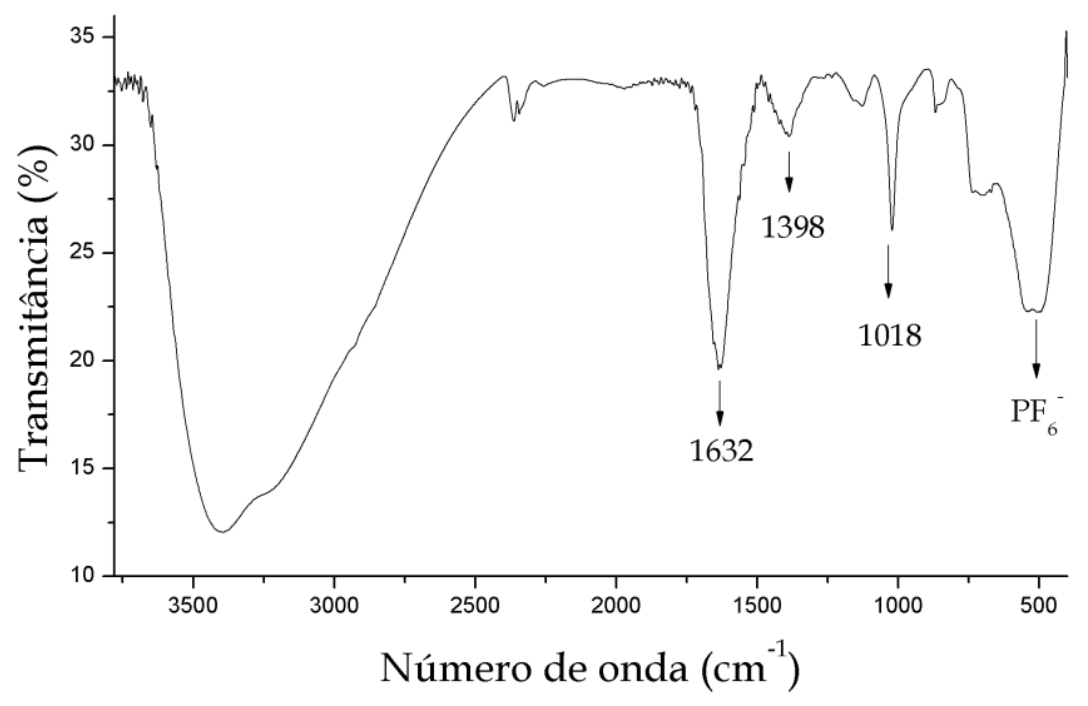

Figura 18: Espectro de infravermelho do produto da decomposição do composto $\left[\mathrm{Fe}(\mathrm{TIM})\left(\mathrm{CH}_{3} \mathrm{CN}\right)_{2}\right]\left(\mathrm{PF}_{6}\right)_{2}$ feito em pastilhas de $\mathrm{KBr}$.

A banda em $1632 \mathrm{~cm}^{-1}$ é característica dos estiramentos de carbonilas, e a banda em $1398 \mathrm{~cm}^{-1}$ pode ser atribuída como $\delta(\mathrm{CH})$, não sendo possível observar os outros tipos de deformações da ligação $\mathrm{C}-\mathrm{H}$. O bending de aminas aparecem na região de $1200 \mathrm{~cm}^{-1} 78$, porém se estas estiverem coordenadas, é razoável que o sinal apareça em números de onda menores, como, por exemplo, $1018 \mathrm{~cm}^{-1}$, como pode ser visto no espectro.

Com a finalidade de comparação, fez-se o espectro de infravermelho do composto [Ni(TIM)]( $\left.\mathrm{PF}_{6}\right)_{2}$, e os espectros estão dispostos nas figuras 19 e 20: 


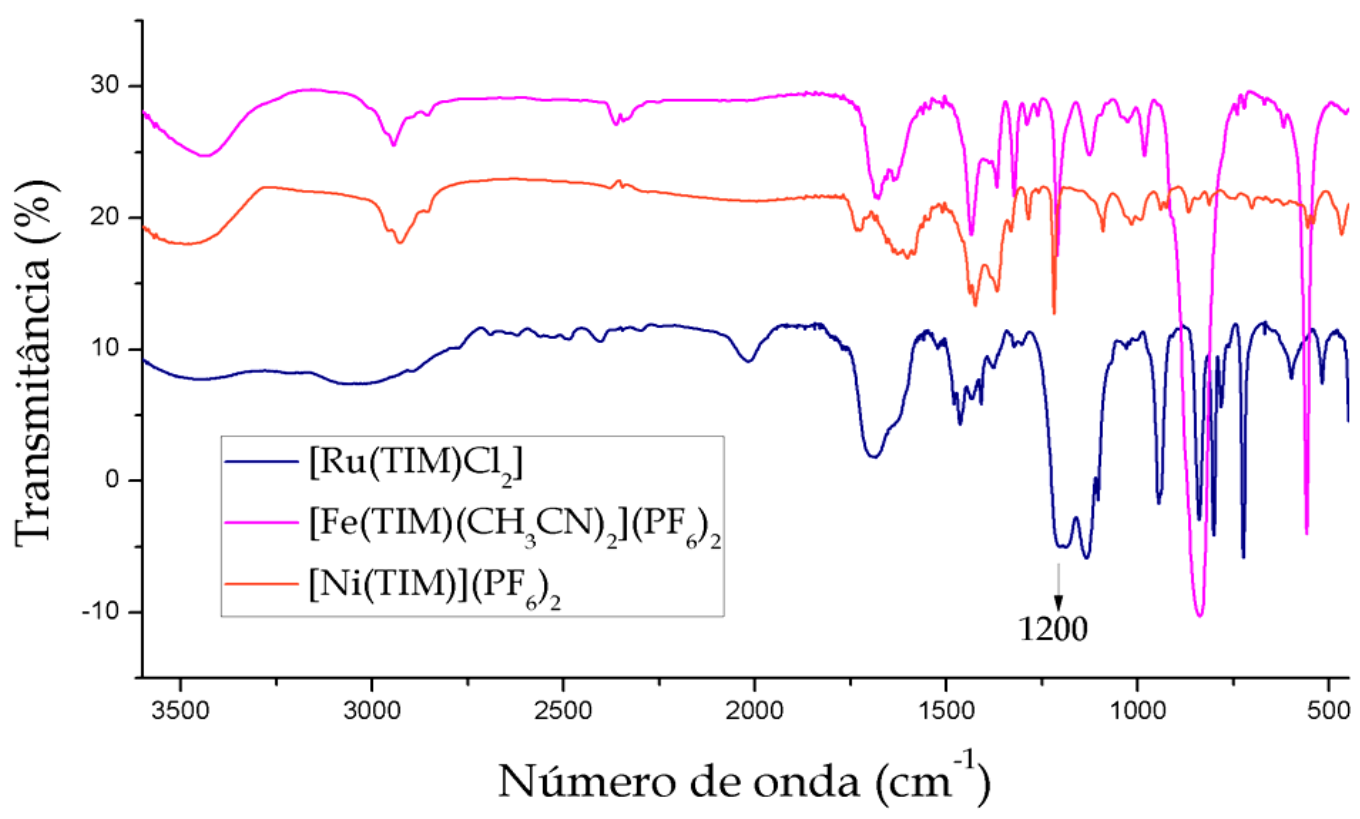

Figura 19: Sobreposição dos espectros de infravermelho, feitos em pastilhas de $\mathrm{KBr}$, dos compostos $\left[\mathrm{Ru}(\mathrm{TIM}) \mathrm{Cl}_{2}\right]$, [ $\left.\mathrm{Fe}(\mathrm{TIM})\left(\mathrm{CH}_{3} \mathrm{CN}\right)_{2}\right]\left(\mathrm{PF}_{6}\right)_{2}$ e $[\mathrm{Ni}(\mathrm{TIM})]\left(\mathrm{PF}_{6}\right) 2$. 


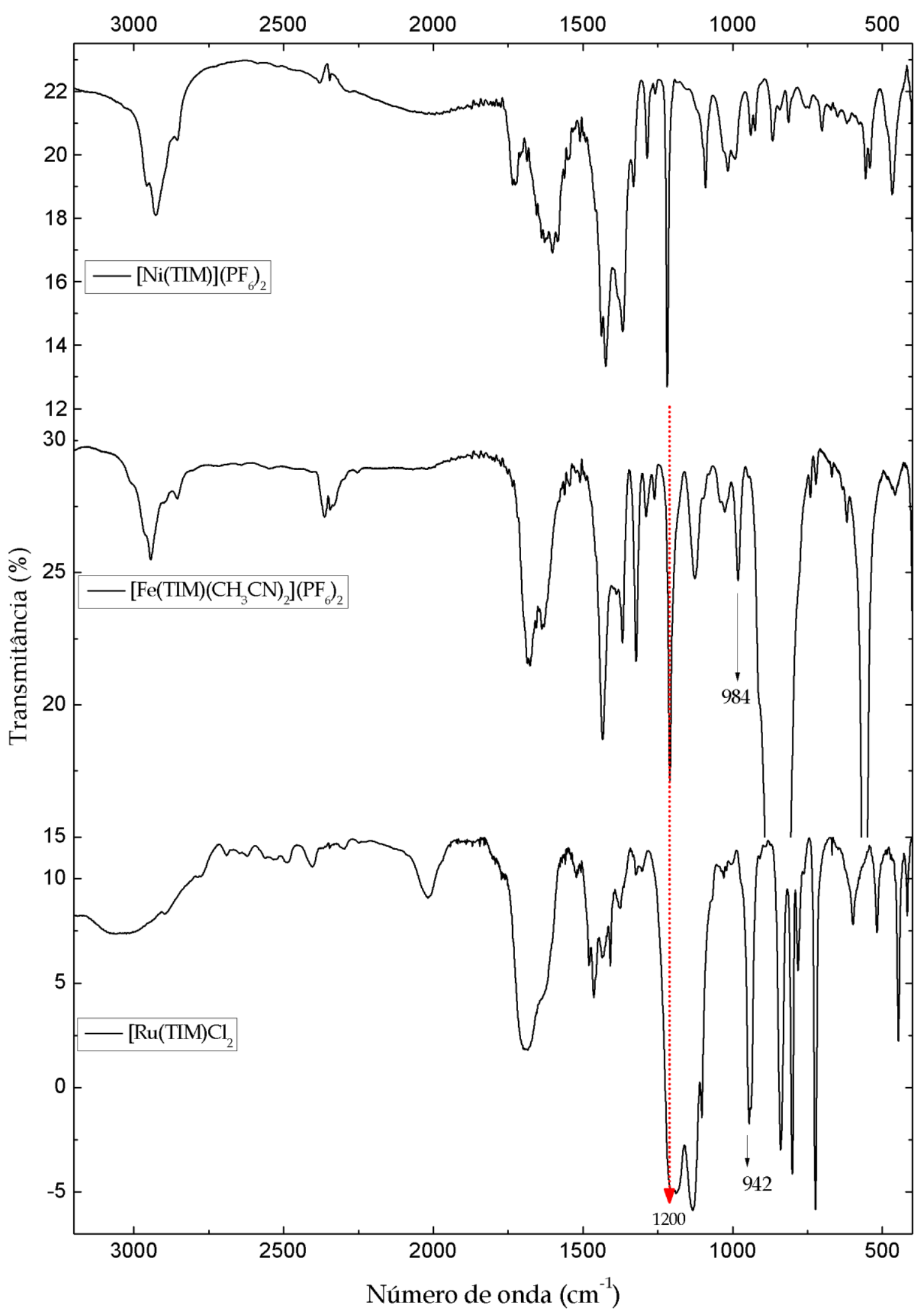

Figura 20: Correlação entre os espectros de infravermelho, feitos em pastilhas de $\mathrm{KBr}, \quad$ dos compostos $[\mathrm{Ni}(\mathrm{TIM})]\left(\mathrm{PF}_{6}\right)_{2}, \quad\left[\mathrm{Fe}(\mathrm{TIM})\left(\mathrm{CH}_{3} \mathrm{CN}\right)_{2}\right]\left(\mathrm{PF}_{6}\right)_{2} \quad$ e $\left[\mathrm{Ru}(\mathrm{TIM}) \mathrm{Cl}_{2}\right]$. 
Pela correlação feita entre os espectros de infravermelho dos complexos de níquel, ferro e rutênio com o ligante TIM, é possível notar que há várias similaridades entre eles, como a banda na região em $1200 \mathrm{~cm}^{-1} \mathrm{e}$, nos espectros dos compostos de ferro e rutênio, em torno de $900 \mathrm{~cm}^{-1}$, correspondentes às vibrações do anel. Além das bandas correspondentes às vibrações das ligações $\mathrm{C}=\mathrm{NeC}-\mathrm{H}$ que aparecem nos três espectros, existem as vibrações correspondentes ao anel, o que indicaria que um composto de rutênio com ligante TIM deve ter sido de fato sintetizado, mas não isolado.

Os espectros de RMN foram feitos em $\mathrm{CD}_{3} \mathrm{CN}$ e em $\mathrm{D}_{2} \mathrm{O}$, mas, como poderá ser visto, as informações extraídas deles permitem uma análise mais qualitativa. As figuras 21 e 22 trazem os espectros de RMN do composto [Fe(TIM) $\left.\left(\mathrm{CH}_{3} \mathrm{CN}\right)_{2}\right]\left(\mathrm{PF}_{6}\right)_{2}$ em acetonitrila e em água respectivamente: 


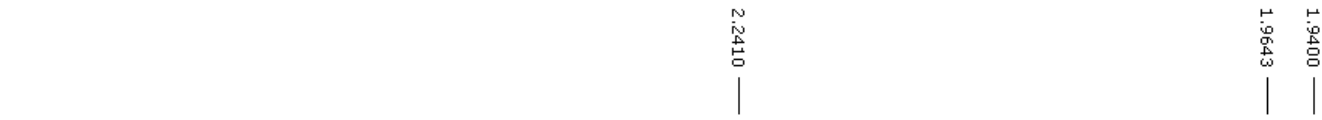

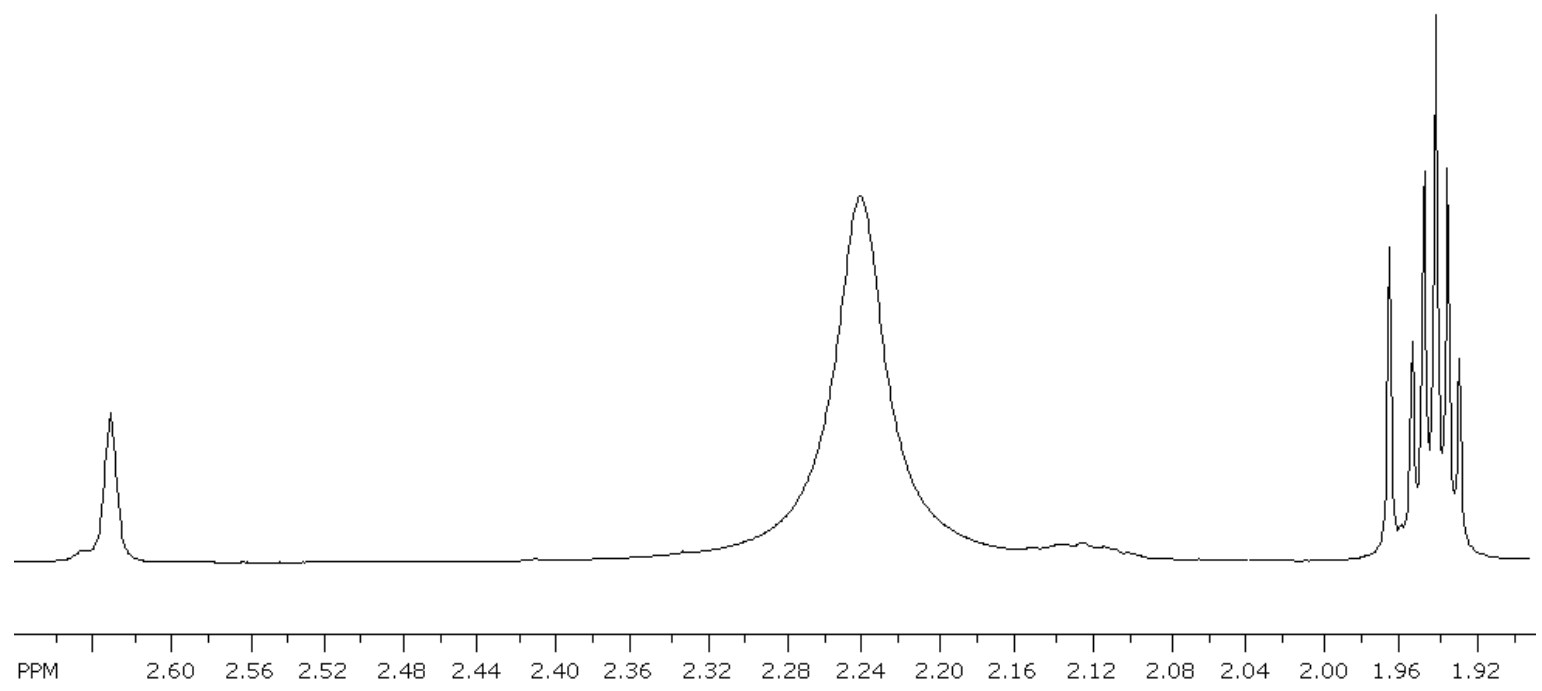

Figura 21: Espectro de $\mathrm{RMN}$ do composto $\left[\mathrm{Fe}(\mathrm{TIM})\left(\mathrm{CH}_{3} \mathrm{CN}\right)_{2}\right]\left(\mathrm{PF}_{6}\right)_{2}$ feito em $\mathrm{CD}_{3} \mathrm{CN}$.

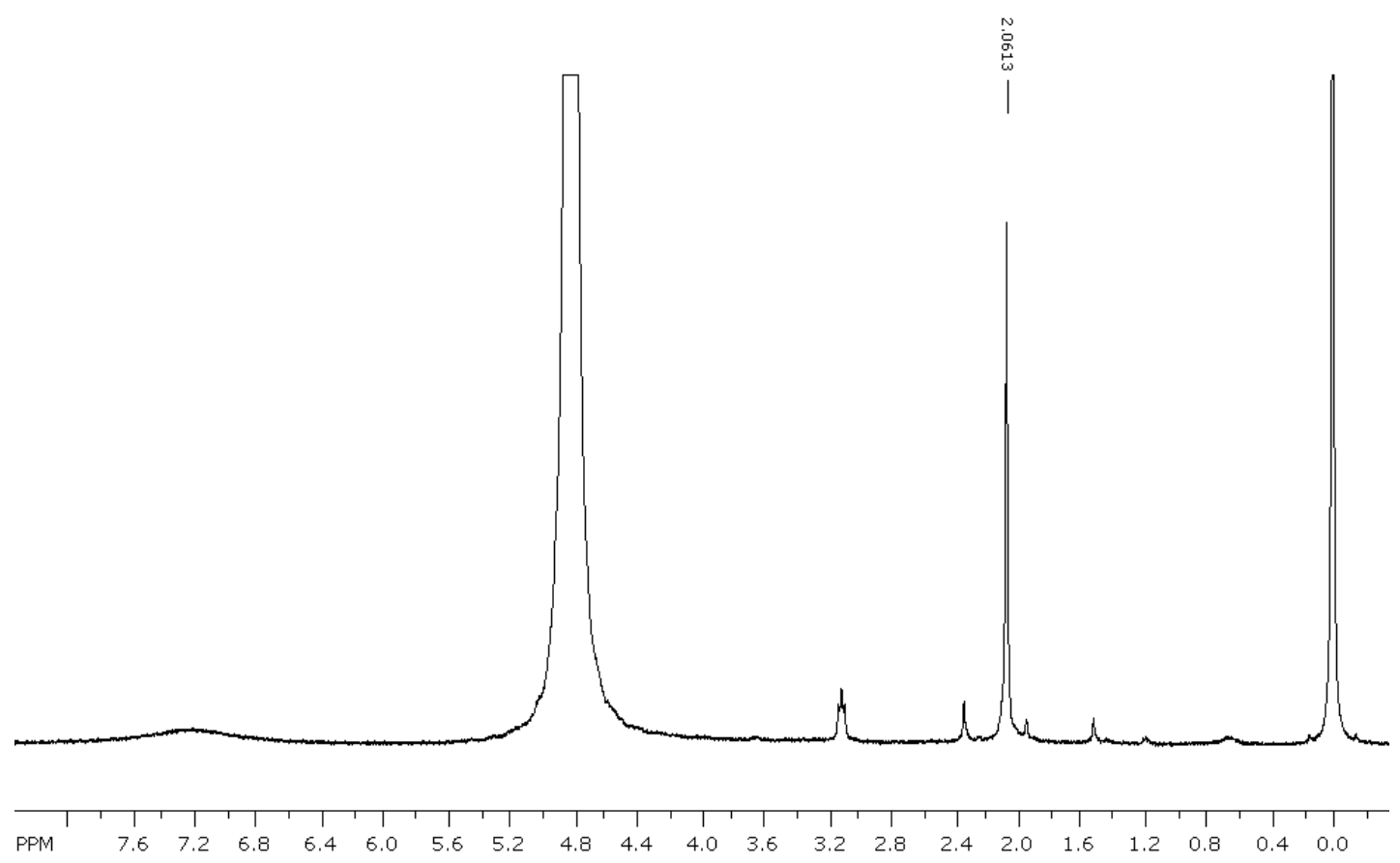

Figura 22: Espectro de RMN do composto $\left[\mathrm{Fe}(\mathrm{TIM})\left(\mathrm{CH}_{3} \mathrm{CN}\right)_{2}\right]\left(\mathrm{PF}_{6}\right)_{2}$ feito em $\mathrm{D}_{2} \mathrm{O}$. 
A primeira observação a ser feita sobre os dois espectros apresentados é que a mudança do solvente causou a mudança na estrutura do composto, o que exclui a hipótese de solvatocromismo, conforme já foi discutido. O que pode ser dito a cerca do espectro em feito em acetonitrila- $\mathrm{d}_{3}$ é que a presença do quintupleto em 1.94 ppm é característica deste solvente. Devido à estrutura do complexo, esperava-se um quintupleto na mesma região em que o sinal do solvente aparece. O singleto na região de 1.96 ppm pode ser correspondente aos hidrogênios das quatro metilas do anel. O sinal alargado em 2.24 ppm foi gerado pela presença de água residual do solvente deuterado. Além disso, nota-se um sinal menos intenso em 2.64 ppm que pode ser correspondente a um tripleto mal resolvido. No espectro do composto $\left[\mathrm{Fe}(\mathrm{TIM})\left(\mathrm{CH}_{3} \mathrm{CN}\right)_{2}\right]\left(\mathrm{PF}_{6}\right)_{2}$ em $\mathrm{D}_{2} \mathrm{O}$, observa-se um singleto em $2.06 \mathrm{ppm}$ que, como descrito por Shepherd et alii. ${ }^{23}$, está relacionado à presença de 2,3-butanodiona, gerada na decomposição do ligante macrocíclico, como já foi discutido.

\subsection{Síntese do composto cis-[Ru(1,7-CT) $\left.\mathrm{Cl}_{2}\right] \mathrm{Cl}$}

A segunda estratégia para obtenção do composto de rutênio com ligante tetraazamacrocíclico insaturado foi a metalação do ligante. Tendo em vista que o composto de rutênio com ligante TIM apresentou uma grande instabilidade, pensou-se que a diminuição do grau de insaturação, utilizando o ligante 1,7$\mathrm{CT}$, pudesse aumentar a estabilidade do composto, além de aumentar a flexibilidade do anel, permitindo a formação do isômero cis, ou, até mesmo de um isômero fac, onde o ligante tetraazamacrocíclico está coordenado por três 
nitrogênios ao rutênio, como já relatado na literatura ${ }^{81,82}$. Para isso, utilizou-se o composto cis-diclorotetrakis(dmso)rutênio(II) (cis-[ $\left.\mathrm{RuCl}_{2}\left(\mathrm{dmso}_{4}\right]\right)$, assim como é feito para a obtenção do cis-[Ru(cyclam) $\left.\mathrm{Cl}_{2}\right] \mathrm{Cl}$ 74. A vantagem da utilização deste precursor é a labilidade dos ligantes DMSO e o direcionamento da reação para formação do isômero cis, que é de mais fácil obtenção do que o isômero trans.

O composto cis- $\left[\mathrm{RuCl}_{2}(\mathrm{dmso})_{4}\right]$ foi caracterizado por espectroscopia de infravermelho, como mostra a figura 23. Este ligante já foi utilizado com bastante sucesso nas sínteses dos compostos de rutênio (na forma cis) com cyclen (1,4,7,10-tetraazaciclododecano) ${ }^{17}$ e com cyclam ${ }^{74}$, como uma maneira mais simples de obtenção do cis-[ $\mathrm{RuCl}_{2}$ (cyclam) $] \mathrm{Cl}$ do que foi descrito anteriormente ${ }^{15}$.

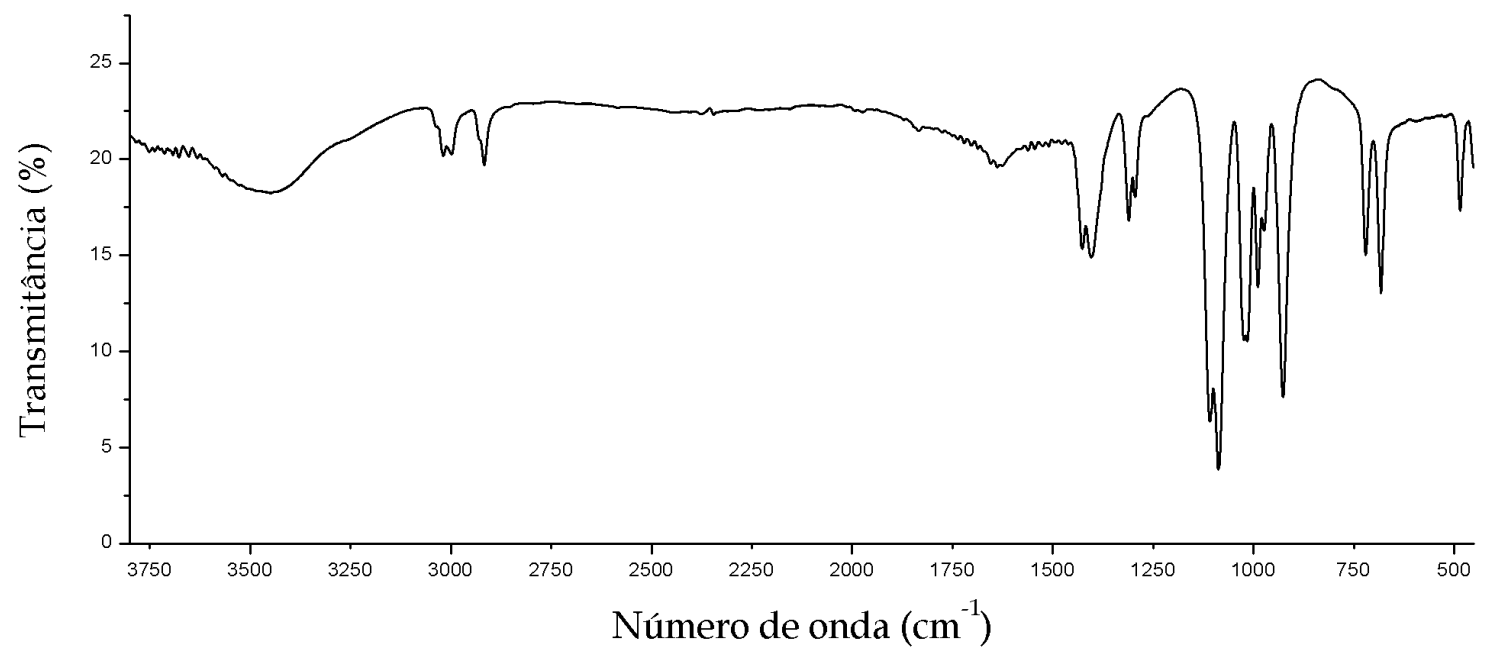

Figura 23: Espectro de Infravermelho do composto cis-[ $\left[\mathrm{RuCl}_{2}\left(\mathrm{dmso}_{4}\right]\right.$ em pastilha de KBr. 
As informações contidas no espectro obtido em pastilha $\mathrm{KBr}$ são bastante próximas às encontradas na literatura ${ }^{74}$, como $v_{\mathrm{CH}}$ em 3001 e $2918 \mathrm{~cm}^{-}$ 1, vso em 1119 e $1084 \mathrm{~cm}^{-1}$ referentes à ligação pelo enxofre e em $921 \mathrm{~cm}^{-1}$ referente à ligação pelo oxigênio. Os valores encontrados na literatura são respectivamente: $v_{\mathrm{CH}} 3000$ e $2908 \mathrm{~cm}^{-1}$, vso 1120 e $1090 \mathrm{~cm}^{-1}$ e $v_{\mathrm{SO}} 921 \mathrm{~cm}^{-1}$. As bandas em $1434 \mathrm{~cm}^{-1}, 1400 \mathrm{~cm}^{-1}, 1306 \mathrm{~cm}^{-1}$ e $1292 \mathrm{~cm}^{-1}$ são correspondentes às deformações da ligação $\mathrm{C}-\mathrm{H}$, e, da mesma forma que os outros valores, estes são similares aos encontrados na literatura: $1430 \mathrm{~cm}^{-1}, 1400 \mathrm{~cm}^{-1}, 1303 \mathrm{~cm}^{-1} \mathrm{e}$ $1282 \mathrm{~cm}^{-1}$ respectivamente.

O ligante 5,7,7,12,14,14-hexametil-1,4,8,11-tetraazaciclotetradeca-4,11dieno (1,7-CT) foi sintetizado de acordo com o descrito na literatura ${ }^{75}$ e foi caracterizado por espectroscopia de infravermelho e RMN.

O espectro de infravermelho do 1,7-CT (fig. 24) apresenta bandas em $3130 \mathrm{~cm}^{-1}, 2910 \mathrm{~cm}^{-1}, 1663 \mathrm{~cm}^{-1}$, e $1547 \mathrm{~cm}^{-1}$, concordantes com as bandas relatadas na literatura, as quais são $v_{\mathrm{NH}}$ em $3150 \mathrm{~cm}^{-1}, v_{\mathrm{C}=\mathrm{N}}$ em $1660 \mathrm{~cm}^{-1}$, e $v_{\mathrm{NH}_{2}}{ }^{+}$em $1544 \mathrm{~cm}^{-1} 75$. 


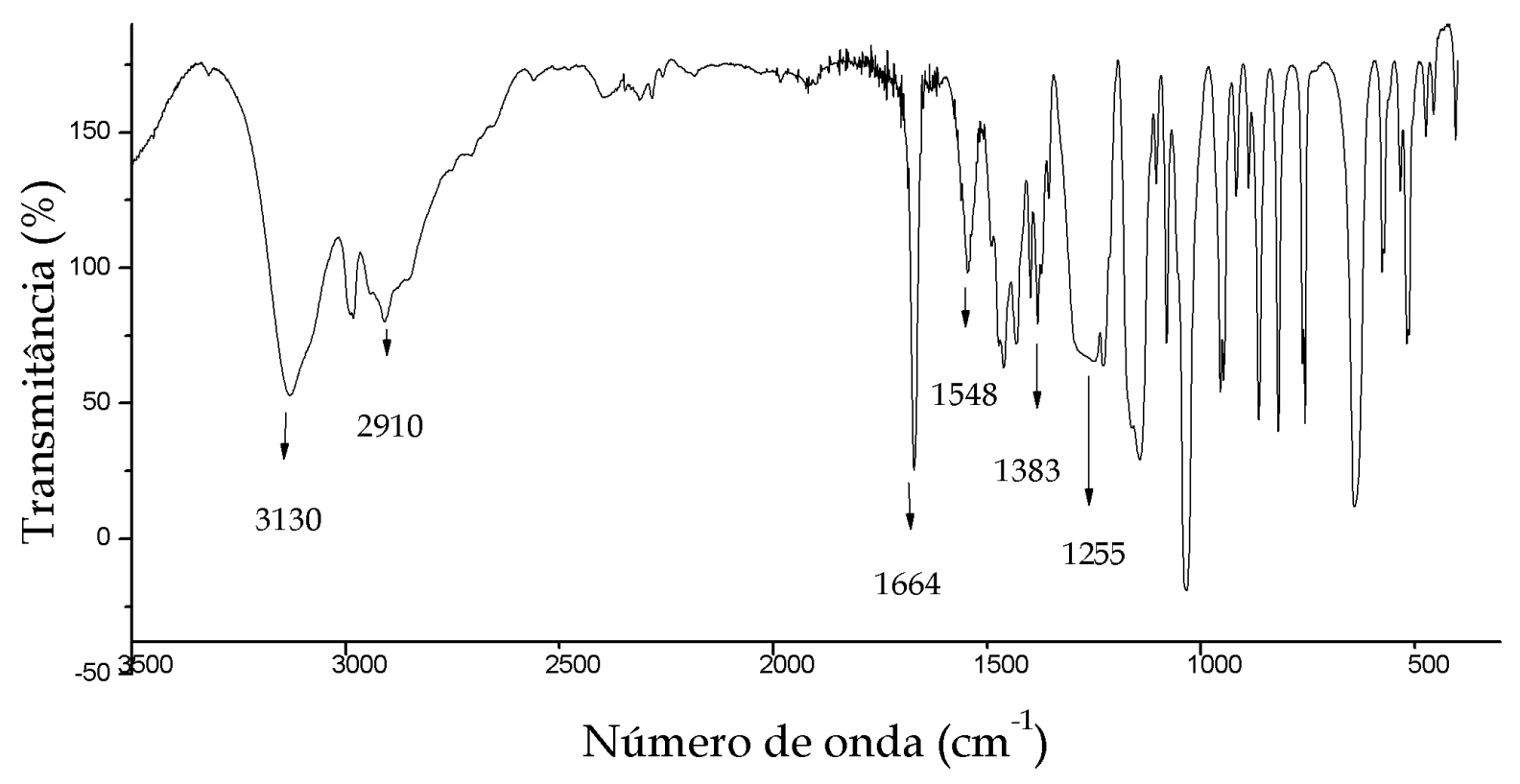

Figura 24: Espectro de Infravermelho do 5,7,7,12,14,14-hexametil-1,4,8,11tetraazaciclotetradeca-4,11-dieno (1,7-CT) feito em pastilha de KBr.

O espectro de $\mathrm{RMN}-{ }^{1} \mathrm{H}$ (fig. 25) do ligante 1,7-CT mostra que os deslocamentos químicos são condizentes com o esperado, embora não haja nenhuma informação presente na literatura a cerca das posições dos picos. 


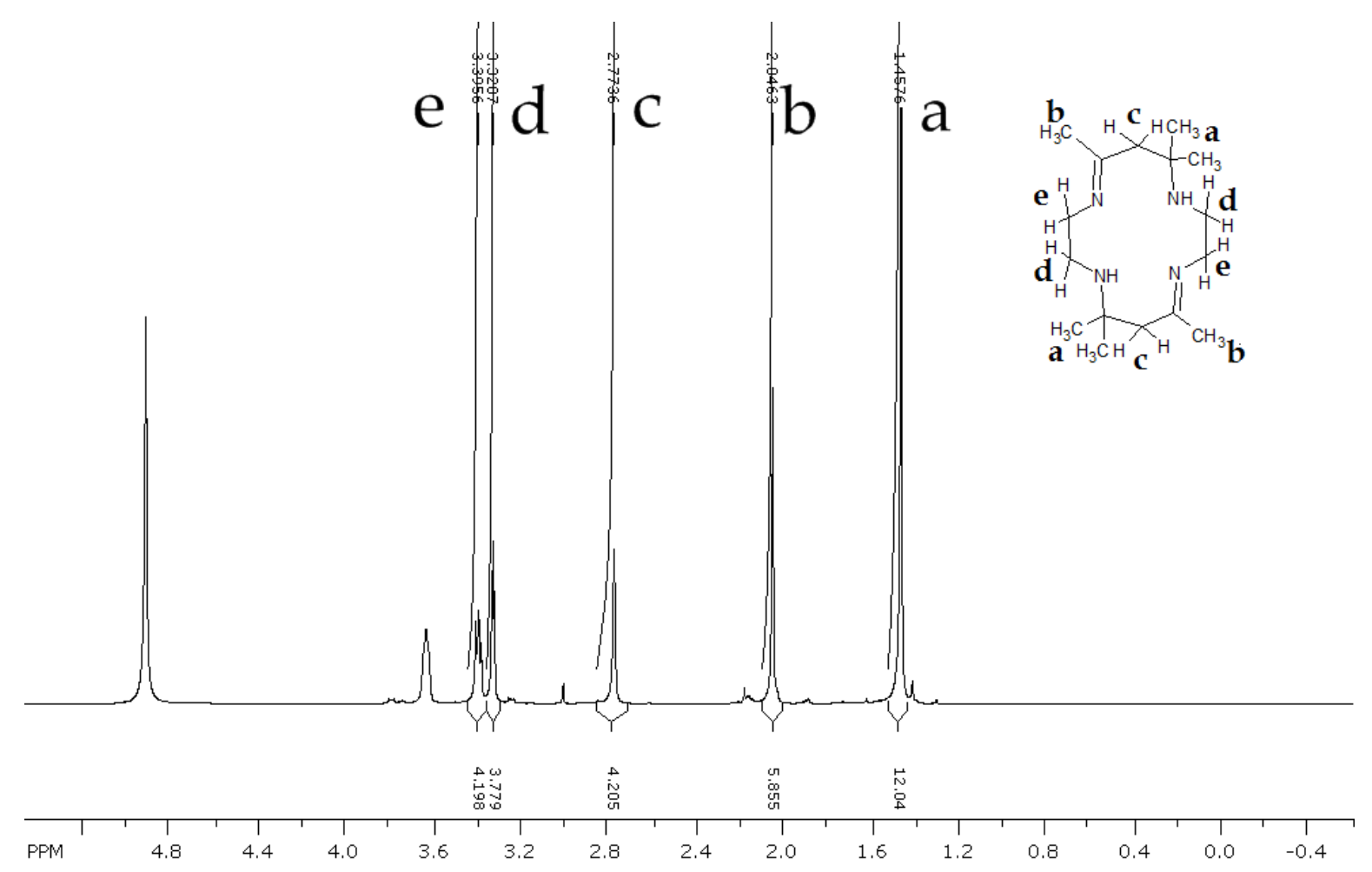

Figura 25: Espectro de $\mathrm{RMN}-{ }^{1} \mathrm{H}$ do 5,7,7,12,14,14-hexametil-1,4,8,11tetraazaciclotetradeca-4,11-dieno (1,7-CT) em $\mathrm{CD}_{3} \mathrm{OD}$.

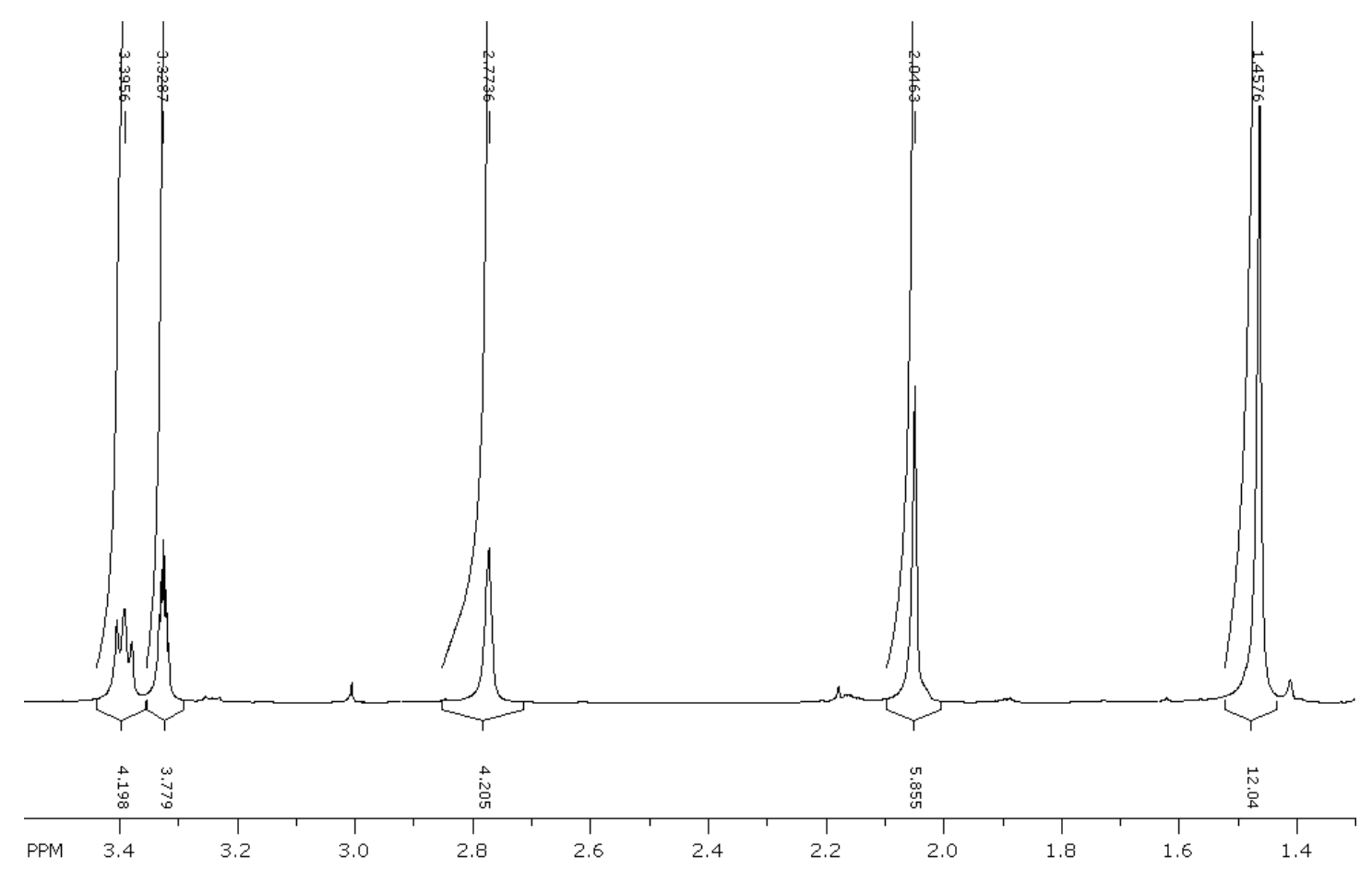

Figura 26: Ampliação do espectro de RMN - ${ }^{1} \mathrm{H}$ do 5,7,7,12,14,14hexametil-1,4,8,11-tetraazaciclotetradeca-4,11-dieno (1,7-CT) em $\mathrm{CD}_{3} \mathrm{OD}$. 
A integração dos picos do espectro fornece um valor que corresponde a trinta hidrogênios, sendo que os hidrogênios das aminas não aparecem neste espectro, devido à troca de deutérios do solvente com os hidrogênios da $\operatorname{amina}^{77}$.

Com base na análise dos espectros, pode-se dizer que a síntese do ligante foi bem sucedida e este pôde ser utilizado na tentativa de metalação do $1,7-\mathrm{CT}$.

A tentativa de síntese do composto de rutênio com ligante 1,7-CT foi baseada na síntese do cis-[ $\left.\mathrm{RuCl}_{2}(\mathrm{cyclam})\right] \mathrm{Cl}$, utilizando o cis-[ $\mathrm{RuCl}_{2}\left(\mathrm{dmso}_{4}\right]$ como precursor. A princípio, pensou-se que seria mais fácil obter um complexo de rutênio com um ligante tetraazamacrocíclico com menor grau de insaturação, devido à presença de apenas duas duplas ligações, o que aumentaria a flexibilidade do anel para formação de um complexo na forma cis, já que, como relatado na literatura ${ }^{10}$, a inflexibilidade das estruturas muito insaturadas é um dos fatores para que estas sejam encontradas preferencialmente em sua forma planar (trans). Um fato que talvez atrapalhasse a formação do complexo com o ligante 1,7-CT coordenado na forma cis, além das duas insaturações, é a presença dos grupos metil, que aumentaria as interações estéricas no anel do macrociclo, tornando esta conformação menos estável. Tendo isto em vista, a tentativa de metalação do ligante 1,7-CT não foi bem sucedida como o esperado. Além de um rendimento muito pequeno (por volta de $5 \mathrm{mg}$ de complexo), as informações 
obtidas no espectro de RMN (fig. 27) não são condizentes com o esperado: algumas modificações com relação aos deslocamentos químicos quando comparado ao espectro do ligante.

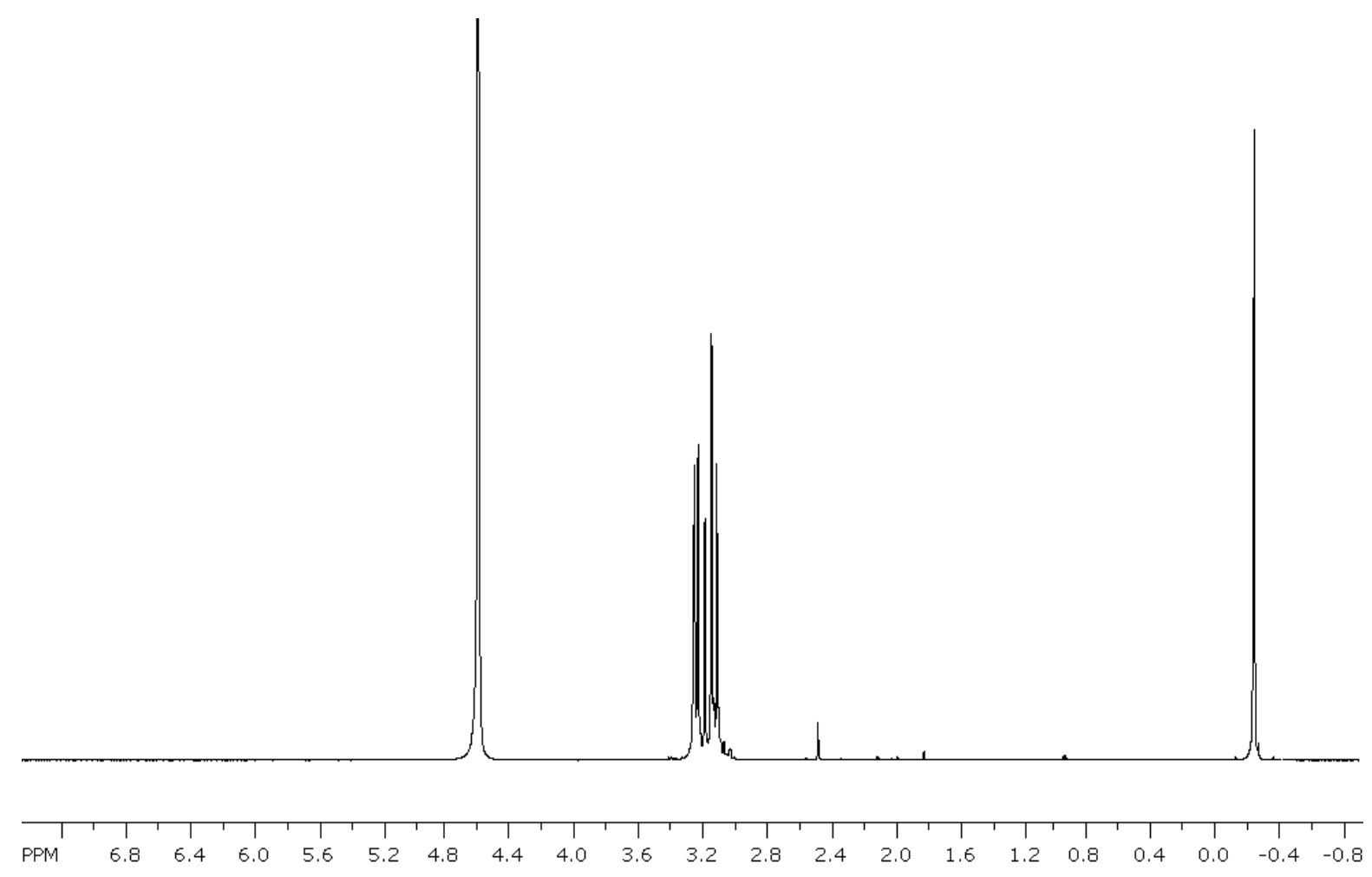

Figura 27: Espectro de $\mathrm{RMN}-{ }^{1} \mathrm{H}$ em $\mathrm{D}_{2} \mathrm{O}$ do suposto complexo de rutênio com o ligante 1,7-CT. 


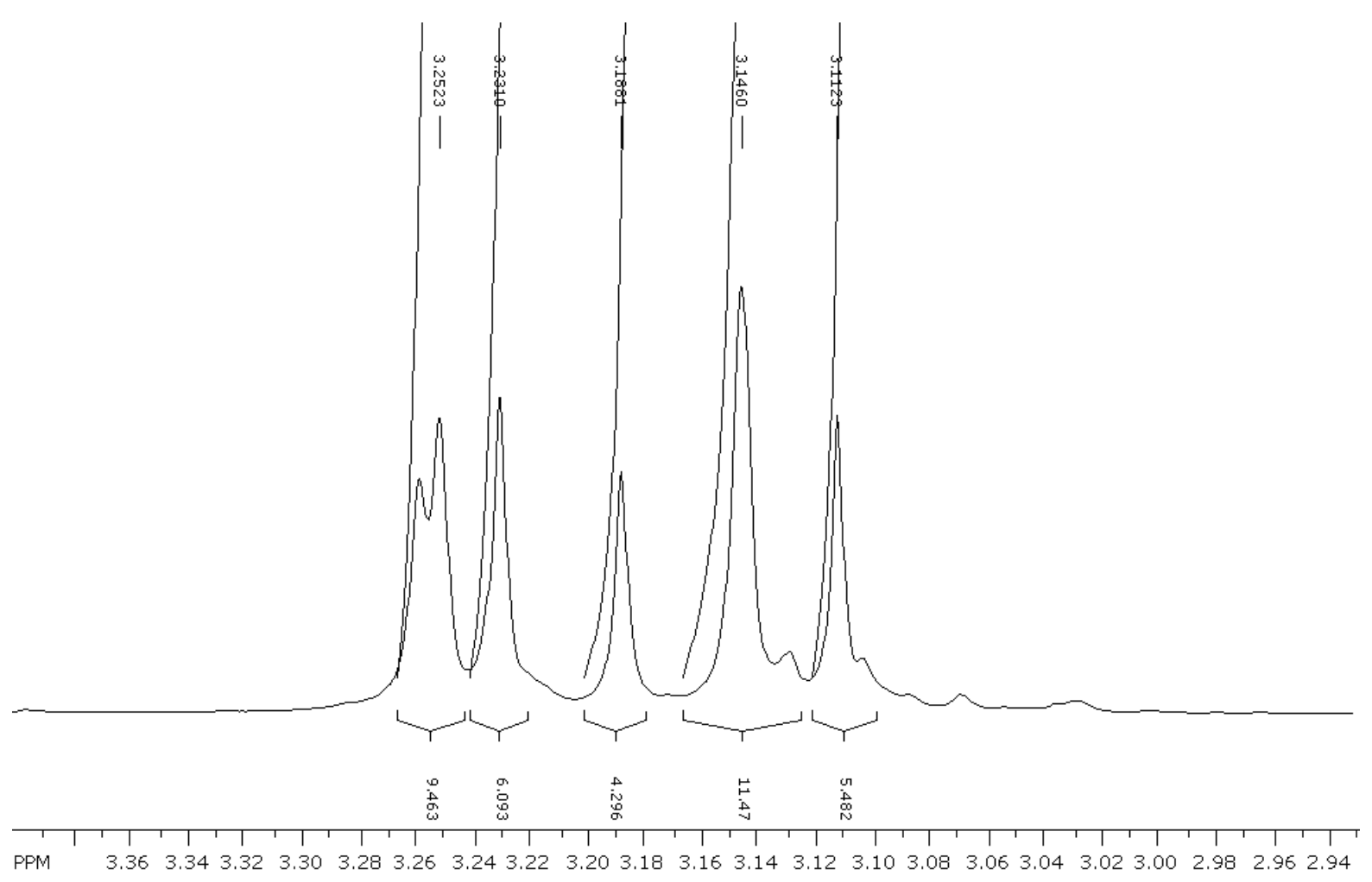

Figura 28: Ampliação do espectro de $\mathrm{RMN}$ - ${ }^{1} \mathrm{H}$ em $\mathrm{D}_{2} \mathrm{O}$ do suposto complexo de rutênio com o ligante 1,7-CT.

Como pode ser visto, o espectro $\mathrm{RMN}$ - ${ }^{1} \mathrm{H}$ obtido do produto da reação é diferente daquele obtido a partir do ligante livre, o que era esperado, já que o rutênio teria estado de oxidação +3, sendo, desta forma, paramagnético. Porém, não foi possível verificar as semelhanças esperadas entre os espectros do ligante livre e do suposto complexo com $\mathrm{Ru}(\mathrm{III})$. 
Existem exemplos de compostos de rutênio com ligantes tetraazamacrocíclicos que apresentam somente um tipo de isômero, como resume a tabela 4:

Tabela 4: Ligantes tetraazamacrocíclicos e seus respectivos complexos de rutênio

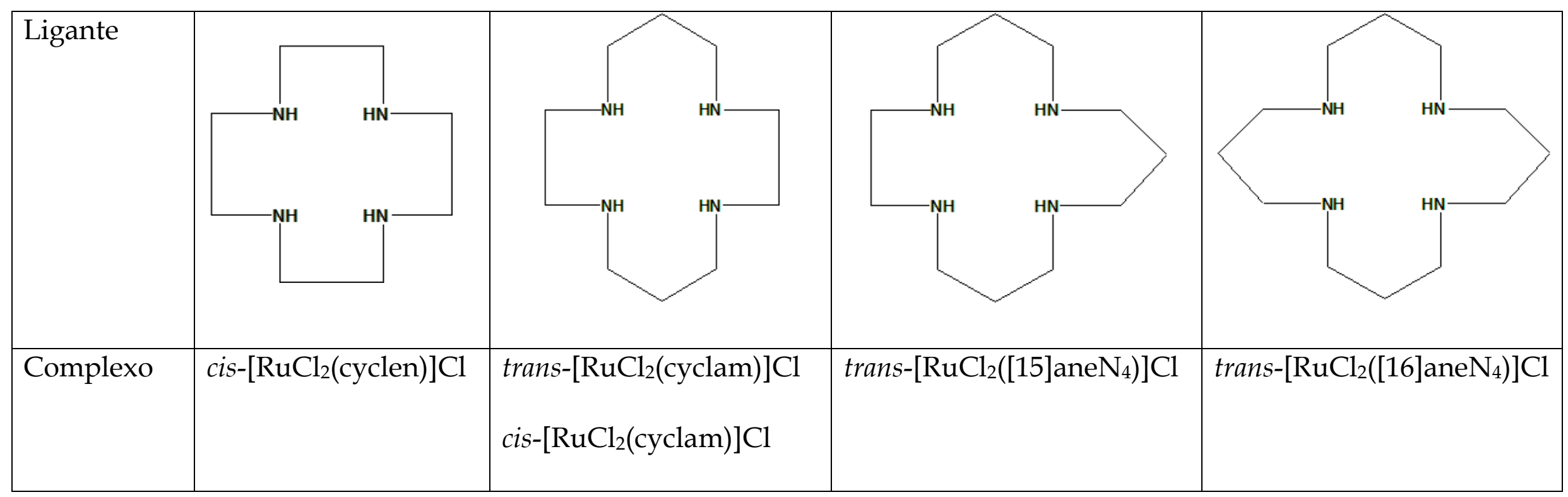


Assim como os casos apresentados, pode ser que o complexo exista apenas na forma do isômero trans, ou que a estratégia para a sua obtenção via metalação do ligante não seja a mais adequada.

O espectro de infravermelho do precipitado (fig. 29) foi feito com a intenção de complementar as informações contidas no espectro de RMN, porém ainda assim, não é possível afirmar que o composto obtido é o cis$\left[\mathrm{Ru}(1,7-\mathrm{CT}) \mathrm{Cl}_{2}\right] \mathrm{Cl}$.

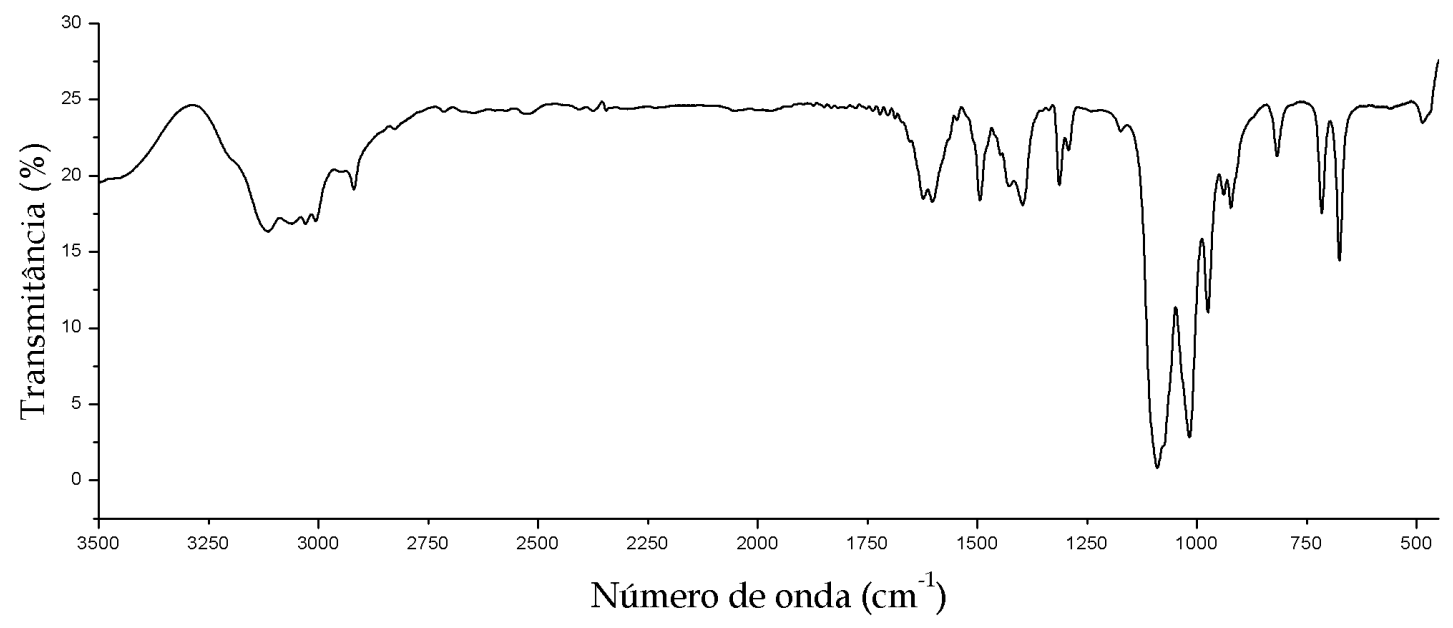

Figura 29: Espectro de infravermelho do suposto composto cis-[Ru(1,7CT) $\left.\mathrm{Cl}_{2}\right] \mathrm{Cl}$ feito em pastilhas de $\mathrm{KBr}$.

As figuras a seguir mostram a sobreposição dos espectros de infravermelho do produto obtido e de seus precursores: 


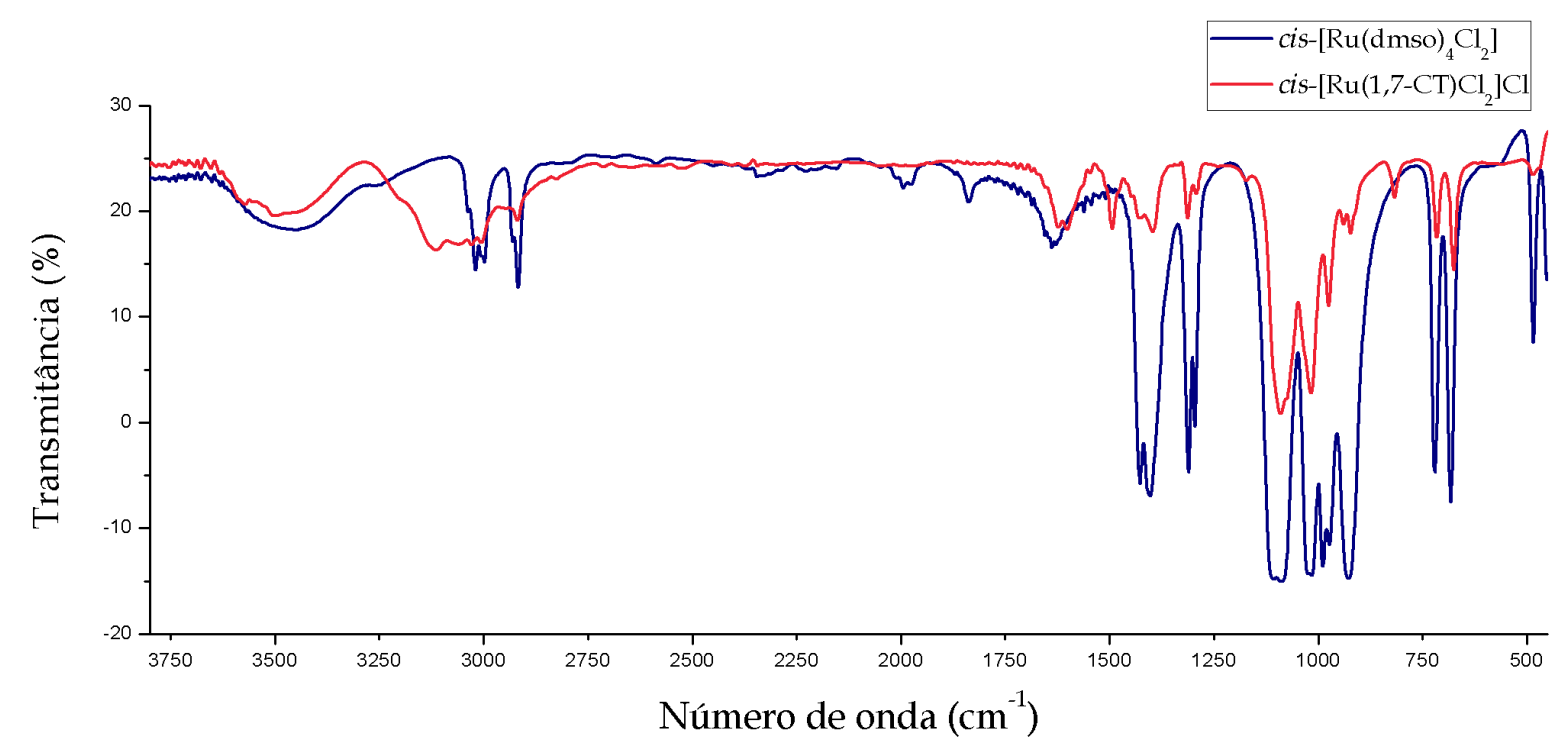

Figura 30: Sobreposição dos espectros de infravermelho do suposto composto $c i s-\left[\mathrm{Ru}(1,7-\mathrm{CT}) \mathrm{Cl}_{2}\right] \mathrm{Cl}$ e de seu precursor cis-[Ru(dmso $\left.{ }_{4} \mathrm{Cl}_{2}\right]$.

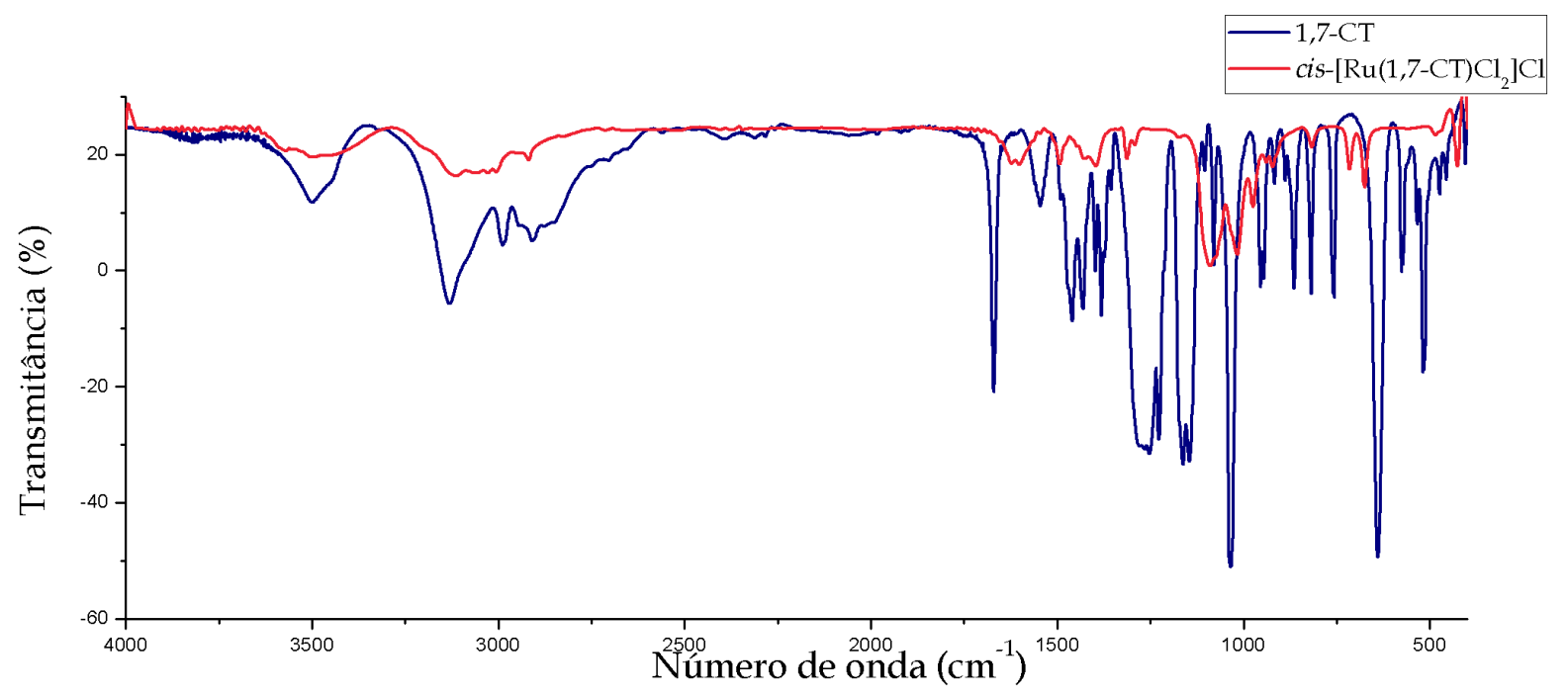

Figura 31: Sobreposição dos espectros de infravermelho do suposto composto $c i s-\left[\mathrm{Ru}(1,7-\mathrm{CT}) \mathrm{Cl}_{2}\right] \mathrm{Cl}$ e do ligante 1,7-CT. 


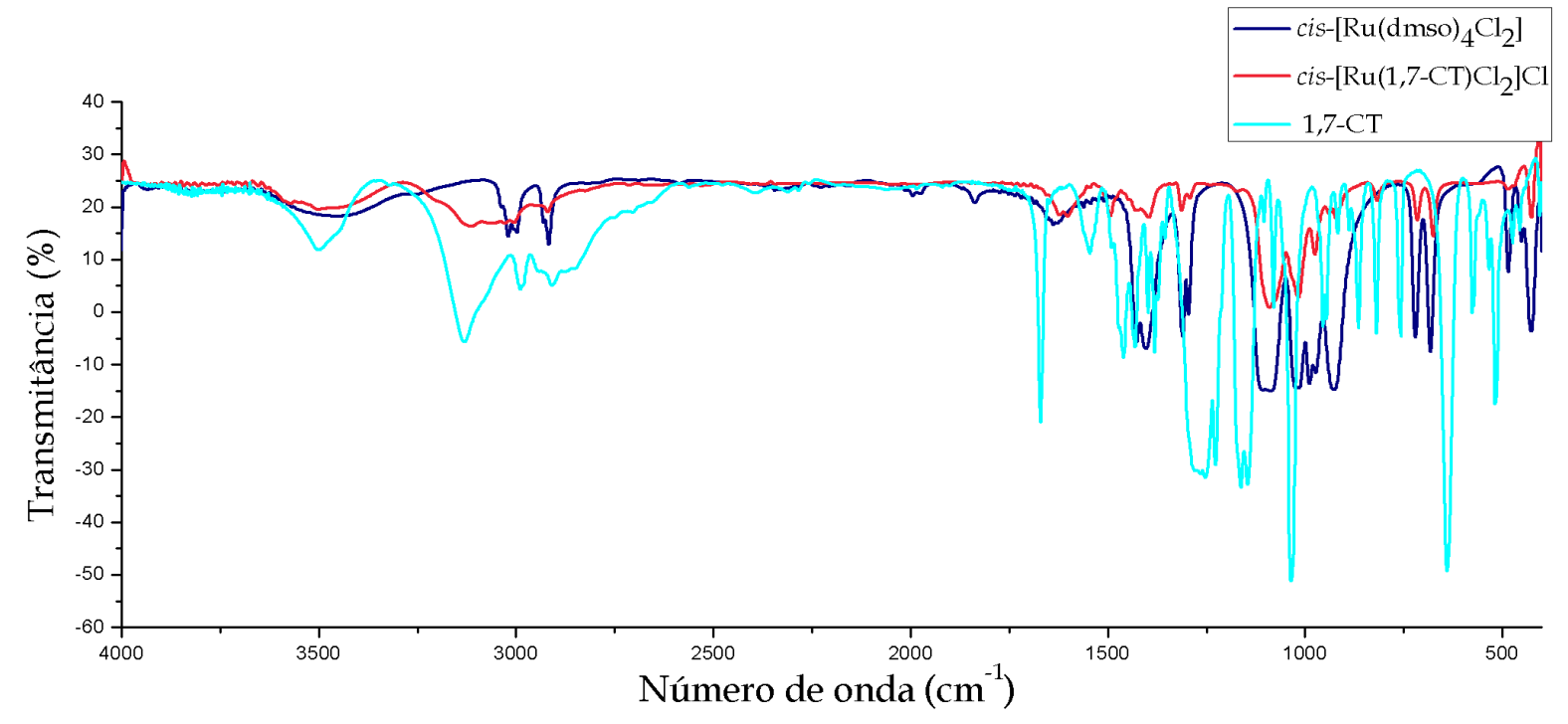

Figura 32: Sobreposição dos espectros de infravermelho do suposto composto cis-[Ru(1,7-CT)Cl 2$] \mathrm{Cl}$, de seu precursor cis- $\left[\mathrm{Ru}(\mathrm{dmso})_{4} \mathrm{Cl}_{2}\right]$ e do ligante 1,7-CT.

Quando comparamos os espectros de infravermelho do possível composto cis-[Ru(1,7-CT) $\left.\mathrm{Cl}_{2}\right] \mathrm{Cl}$ com seus precursores, pode-se notar que, qualitativamente, a sobreposição entre os espectros do suposto cis-[Ru(1,7$\left.\mathrm{CT}) \mathrm{Cl}_{2}\right] \mathrm{Cl}$ e do cis-[ $\left.\mathrm{Ru}(\mathrm{dmso})_{4} \mathrm{Cl}_{2}\right]$ fornece uma maior coincidência com relação à presença e forma das bandas do que a sobreposição com o espectro do ligante 1,7-CT, o que pode indicar que, na verdade, não houve a formação do complexo, como o esperado.

Como dito anteriormente, o fato de o complexo cis- $\left[\mathrm{Ru}(1,7-\mathrm{CT}) \mathrm{Cl}_{2}\right] \mathrm{Cl}$ não ter sido obtido está relacionado ao fato de que a formação deste isômero pode não ser favorecida devido ao impedimento estérico imposto pelos grupos metil ligados ao anel, e/ou porque as insaturações tornam o anel 
rígido demais para adquirir a conformação necessária nesse isômero. A formação do isômero fac, como é o caso do complexo fac$\left[\mathrm{Ru}(\mathrm{NO}) \mathrm{Cl}_{2}\left(\mathrm{~K}^{3} \mathrm{~N}^{4}, \mathrm{~N}^{8}, \mathrm{~N}^{11}\right.\right.$ (1-carboxipropil)cyclam) $] \mathrm{Cl} \cdot \mathrm{H}_{2} \mathrm{O} \quad 81,82$, poderia $\quad$ ter ocorrido, já que esta seria uma conformação mais estável para o caso da inflexibilidade do anel e/ou impedimento estérico. Porém, não há evidências de que o metal tenha se coordenado ao ligante macrocíclico.

Além do já citado caso dos complexos com cyclen 17 e cyclam ${ }^{74}$, o complexo cis-[RuCl(imcyclen)(NO)]( $\left.\mathrm{PF}_{6}\right)_{2}$ também foi obtido via metalação do ligante com posterior oxidação do macrociclo durante a coordenação do NO 60, sendo que a cavidade do imcyclen é ainda menor do que do seu complexo análogo com cyclen, o que pode significar que o passo determinante para não obtenção do complexo de rutênio com ligante 1,7-CT foi o impedimento estérico causado pelas seis metilas que estão substituindo o anel nas posições $5,7,12$ e 14

Resultados preliminares de estudos teóricos realizados no laboratório do Prof. Dr. Luís Gustavo Dias mostram que, assim como já era esperado, a cavidade do anel do macrociclo TIM é pequena demais para acomodar o rutênio, diferente do que acontece com o caso do níquel, como mostram as figuras: 


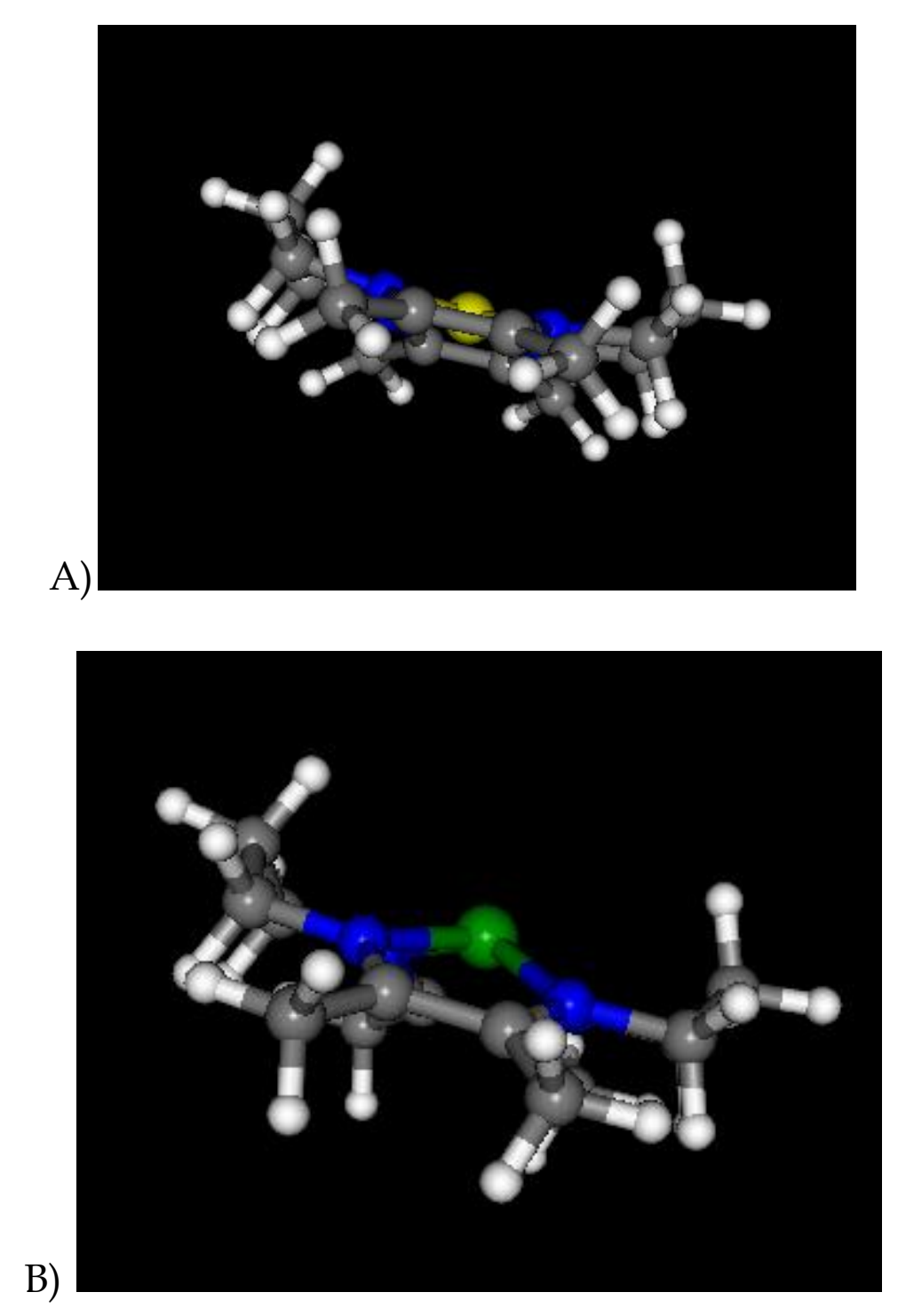

Figura 33: Modelos teóricos dos complexos com ligante TIM: A) Complexo com níquel e B) Complexo com rutênio.

O fato de o metal não estar completamente encaixado na cavidade do anel pode tornar o complexo mais instável, porém estes estudos são apenas preliminares. 
A terceira estratégia para obtenção de complexos com ligantes insaturados é a oxidação dos macrociclos após estes já estarem coordenados ao metal. Mahoney e Beattie ${ }^{83}$ relataram a obtenção de um complexo de rutênio(II) com ligante a-diimínico através da oxidação da etilenodiamina coordenada ao precursor $\left[\mathrm{Ru}(\mathrm{phen})_{2}(\mathrm{en}) \mathrm{I}_{2}\right.$, através da reação com $\mathrm{AgCl}$ e hipoclorito de sódio. Che e Poon ${ }^{27}$ relataram a obtenção do complexo de rutênio(III) com ligante 5,7,7,12,14,14-tetraazaciclotetradeca-1,3,8,10-tetraeno, através da oxidação do macrociclo já coordenado ao metal. Embora a síntese e caracterização tenham sido relatadas, nada foi dito com relação à estabilidade deste composto. A sua estrutura é semelhante à do complexo com ligante TIM, o que, como os cálculos preliminares indicaram para o último caso, pode significar que o complexo obtido por Che e Poon também seja instável em solução.

Devido às possíveis complicações que poderiam ocorrer durante as desidrogenações oxidativas, como desproporcionamento do $\mathrm{Ru}(\mathrm{III})$, a estratégia que utiliza síntese template pareceu ser mais acessível para a obtenção dos complexos com ligantes tetraazamacrocíclicos insaturados, já que a obtenção é direta, as condições não são severas, porém a aparente instabilidade do complexo em solução, como já dito anteriormente, se mostrou o passo determinante para que este não fosse isolado do meio reacional. 


\section{CONCLUSÃO}

A primeira consideração a ser feita sobre as estratégias apresentadas neste trabalho é o fato de que elas não se mostraram triviais, e que, embora já tenham sido aplicadas com bastante sucesso para outros sistemas, as tentativas não foram tão bem sucedidas como o esperado para os complexos com TIM e $1,7-\mathrm{CT}$.

Como já dito anteriormente, a estratégia utilizando a síntese template foi bastante utilizada para obtenção de complexos com níquel, cobalto, ferro com ligante TIM, porém, quando tentou-se a síntese com rutênio, esta estratégia não se mostrou tão eficiente, principalmente pelo fato de que o produto da síntese não pode ser isolado do meio reacional devido à sua instabilidade. Apesar de não ter sido isolado e purificado, os dados espectroscópicos, obtidos através do extrato seco da reação, mostram que o produto foi obtido, e, a comparação com os complexos análogos com níquel e ferro enriqueceu o trabalho. Ao longo das sucessivas tentativas, notou-se que a instabilidade em solução destes complexos seria um problema não só para seu isolamento e purificação, para que a caracterização e estudos pudessem ser feitos, mas também para sua aplicação como possíveis metalofármacos. Obter os complexos pelo método da desidrogenação oxidativa poderia confirmar sua instabilidade. 
A estratégia que utiliza a metalação do ligante vem sendo utilizada com sucesso há algum tempo, e foi utilizando esta estratégia que muitos compostos de rutênio com ligantes macrocíclicos 14-18,21,24,26,28,45,60,74,81,82,84-86 foram sintetizados, e foi baseado nisso que tentou-se metalar o ligante 1,7-CT, porém a síntese não teve o sucesso esperado, e isto pode ter sido provocado pelo impedimento estérico causado pelos substituintes do anel.

Um ponto importante a ser ressaltado é que o insucesso nas sínteses pode estar relacionado à possível instabilidade dos complexos. A síntese de complexos análogos proporcionou o melhor entendimento dos sistemas, como a instabilidade em solução destes compostos, o que poderá auxiliar em tentativas futuras de obtenção dos complexos de rutênio com ligantes tetraazamacrocíclicos insaturados, cuja instabilidade será investigada através de cálculos teóricos.

\section{TRABALHOS FUTUROS}

$\mathrm{Na}$ continuidade deste trabalho, a estratégia de oxidação dos macrociclos será investigada, bem como a estabilidade dos complexos de rutênio com ligantes tetraazamacrocíclicos insaturados obtidos a partir destas sínteses. Além disso, os estudos teóricos terão continuidade de forma que estes sistemas possam ser mais bem entendidos. 


\section{REFERÊNCIAS BIBLIOGRÁFICAS}

(1) Melson, G. A. Coordination Chemistry of Macrocyclic Compounds; Plenum Press, 1979.

(2) Linstead, R. P.; Whalley, M. Journal of the Chemical Society 1952, 4839-4846.

(3) Curtis, N. F. Journal Chemical Society 1960, 4409.

(4) Curtis, N. F. Coordination Chemistry Reviews 1968, 3, 3-47.

(5) Thompson, M. C.; Busch, D. H. Journal of the American Chemical Society 1964, 3842.

(6) Blinn, E. L.; Busch, D. H. Inorganic Chemistry 1968, 7, 820-824.

(7) Van Alphen, J. Recueil des Travaux Chimiques des Pays-Bas 1936, 55, 835-840.

(8) Bosnich, B.; Poon, C. K.; Tobe, M. L. Inorganic Chemistry 1965, 1102-1108.

(9) Barefield, K. E. Inorganic Chemistry 1972, 11, 2273-2274.

(10) Jackels, S. C.; Farmery, K.; Rose, N. J.; Busch, D. H. Inorganic Chemistry 1972, 11, 2893 2901.

(11) Barefield, K. E.; Lovecchio, F. V; Tokel, N. E.; Ochiai, E.; Busch, D. H. Inorganic Chemistry 1972, 11, 283-288.

(12) Baldwin, D. A.; Pfeiffer, R.; Reichgott, D.; Rose, N. J. Journal of the American Chemical Society 1973, 95, 5152-5158.

(13) Collman, J. P.; Schneider, P. W. Inorganic Chemistry 1966, 5, 1380-1384.

(14) Chan, P. K.; Isabirye, D.; Poon, C. K. Inorganic Chemistry 1975, 14, 2579-2580.

(15) Isied, S. S. Inorganic Chemistry 1980, 19, 911-914.

(16) Walker, D. D.; Taube, H. Inorganic Chemistry 1981, 2828-2834.

(17) Ferreira, K. Q.; Lucchesi, A. M.; Da Rocha, Z. N.; Da Silva, R. S. Inorganica Chimica Acta 2002, 328, 147-151.

(18) Da Silva, R. S.; Tfouni, E. Inorganic Chemistry 1992, 31, 3313-3316.

(19) Da Silva, R. S.; Gambardella, M. T. P.; Santos, R. H. A.; Mann, B. E.; Tfouni, E. Inorganica Chimica Acta 1996, 245, 215-221.

(20) Silva, M.; Tfouni, E. Inorganic Chemistry 1997, 36, 274-277.

(21) Lang, D. R.; Davis, J. A.; Lopes, L. G.; Ferro, A. A.; Vasconcellos, L. C.; Franco, D. W.; Tfouni, E.; Wieraszko, A.; Clarke, M. J. Inorganic Chemistry 2000, 39, 2294-300. 
(22) Cabbiness, D.; Margerum, D. Journal of the American Chemical Society 969, 6540-6541.

(23) Chen, Y.; Sweetland, M. A.; Shepherd, R. E. Inorganica Chimica Acta 1997, 260, 163-172.

(24) Tfouni, E.; Ferreira, K. Q.; Doro, F. G.; Da Silva, R. S.; Da Rocha, Z. N. Coordination Chemistry Reviews 2005, 249, 405-418.

(25) Poon, C. K.; Che, C. M. Jounal of the Chemical Society, Chemical Communications 1979, 861-862.

(26) Poon, C. K. ; Che, C. M. Journal of the Chemical Society - Dalton Transactions 1980, 756762.

(27) Poon, C. K.; Che, C. M. Journal of the Chemical Society 1981, 1, 1019-1023.

(28) Che, C. M.; Tang, W.; Wong, W. T.; Lam, H. W.; Lai, T. F. Journal of the Cemical Society Dalton Transactions 1990, 4, 2077-2079.

(29) Butler, A.; Linck, R.G. Inorganic Chemistry 1984, 23, 2227-2231.

(30) Butler, A.; Linck, R. G. Inorganic Chemistry 1984, 23, 4545-4549.

(31) Hess, C. R.; Weyhermüller, T.; Bill, E.; Wieghardt, K. Angewandte Chemie 2009, 48, 3703-3706.

(32) Hess, C. R.; Weyhermüller, T.; Bill, E.; Wieghardt, K. Inorganic chemistry 2010, 49, 56865700 .

(33) Ignarro, L. Nitric oxide: biology and pathology; Academic Press, 2000.

(34) Ford, P. C.; Lorkovic, I. M. Chemical Reviews 2002, 102, 993-1018.

(35) Ignarro, L.; Buga, G.; Wood, K. S.; Byrns, R. E.; Chaudhuri, G. Proceedings of the National Academy od Sciences 1987, 84, 9265-9269.

(36) Hrabie, J. A.; Keefer, L. K. Chemical Reviews 2002, 102, 1135-1154.

(37) Singh, R. J.; Hogg, N.; Joseph, J.; Kalyanaraman, B. The Journal of Biological Chemistry 1996, 271, 18596-18603.

(38) Ostrowski, A. D.; Deakin, S. J.; Azhar, B.; Miller, T. W.; Franco, N.; Cherney, M. M.; Lee, A. J.; Burstyn, J. N.; Fukuto, J. M.; Megson, I. L.; Ford, P. C. Journal of Medicinal Chemistry 2010, 53, 715-22.

(39) Leo, M.; Ford, P. C. Journal of the American Chemical Society 1999, 121, 1980-1981.

(40) Derosa, F.; Bu, X.; Ford, P. C. Inorganic Chemistry 2005, 44, 4157-65.

(41) Merkle, A. C.; Fry, N. L.; Mascharak, P. K.; Lehnert, N. Inorganic Chemistry 2011, 50, 12192-12203. 
(42) Tfouni, E.; Krieger, M.; McGarvey, B. R.; Franco, D. W. Coordination Chemistry Reviews 2003, 236, 57-69.

(43) Tfouni, E.; Doro, F. G.; Figueiredo, L. E.; Pereira, J. C. M.; Metzker, G.; Franco, D. W. Current medicinal chemistry 2010, 17, 3643-57.

(44) Tfouni, E.; Truzzi, D. R.; Tavares, A.; Gomes, A. J.; Figueiredo, L. E.; Franco, D. W. Nitric oxide: biology and chemistry 2012, 26, 38-53.

(45) Tfouni, E.; Doro, F. G.; Gomes, A. J.; Silva, R. S. Da; Metzker, G.; Benini, P. G. Z.; Franco, D. W. Coordination Chemistry Reviews 2010, 254, 355-371.

(46) Slocik, J. M.; Shepherd, R. E. Inorganica Chimica Acta 2000, 311, 80-94.

(47) Fortney, C. F.; Shepherd, R. E. Inorganic Chemistry Communications 2004, 7, 1065-1070.

(48) Roncaroli, F.; Olabe, J. a; Van Eldik, R. Inorganic Chemistry 2003, 42, 4179-89.

(49) Lehninger, A. L.; Nelson, D. L.; Cox, M. M. Lehninger Principles of Biochemistry; Macmillan Higher Education, 2008.

(50) Broderick, K.; Balasubramanian, M.; Chan, A.; Potluri, P.; Feala, J.; Belke, D.; McCulloch, A.; Sharma, V.; Pliz, R.; Bigby, T.; Boss, G. Experimental Biology and Medicine 2007, 232, 789-798.

(51) Wolak, M.; Stochel, G.; Van Eldik, R. Journal of the American Chemical Society 2003, 125, 1334-51.

(52) Davies, N. a.; Wilson, M. T.; Slade, E.; Fricker, S. P.; Murrer, B. a.; Powell, N. a.; Henderson, G. R. Chemical Communications 1997, 47-48.

(53) Chen, Y.; Shepherd, R. E. Journal of Inorganic Biochemistry 1997, 68, 183-193.

(54) Basolo, F.; Pearson, R. G. Mechanisms of inorganic reactions: a study of metal complexes in solution; John Willey \& Sons: Nova Iorque, 1967.

(55) Ford, P. Coordination Chemistry Reviews 1970, 5, 75-99.

(56) Tfouni, E. Coordination Chemistry Reviews 2000, 196, 281-305.

(57) Clarke, M. J. Coordination Chemistry Reviews 2003, 236, 209-233.

(58) Calandreli, I.; Oliveira, F. de S.; Liang, G.; Da Rocha, Z. N.; Tfouni, E. Inorganic Chemistry Communications 2009, 12, 591-595.

(59) Calandreli, I. “Síntese, Caracterização e Reatividade Química de Complexos de Cloro e Nitrosil de trans-Tetrakispiridina de Rutênio", Universidade de São Paulo, 2009.

(60) Ferreira, K. Q.; Santos, F. G.; Da Rocha, Z. N.; Guaratini, T.; Da Silva, R. S.; Tfouni, E. Inorganic Chemistry Communications 2004, 7, 204-208. 
(61) Gomes, A. J.; Barbougli, P. a; Espreafico, E. M.; Tfouni, E. Journal of Inorganic Biochemistry 2008, 102, 757-66.

(62) Carlos, R. M.; Ferro, A. A.; Silva, H. a. S.; Gomes, M. G.; Borges, S. S. S.; Ford, P. C.; Tfouni, E.; Franco, D. W. Inorganica Chimica Acta 2004, 357, 1381-1388.

(63) Iskander, D.; Weller, R. The British Journal of Dermatology 2007, 847.

(64) Da Rocha, Z. N.; De Lima, R. G.; Doro, F. G.; Tfouni, E.; Da Silva, R. S. Inorganic Chemistry Communications 2008, 11, 737-740.

(65) Sauaia, M. G.; Oliveira, F. D. S.; Lima, R. G. De; Cacciari, A. D. L.; Tfouni, E.; Da Silva, R. S. Inorganic Chemistry Communications 2005, 8, 347-349.

(66) Rose, M.; Fry, N.; Marlow, R. Journal of the American Chemical Society 2008, 130, 88348846.

(67) Neuman, D.; Ostrowski, A. D.; Absalonson, R. O.; Strouse, G. F.; Ford, P. C. Journal of the American Chemical Society 2007, 129, 4146-7.

(68) Neuman, D.; Ostrowski, A. D.; Mikhailovsky, A. a; Absalonson, R. O.; Strouse, G. F.; Ford, P. C. Journal of the American Chemical Society 2008, 130, 168-75.

(69) Sauaia, M. G.; De Lima, R. G.; Tedesco, A. C.; Da Silva, R. S. Journal of the American Chemical Society 2003, 125, 14718-9.

(70) Oleinick, N. L.; Morris, R. L.; Belichenko, I. Photochemical \& Photobiological Sciences 2002, 1, 1-21.

(71) Catorze, M. G. Medicina Cutánea Ibero-Latino-Americana 2009, 37, 5-27.

(72) Armarego, W. L. F.; Chai, C. L. L. Purification of Laboratory Chemicals; ButterworthHeinemann, 2009.

(73) Judd, R. J.; Cao, R.; Biner, M.; Armbruster, T.; Buergi, H.-B.; Merbach, A. E.; Ludi, A. Inorganic Chemistry 1995, 34, 5080-5083.

(74) Vidal, R. D. S.; Doro, F. G.; Ferreira, K. Q.; Da Rocha, Z. N.; Castellano, E. E.; Nikolaou, S.; Tfouni, E. Inorganic Chemistry Communications 2012, 15, 93-96.

(75) Tait, A. M.; Busch, D. H. Inorganic Syntheses 1978, 18.

(76) Rose, D.; Wilkinson, G. Journal of the Chemical Society (A) 1970, 1-5.

(77) Pavia, D. L. Introduction to Spectroscopy; Cengage Learning, 2009.

(78) Silverstein, R. M.; Webster, F. X.; Kiemle, D. J. Spectrometric identification of organic compounds; John Wiley \& Sons, 2005. 
(79) Nakamoto, K. Infrared and Raman Spectra of Inorganic and Coordination Compounds: Applications in coordination, organometallic, and bioinorganic chemistry; Wiley, 1997.

(80) De Souza, T. C. R. "Estudos de reatividade, espectroscopia e eletroquímica de complexos diimínicos de ferro e cobalto, com interesse bioinorgânico", Universidade Federal de Santa Catarina, 1998.

(81) Doro, F. G.; Castellano, E. E.; Moraes, L. A. B.; Eberlin, M. N.; Tfouni, E. Inorganic Chemistry 2008, 47, 4118-25.

(82) Doro, F. G.; Pepe, I. M.; Galembeck, S. E.; Carlos, R. M.; Da Rocha, Z. N.; Bertotti, M.; Tfouni, E. Dalton transactions 2011, 40, 6420-6432.

(83) Mahoney, D.; Beattie, J. Inorganic Chemistry 1973, 12, 2561-2565.

(84) Ochiai, E.; Busch, D. H. Inorganic Chemistry 1980, 787.

(85) Sadasivan, N.; Kernohan, J.; Endicott, J. Inorganic Chemistry 1967, 6, 770-780.

(86) Lopes, L. G. F.; Sousa, E. H. S.; Miranda, J. C. V.; Oliveira, C. P.; Carvalho, I. M. M.; Batista, A. a.; Ellena, J.; Castellano, E. E.; Nascimento, O. R.; Moreira, Í. S. Journal of the Chemical Society, Dalton Transactions 2002, 1903-1906. 